\title{
AVALIAÇÂO DA CODIFICAÇÂO E DO PROCESSAMENTO DAS CAUSAS DE MORTE PELO SISTEMA ACME NO ESTADO DE SÃO PAULO, 1992
}

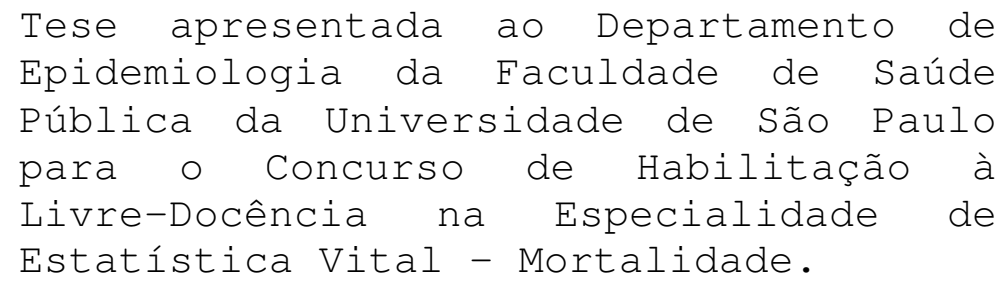

SÃO PAULO

1994

\section{4}


DEDICATÓRIA 
A meu pai, Abílio, com gratidão, A minha mãe, Anna, com saudade, A minha esposa, Isabel, com amor. 


\section{AGRADECIMENTOS}


A Robert A. Israel, Diretor do Centro Colaborador da OMS para a Classificação de Doenças da América do Norte e Diretor Associado para Estatísticas Internacionais do "National Center for Health Statistics",

A Sra. June Pearce, do "National Center for Health Statistics", Research Triangle Park, Carolina do Norte,

A Fundação Sistema Estadual de Análise de Dados, nas pessoas de Carlos Eugênio de Carvalho Ferreira, Eliana Monteiro Rodrigues, Luis Patrício Ortiz Flores, Antonio Benedito Marangone Camargo, Margarete Silva Jordani, Maria Aparecida Teixeira e Sergio Freire França Filho,

A Cássia Maria Buchalla, Cecília Amaro de Lólio e Ruy Laurenti,

AS bibliotecárias da Faculdade de saúde Pública,

A Mirian de Oliveira, Elizabeth Vieira dos Santos e Dalva Lória,

e, àquelas a quem este trabalho também é dedicado, ás codificadoras e supervisoras de codificação da Fundação SEADE, pela amizade e atenção durante os anos de convívio: Ana Miriam Alcarpe Martins, Dulce Helena de Brito, Elizabete Amélia Andrade, Filomena Fátima de Freitas, Isabel Cristina da Costa Ferreira Domingos, Karina Alcarpe, Maria Aparecida Camargo César Simões, Neusa Maria da Silva, Rosmari Pessl e Shirley dos Santos Di Cunto. 
RESUMO 
Foi avaliada a qualidade da codificação e do processamento das causas de morte pelo sistema ACME (sigla de "Automated Classification of Medical Entities) utilizado pela Fundação Sistema Estadual de Análise de Dados (SEADE) para a elaboração das estatísticas de mortalidade no Estado de São Paulo.

O material de estudo constituiu-se de uma amostra sistemática de 3.313 Declarações de óbito de residentes no Estado de São Paulo e registrados no ano de 1992, correspondente a 1,6\% do total dos respectivos óbitos. A revisão critica da codificação das causas de morte e do processamento da causa básica orientou-se pelas disposições da Classificação Internacional de Doenças e pelos manuais de instrução para entrada de dados, decisão e procedimentos operacionais do Sistema ACME.

Foram observados 177 erros, dos quais 114 comprometeram a causa básica e 63 a causa associada de morte. A taxa de erros para a causa básica foi de 3,4\% em relação aos óbitos analisados da amostra. A taxa de erros para causas múltiplas foi de 2,1\%, obtida pela relação dos 177 erros totais com 8.430 diagnósticos estimados terem sido mencionados nas Declarações de óbito da amostra.

Verificou-se certa concentração de erros para as causas de morte incluídas nos Capítulos das "Doenças Infecciosas e Parasitárias", "Neoplasias", "Algumas Afecções Originadas no Período Perinatal", "Sintomas, Sinais e Afecções Mal Definidas" e na "Classificação Suplementar de Causas Externas de Lesões e de Envenenamentos", bem como, de forma coincidente, em grupos etários em que predominam tais causas, em menores de um ano de idade e em falecidos com idades mais avançadas. 
SUMMARY 
The evaluation of the medical coding quality and of the underlying cause of death processing involved with the use of the ACME System (acronym for Automated Classification of Medical Entities) by Fundação Sistema Estadual de Análise de Dados (SEADE) for compilation of mortality statistics in the state of São Paulo was undertaken.

The data for the study was produced by a systematic sample of 3.313 death certificates of persons that used to reside in the State of São Paulo and whose death was registered during the year of 1992, corresponding to 1.6\% of the total deaths of the year. The critical revision of the coding of the causes of death and of the processing of the underlying cause was based on the guidance of the International Classification of Diseases and of the instructions manuals for data entry, decision tables and operational procedures of the ACME system.

A total of 177 errors was observed, 144 of which related to the underlying cause and 63 related to associated causes of death. The error rate for the coding of the underlying cause of death was 3.4\%, considered for the death certificates of the sample. The error rate for multiple causes was 2.1\%, which was calculated by dividing the 177 total errors by 8.430, the estimated number of mentions of conditions in the death certificates of the sample.

A certain concentration of errors was noticed to occur in Chapters of the International Classification of Diseases entitled "Infectious and Parasitic Diseases", "Neoplasms", "Certain Conditions Originating in the Perinatal Period", "Symptoms, Signs and Ill-defined Conditions" and in the "Supplementary Classification of External Causes of Injury and Poisoning", as well as, coincidently, in age groups where these causes are more frequent, i.e., under 1 year of age and in persons of older ages. 


\section{ÍNDICE}




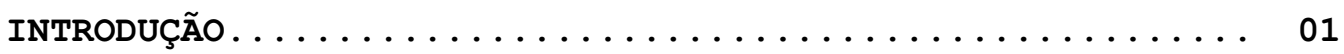

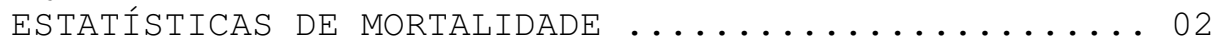

FLUXO DA DECLARAÇÃO DE ÓBITO ............... 10

DESENVOLVIMENTO DAS TABELAS DE DECISÃO

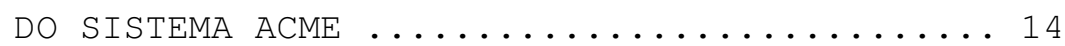

CONTROLE DE QUALIDADE DA CODIFICAÇÃO E DO PROCESSAMENTO DAS CAUSAS DE MORTE ........ 18

JUSTIFICATICA DO TRABALHO .............. 23

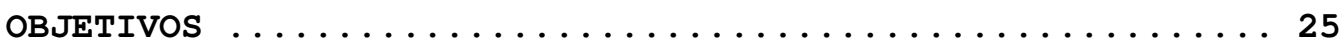

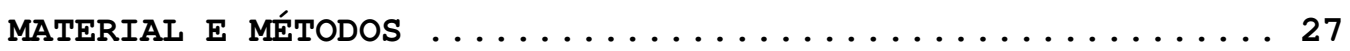

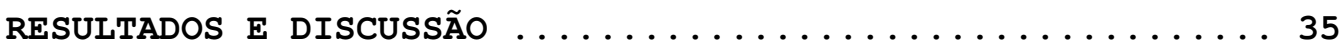

ASPECTOS GERAIS .................... 36

QUESTÕES DE SINTAXE E DE SÍMBOLOS ............ 42

QUESTÕES RELATIVAS A CÓDIGOS ESPECIAIS CRIADOS ....4 45

AFECÇÕES ESPECIFICADAS ENTRE PARÊNTESES ........ 47

EFEITO DA IDADE DO FALECIDO SOBRE A CODIFICAÇÃO .... 49 LIMITAÇÕES DE SEXO ................... 51

LOCALIZAÇÃO IMPLÍCITA DE AFECÇÕES ............. 51

QUESTÕES DE FORMATO ................. 53

DIAGNÓSTICOS COLOCADOS COMO DUVIDOSOS ......... 56

CODIFICAÇÃO DE MENÇÕES DO TIPO "IDEM",

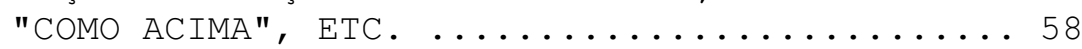

TERMOS NÃO INDEXADOS OU ILEGÍVEIS ........... 59

USO DE CÓDIGOS DE REJEIÇÃO OU DE EXCLUSÃO

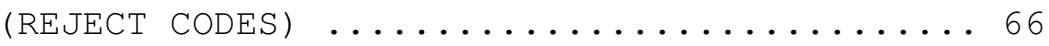

USO DE SIGLAS ...................... 70

COLOCAÇÃO DE CÓDIGOS DA

CLASSIFICAÇÃO INTERNACIONAL DE DOENÇAS ..... 71

CAUSAS DE MORTE CONDICIONADAS A

RESULTADOS DE EXAMES ............. 72

LEGISLAÇÃO CITADA NA DECLARAÇÃO DE ÓBITO . . . . . . 74

MENÇÃO DE BOLETIM DE OCORRÊNCIA POLICIAL ........75

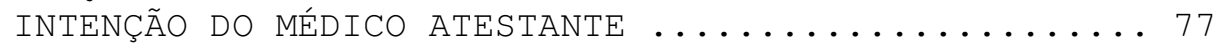

CLASSIFICAÇÃO DE ALGUMAS CATEGORIAS

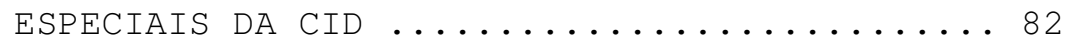

SUMÁRIO DOS ERROS DE CODIFICAÇÃO ............ 88

AVALIAÇÃO DO PROCESSAMENTO DAS CAUSAS DE MORTE... .99

COMENTÁRIOS E RECOMENDAÇÕES $\ldots \ldots \ldots \ldots \ldots \ldots \ldots \ldots \ldots \ldots \ldots \ldots$

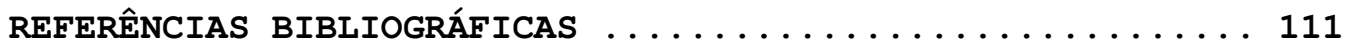

ANEXOS 


\section{INTRODUÇÃO}


ESTATİSTICAS DE MORTALIDADE

Dados sobre mortalidade geram informações que desempenham importante papel no planejamento local, regional e nacional, contribuem para a identificação da situação demográfica do país e permitem fazer inferências sobre o futuro. Os dados sobre mortalidade são também medidas importantes das condições socioeconômicas e de saúde e permitem evidenciar o progresso numa das áreas de maior preocupação do homem, qual seja, a do prolongamento da vida e da prevenção da morte prematura. As chamadas estatisticas de mortalidade também se constituem em indicadores muito sensíveis de diferenças existentes nas populações, possibilitando a identificação de grupos de maior risco a fim de instituir programas especiais de saúde e de desenvolvimento. São úteis, por outro lado, para a avaliação dos programas já realizados (63)

No Brasil, o Sistema Nacional de Informações sobre Mortalidade (SIM) é talvez o único sistema com características de continuidade, padronização e cobertura nacional na área da saúde. Criado em 1975 pelo Ministério da Saúde (36), conta com a participação de todas as Unidades da Federação e órgãos de assessoria especiais, dentre os quais o Centro Colaborador da Organização Mundial da Saúde para a Classificação de Doenças em Português (Centro Brasileiro de Classificação de Doenças - CBCD) (34, 54). A publicação dos óbitos de 1977 se constituiu no início da mais longa e ininterrupta série sobre dados relacionados à saúde consolidados para todo o país. O uso destes dados supera o de outros existentes no campo da saúde nestes últimos anos.

No Estado de São Paulo, os dados sobre mortalidade, bem como dos demais eventos vitais, são produzidos pela Fundação Sistema Estadual de Análise de Dados (Fundação SEADE).

Numerosas variáveis, tais como sexo, idade, estado civil, local de residência e ocorrência, ocupação, entre outras, são levados em consideração pelos estudos estatísticos de mortalidade que as usam para a feitura de analises pormenorizadas. Assim, apenas como exemplo, quanto à variável idade, a mortalidade infantil é um dos mais sensíveis indicadores de nível de saúde de populações. No entanto, além destas variáveis, deve ser lembrada a causa de morte por constituir-se em outra das mais importantes formas de sua análise. O conhecimento preciso de padrões de mortalidade segundo a causa de morte permite a pesquisa de eventuais 
fatores etiológicos e a tomada de decisões visando à prevenção desses fatores. MACMAHON e PUGH (30) referem que as mudanças de taxas de mortalidade podem oferecer as primeiras indicações sobre eventos epidêmicos e que taxas específicas de mortalidade constituem a única e a mais útil fonte de informação disponível para muitas doenças. Em numerosos países, os dados sobre mortalidade constituem-se na mais longa e ininterrupta série de dados nacionais relacionados á saúde (24).

A Primeira Conferência Internacional para a Revisão das Listas Internacionais de Causas de Morte, realizada em 1900, ratificou como norma a prática usada por Graunt, no século XVII, de atribuir para o óbito apenas uma causa (41, 57). A Organização Mundial da Saúde adotou, para a mesma, a denominação de causa básica de morte, conceituando-a como "(a) a doença ou lesão que iniciou a sucessão de eventos mórbidos que conduziram diretamente a morte, ou (b) as circunstâncias do acidente ou violência que produziram a lesão fatal" durante a "Conferência Internacional da Revisão da Classificação", em 1948, ao aprovar a Sexta Revisão da Classificação Internacional de Doenças (32) .

$\mathrm{Na}$ mesma ocasião, convencionou-se que as causas de morte devem figurar na parte denominado "Atestado Médico", modelo recomendado para adoção por todos os países, e foram também previstas regras e disposições para a identificação e a classificação da causa básica. A partir de então, são usados internacionalmente o mesmo modelo de atestado de óbito, a mesma definição para a causa a ser tabulada e os mesmos procedimentos para a identificação desta causa, ensejando a padronização de procedimentos e contribuindo para que as estatísticas de mortalidade se tornem comparáveis e uniformes internacionalmente. $(41,55,56)$.

O Modelo Internacional de Atestado Médico de Causa de Morte", que é reproduzido nos itens 35 e 36 da Declaração de óbito (Anexo 1), foi desenhado para colher adequadamente a informação sobre o processo mórbido da morte com vistas a facilitar a escolha da causa básica quando duas ou mais causas forem informadas conjuntamente.

$\mathrm{Na}$ Parte I registram-se a causa que diretamente conduziu a morte - causa direta, imediata, ou terminal, escrita na alínea (a) - e ainda os estados patológicos antecedentes alíneas (b) e (c) - que ocasionaram a causa anotada em (a), informando-se a causa básica em último lugar na sucessão de eventos mórbidos, isto é, na última alínea usada. Não será 
necessário o uso das alíneas (b) ou (c) se a doença que levou diretamente ao óbito, e que consta em (a), descrever de forma completa o curso dos acontecimentos. As causas que são produzidas pela causa básica têm sido, entre nós, designadas de causas conseqüenciais, incluindo-se a causa direta (31, $55)$.

$\mathrm{Na}$ parte II registra-se qualquer outra afecção mórbida significativa que tenha influído desfavoravelmente na evolução do processo patológico, contribuindo assim para a morte do paciente, sem estar, porém, relacionada com a doença ou estado patológico que causou diretamente a morte (31). Esta causa ou causas são chamadas de causas contribuintes (55).

As causas conseqüenciais e causas contribuintes, em conjunto, são denominadas de causas associadas, que, somadas à causa básica, configuram as causas múltiplas de morte (55).

Para um determinado óbito, a causa básica de morte deriva das informações dadas pelo médico ao certificá-lo, utilizando-se, para sua codificação, a estrutura, as regras de seleção e de modificação e as disposições correlatas da revisão em vigor da Classificação Internacional de Doenças. As regras de seleção permitem a identificação da causa básica de morte tendo em vista a posição das afecções mencionadas pelo médico no Modelo Internacional de Atestado Médico de Causa de Morte e a relação causal entre as mesmas. As regras de modificação têm a finalidade de aprimorar a informação sobre esta causa selecionada, dando preferência a determinadas afecções em detrimento de outras ou associando duas ou mais afecções segundo uma rubrica da Classificação Internacional de Doenças. Como já assinalado, tais regras para a codificação da causa básica de morte vem sendo apresentadas na Classificação Internacional de Doenças há décadas, com a finalidade de padronizar sua identificação, fato que contribui para a comparabilidade universal das estatísticas de mortalidade (56).

As chamadas tabulações primárias de mortalidade, segundo a causa básica, fazem corresponder a cada óbito uma só causa, constituindo-se em dados estatísticos simples, unidimensionais e de fácil compreensão, sendo, portanto medidas de mortalidade usualmente divulgadas. Apresentam as causas iniciais do processo mórbido e assim podem ser usadas pelos responsáveis pela saúde pública para a prevenção ou controle desse processo. Entretanto, apesar das numerosas vantagens como dado estatístico, algumas limitações vem sendo 
apontadas em relação ao uso da causa básica para a descrição e análise da mortalidade (9, 11, 12, 15, 62).

Dado que apenas a causa básica é indicada, são desprezadas as demais afecções informadas no atestado médico. Por vezes, esta seleção, se bem que com normas uniformes e padronizadas, é arbitrária e exclui das tabulações estatísticas doenças que desempenham importante papel no processo mórbido que conduz a morte. Desta seleção são desprezadas as chamadas causas associadas, que incluem as causas conseqüenciais, importantes para a compreensão da cadeia mórbida que leva diretamente a morte, bem como também são desprezadas as causas contribuintes, isto é, aquelas afecções presentes no momento da morte, porém não relacionadas com a causa básica. Deste modo, não se capta o quadro global do processo mórbido. Nas mortes violentas, do mesmo modo, apenas são apresentados dados sobre as circunstâncias de sua ocorrência, as chamadas causas externas, omitindo-se a natureza da lesão (5, 6, 8).

A apresentação das mortes segundo uma só causa era adequada para o tipo das causas comuns no início do século, principalmente as doenças agudas, infecciosas ou a causas violentas. ̇̀ medida que tais afeç̧ões passaram a ser controladas, a sobrevida das pessoas aumentou conseqüentemente. Com isso, o número de idosos e adultos aumenta, e nesta parcela da população aparecem as denominadas doenças crônicas, que se tornam então as principais causas de morte. Para a descrição destas mortes, o conceito de causa básica já não é tão satisfatório, desde que, mesmo o médico, por vezes, não é capaz de identificar a afecção que iniciou a sucessão de eventos patológicos, observando, antes, uma coexistência de doenças. As mortes devidas às doenças crônicas são determinadas por diversas afecções presentes no falecido, as quais nem sempre tem entre si relação de causalidade bem estabelecida com vistas à seleção de uma causa básica claramente determinada.

Considerando as limitações ligadas às estatísticas de mortalidade que levam em conta somente uma causa e, particularmente 0 fato de que nem sempre a morte depende apenas de uma causa isolada, há décadas vem sendo sentida a necessidade de estudar-se a mortalidade segundo causas múltiplas. Tais estatísticas são obtidas pela classificação de todas as causas - básica e associadas - informadas no atestado de óbito, e forneceriam um volume de dados sensivelmente maior que aquele oferecido apenas pela causa básica $(7,12,13,20,21,28,29,55)$. 
Apesar das considerações que são feitas sobre suas limitações, o emprego da causa básica de morte continua a ser essencial para o estudo de tendências históricas e para a comparabilidade entre países. Não se pretende substituíla pela metodologia das causas múltiplas. Numerosas séries históricas importantes formadas no conceito da causa básica já contam décadas de existência. Nem todos os países possuem certificação médica da morte com qualidade e pormenor suficientes para justificar o uso de causas múltiplas. Portanto, a comparabilidade internacional dos dados de mortalidade seria gravemente comprometida se o uso da causa básica viesse a ser abandonado. Recomenda-se, isto sim, que as causas múltiplas tenham um caráter complementar à metodologia tradicional, dando nova dimensão às estatísticas de mortalidade (24).

Várias dificuldades têm sido apontadas para o emprego generalizado de causas múltiplas. O grande volume de dados a ser trabalhado é citado como principal óbice. O trabalho seria, no mínimo, duplicado, considerando o número médio superior a dois diagnósticos por atestado. De modo especial, são encontrados problemas de codificação com o uso da Classificação Internacional de Doenças que está muito mais estruturada para identificar a causa básica, sendo particularmente problemático o uso de rubricas correspondentes a duas ou mais afecções classificadas de modo conjunto. Além disso, deve ser lembrado que inexiste experiência internacional disseminada sobre tabulação e análise de causas múltiplas.

As citadas dificuldades relacionadas ao volume de dados foram resolvidas com o advento dos computadores que facultam o seu processamento eletrônico. Tal fato permitiu o desenvolvimento, por parte do "National Center for Health Statistics" (NCHS), dos Estados Unidos, de um sistema automático para classificar, além da causa básica, todas as demais afecções indicadas no atestado de óbito (5, 23, 26). Denominado ACME, sigla para "Automated Classification of Medical Entities", este sistema apresenta-se não só como alternativa adequada ao trabalho manual para a classificação da causa básica de morte, como também permite o registro de todos os diagnósticos das afecções presentes no atestado médico, tornando possível dados sobre causas múltiplas. Portanto, o sistema ACME realiza fundamentalmente dois trabalhos: identifica a causa básica e arquiva dados sobre as demais causas associadas de morte.

Tradicionalmente, a classificação da causa básica tem sido feita manualmente pelos chamados codificadores. Esse trabalho 
é realizado utilizando-se a estrutura da Classificação Internacional de Doenças, suas quatro regras de seleção e nove de modificação e disposições correlatas. Para tanto, o codificador recebe treinamento intensivo, o qual é padronizado internacionalmente pela Organização Mundial de Saúde. Alguns autores consideram que a codificação das afecções informadas como causas de morte no Atestado Médico é um das atividades mais difíceis e complicadas dentre aquelas para o processamento dos dados sobre mortalidade (22, 25, 61). Entretanto, é um trabalho sujeito a falhas. O Sistema ACME dá margem a maior precisão e controle sobre o processo de codificação da causa básica, desde que automatiza os procedimentos envolvidos nesse processo. A causa básica é identificada eletronicamente por meio de tabelas de decisão às quais foi incorporada toda a estrutura de códigos da Classificação Internacional de Doenças, as relações etiológicas entre as afecções representadas por tais códigos e interpretadas segundo as disposições das 13 regras de classificação da causa básica. Todos esses elementos foram programados logicamente e de tal forma que se relacionassem entre si perfeitamente. Instruções especiais foram elaboradas para atribuir códigos a todas as afecções, doenças, natureza de lesões, circunstâncias de mortes violentas (acidentes, suicídios, homicídios), procedimentos médicos e demais dados que podem ser mencionados nos atestados de óbito. A programação do ACME recebe a mensagem codificada que transcreve as informações do atestado de óbito e, após processamento, atribui um código à causa básica (5, 6, 23, 55). Pelo uso das potencialidades dos computadores, este sistema abre novos caminhos para o estudo das relações causais antes não disponíveis aos epidemiologistas e outros profissionais na área da saúde (17).

- Centro Colaborador da Organização Mundial da Saúde para a Classificação de Doenças em Português (Centro Brasileiro de Classificação de Doenças - CBCD) da Faculdade de saúde Pública da Universidade de São Paulo, em 1976, tomou conhecimento do sistema $\mathrm{ACME} e$, de imediato, interessou-se pelo mesmo, tendo em vista seu imenso potencial de uso para a elaboração das estatísticas de mortalidade. Estabeleceu-se, a seguir, um intercâmbio entre $\circ \mathrm{CBCD} e \circ \mathrm{NCHS}$, de Washington, para a aquisição de informações pormenorizadas sobre o sistema ACME. Após cuidadosa análise das questões envolvidas, concluiu-se pela conveniência de sua introdução no Brasil. O CBCD consultou a Fundação SEADE (Sistema Estadual de Análise de Dados), que também se interessou pelo sistema e acedeu em testar o seu uso no Estado de São Paulo. O NCHS enviou uma cópia do programa, bem como toda a documentação correlata, ao CBCD, que as cedeu a Fundação SEADE. Teve início um trabalho 
entre $\circ \mathrm{CBCD}$ e aquela Fundação para introduzir o sistema ACME na apuração das causas de morte do Estado de São Paulo, trabalho esse que compreendeu, entre outras atividades, treinamento de codificadores, adaptação do programa e análise de problemas operacionais. A par disso, técnicos do CBCD e da Fundação SEADE realizaram visitas ao NCHS a fim de observar o funcionamento do sistema ACME (57).

Tendo em vista a criação do Sistema Nacional de Informações em Mortalidade e considerando os trabalhos em relação ao Sistema ACME, estabeleceu-se um convênio entre o Ministério da Saúde e a Fundação SEADE para a instalação preliminar do mesmo no Estado de São Paulo, convênio esse que fazia previsão para, oportunamente, a sessão de todas as rotinas técnicas e operacionais ao Ministério, para eventual aplicação em outras Unidades da Federação (33, 57).

A instalação do sistema ACME requer a disponibilidade de computador de grande porte. Por outro lado, a entrada de dados no sistema também demanda retreinamento dos codificadores face às adaptações de códigos da classificação Internacional de Doenças realizadas para o programa de processamento da seleção da causa básica. Assim sendo, como visto, a instalação se deu inicialmente no Estado de são Paulo que apresentava as condições para tal. A disseminação do sistema para outras Unidades da Federação não se concretizou na prática, apesar da previsão neste sentido no convênio entre o Ministério da Saúde e a Fundação Sistema Estadual de Análise de Dados (Fundação SEADE) (33). Durante o ano de 1989, por meio de um esforço conjunto do Ministério da Saúde, do CBCD, da Fundação SEADE, da Secretaria da Saúde do Distrito Federal e de técnico que havia participado da introdução em São Paulo, o sistema ACME foi instalado no Centro de Processamento de Dados do Ministério da Saúde. No início de 1990, a fim de experimentar seu funcionamento, realizou-se o processamento dos óbitos ocorrido no decorrer de um ano no Distrito Federal. Mudanças administrativas e reformulação de prioridades obstaram a continuidade deste trabalho.

A partir de 1983, o processamento das declarações de óbito do Estado de São Paulo, na ocasião em torno de 180.000 ao ano, realiza-se pelo sistema ACME. O CBCD, atendendo aos objetivos perseguidos desde a sua criação, qual seja de trabalhar pelo aprimoramento das informações contidas nas estatísticas de mortalidade, vem, continuamente, prestando colaboração direta à Fundação SEADE. Esta colaboração compreende não só treinamento e supervisão de codificadores, como também a elaboração de tabelas de decisão e de validade de causas de 
morte adequadas ao nosso meio, à promoção de estudos sobre familiarização de procedimentos e sugestão de formas de tabulação final de dados $(18,19,33,55,57)$. 
FLUXO DA DECLARAÇÃO DE ÒBITO

- documento primário para a obtenção das estatísticas de mortalidade é, no Brasil, a Declaração de óbito. Por força da Lei dos Registros Públicos, o óbito deve ser registrado em Cartório de Registro Civil, "em vista do atestado de médico, se houver no lugar, ou, em caso contrário, de duas pessoas qualificadas que tiverem presenciado ou verificado a morte" (2). Com a criação do Sistema Nacional de Informações sobre Mortalidade, recomenda-se que o registro do óbito se faça com a apresentação da Declaração de óbito, documento este que padroniza, para fins estatísticos, o atestado médico previsto na Lei dos Registros Públicos (2).

A orientação para o preenchimento da Declaração de óbito encontra-se descrita no "Manual de Instruções para o Preenchimento da Declaração de óbito, publicado pelo Ministério da Saúde" (38).

A mesma lei prevê que os cartórios devem remeter à Fundação Instituto Brasileiro de Geografia e Estatística (IBGE) mapas sobre os eventos vitais registrados.

A Declaração de óbito, incluída no Anexo 1, compõe-se de duas vias. No Estado de São Paulo, os Cartórios de Registro Civil, em torno de 950, remetem à Fundação SEADE, até o décimo dia do mês seguinte ao do registro, uma das vias da Declaração, acompanhada de mapas (Anexo 2) em que os óbitos são enumerados. Para cerca de 150 cartórios de menor porte, para essa remessa mensal, a Fundação fornece envelope previamente franqueado. O controle dos óbitos recebidos permite identificar aqueles cartórios que por algum motivo não encaminham em tempo os óbitos registrados.

Os dados sobre o falecido que são escritos na primeira via da Declaração se reproduzem ao mesmo tempo na segunda via por meio de um processo análogo ao uso do papel-carbono. Quando a escrita não é firme e vigorosa, a reprodução escrita na segunda via torna-se fraca, ilegível e de difícil interpretação. Este fato determinou a orientação para que os cartórios, após fazer uso da Declaração para o registro e coleta de dados para expedição da Certidão de óbito, encaminhassem ás repartições estatísticas a primeira via da Declaração. Embora houvesse tal recomendação, muitos cartórios preferem reter, para arquivamento, a primeira via e encaminhar a segunda para processamento estatístico. Para 
tornar evidente a necessidade do encaminhamento da primeira via pelos cartórios, o Ministério da saúde incluiu, nas últimas impressões da Declaração de óbito para distribuição ás Unidades da Federação, na Parte I, destinada a ser preenchida pelo cartório, a indicação "la VIA-ESTATÍSTICA DE SAÚDE" e "2a VIA-CARTÓRIO", nas correspondentes folhas.

Os mapas recebidos dos cartórios encapam o conjunto das Declarações de determinado mês. Inicia-se na Fundação SEADE uma série de atividades para o processamento de todas as variáveis contidas na Declaração. Pode-se dizer que este processamento é constituído de etapas, realizadas por equipes distintas de codificadores e digitadores. Dado que os óbitos infantis são apurados manualmente para uma apresentação preliminar, as Declarações correspondentes são separadas. As cópias das Declarações recebidas dos cartórios num determinado mês são numeradas seqüencialmente. Geralmente os óbitos infantis, previamente separados, são colocados no inicio dos lotes mensais. O número aposto na Declaração, o mês e o cartório de registro são os três elementos que permitem identificar determinada Declaração dentre os óbitos de determinado ano.

A orientação para a codificação da maioria das variáveis da Declaração de óbito é apresentada no "Manual de Instruções de Preenchimento da Planilha para Codificação de Declaração de óbito" (39) e, para a codificação do item relativo à profissão do falecido, pela Classificação Brasileira de ocupações para o Subsistema de Informações sobre Mortalidade (37), ambas também publicadas pelo Ministério da saúde. A codificação dos municípios de ocorrência e de residência é feitos de acordo com O IBGE.

Uma das equipes codifica as variáveis incluídas nas partes II e III da Declaração de óbito, ditos dados demográficos, a maioria dos quais são de fácil codificação. A outra equipe, constituída por cerca de seis codificadoras, atribui códigos ás causas de morte e demais dados informados na parte IV da Declaração, a que, como visto, apresenta grau sensivelmente maior de dificuldade.

Para a introdução do uso do Sistema ACME no Estado de São Paulo, os codificadores, que na ocasião codificavam manualmente apenas a causa básica de morte, foram treinados em serviço para atribuir códigos a todas as doenças, estados mórbidos, natureza de lesões, causas externas, procedimentos médicos e outros dados informados no Atestado Médico. Dado que todo o material de orientação estava redigido em inglês, 
os tópicos eram oralmente transmitidos aos codificadores e a aplicação prática do ensino se fazia em exercícios que foram traduzidos do material original. Alguns tópicos, como por exemplo, sobre codificação de atestados com menção de febre reumática e de morte materna, também foram traduzidos e cópias oferecidas às codificadoras por ocasião do treinamento específico.

O codificador identifica o código das afecções informadas nos itens 35 e 36 da Declaração de óbito, separando as registrada nas linhas (a), (b) e (c) por meio de uma barra (/) a fim de indicar mudança de linha e por meio de um asterisco (*) para separar as afecções incluídas na Parte II das anteriores colocadas nas linhas da Parte I do Atestado Médico. Em que pese haver no início deste tópico a instrução para anotar só um diagnóstico por linha, os médicos, por julgarem necessário, informam duas ou mais causas numa linha para descrever com maior propriedade a seqüência de eventos mórbidos que levaram a morte, ou, o que parece ser mais provável, por desconhecerem esta instrução. Um exemplo da forma que recebem os códigos das causas de morte no Atestado Médico apresenta-se a seguir:

Parte I Parte II

\author{
$\mathrm{a} / \mathrm{b} / \mathrm{c}$ \\ $780.0 / 436431 / 401.9 * 250.0440 .9$
}

O Sistema Nacional de Informações sobre Mortalidade, criado em 1975, estabeleceu procedimentos operacionais para a obtenção de estatísticas de mortalidade (34). Dentre os mesmos, previa-se que, para processamento eletrônico, seriam codificadas as variáveis de cada óbito, com a transcrição dos códigos em planilhas padronizadas. Em algumas unidades da Federação a digitação dos dados seria feita diretamente na Declaração de óbito, sem o uso da planilha. Outras unidades encaminhariam as planilhas ao Ministério da Saúde para digitação. O processamento de dados seria feito em Brasília. Alguns estados que tivessem disponibilidade de serviços computadorizados enviariam fitas magnéticas com os dados processados $(34,38,39,40)$. 
Esta última era a situação do Estado de São Paulo. Dado que a Declaração de óbito não previa caselas para a codificação, esta se fazia ao lado da própria variável codificada. Para os dados demográficos, o espaço era suficiente. No entanto, para as causas de morte, que eram codificadas sob a forma linear e intermediadas por símbolos, houve necessidade de uma adaptação, transcrevendo-se as mesmas na parte VII da Declaração de óbito, destinada à identificação do declarante e testemunhas para o registro de óbitos em localidades carentes de médicos. Quando essa parte, por alguma razão outra estivesse preenchida, sobre as linhas correspondentes seria colada uma etiqueta branca para receber a transcrição da codificação.

Codificadas todas as variáveis da Declaração de óbito, seguem-se a digitação das mesmas e o processamento pela Companhia de Processamento de Dados do Estado de São Paulo (PRODESP) . 
DESENVOLVIMENTO DAS TABELAS DE DECISÃO DO SISTEMA ACME

Preliminarmente ao desenvolvimento do Sistema ACME, a Divisão de Processamento de Dados do National Center for Health Statistics realizou uma pesquisa sobre a sua exeqüibilidade a fim de adquirir conhecimento maior sobre as características das informações médicas no atestado de óbito, sobre a extensão em que tais informações atendiam às normas para o seu fornecimento e sobre a potencialidade da seleção automática da causa básica de morte.

Nesta etapa, uma amostra de aproximadamente 15.000 declarações de óbito, correspondentes a um determinado mês, foi usada para este estudo de exeqüibilidade. Esta amostra apresentava a causa básica selecionada por um codificador, bem como códigos para todas as afecções ou outros dados passíveis de classificação. A hipótese de trabalho consistia em ser possível a seleção mecânica da causa básica de forma correta para a maioria dessas declarações por meio da aplicação de três regras de seleção e de uma parte de uma das regras de modificação. O objetivo do estudo era o de medir o grau de concordância entre os métodos de seleção manual e mecânico para: 1) aquelas declarações nas quais a afecção selecionada por aplicação das Regras Geral, Regra 1 ou Regra 2 fosse a causa básica de morte, o que equivale a dizer que esta medida indicaria a extensão em que não seriam usadas regras de modificação para a caracterização da causa básica, e 2) aquelas declarações nas quais a causa básica selecionada pelas Regra Geral, Regra 1 ou Regra 2 viessem a ser modificadas pela parte da Regra 7 (Associação) que dispõe sobre uma associação tipo "com menção de", quando o novo código substituto ocorre em qualquer parte do atestado médico (Parte I ou Parte II) (48).

Esse estudo de exeqüibilidade mostrou que 82,9\% das atribuições de causa básica realizadas mecanicamente, com uma aplicação limitada das regras de mortalidade, coincidiam com aquelas atribuídas pelos codificadores. Esse grau de concordância foi considerado como uma evidência adequada a fim de que maiores esforços viessem a ser desenvolvidos para a realização de um sistema automático mais completo. Além disso, essa experiência demonstrou que o sistema poderia reproduzir os procedimentos manuais para a seleção da causa básica de morte (48). 
O progresso desse desenvolvimento do sistema conduziu ao seu refinamento a ponto de justificar considerações para o seu uso na preparação dos dados de mortalidade a partir de 1968.

O teste do sistema com um volume maior de dados requeria a expansão das tabelas de decisão. Uma primeira abordagem nesse sentido consistiu em especificar, para cada código da Classificação Internacional de Doenças, suas relações com todos os demais códigos segundo as disposições das regras de mortalidade. Esta abordagem não frutificou por razões diversas. A CID continha muitas doenças e afecções que raramente eram mencionadas no atestado médico e dessa forma a especificação de suas relações etiológicas com as demais afecções era tarefa que estava muito além do conhecimento dos codificadores mais experientes. Além disso, uma determinada rubrica da Classificação Internacional de Doenças poderia apresentar termos de inclusão cujas inter-relações com outras afecções não fossem idênticas.

- princípio usado para a classificação das causas de morte consistiu em incorporar ao sistema computadorizado tabelas de decisão contendo dados que efetivamente tenham sido registrados nos atestados de óbito, com previsão para expandir tais tabelas de decisão quando novos fatos fossem encontrados.

As tabelas de decisão iniciais foram construídas com base nos dados reais de uma amostra de 18.539 declarações de óbito de janeiro de 1968. Esperava-se que, subseqüentemente, a incorporação dos dados das amostras de fevereiro e de março de 1968 viesse a revelar que a maneira pela qual tais tabelas expandem corresponderia a uma diminuição nítida de mês a mês e que seria pequeno o número de declarações que seriam influenciadas pela incorporação de novos dados. O Sistema ACME reconheceria as declarações cujos dados não estivessem previstos nas tabelas de decisão. Caso as hipóteses sobre o ritmo da expansão e sobre a influência nas declarações de óbito das tabelas de decisão fossem corretas, a adoção do Sistema ACME seria proposta após esses três meses de preparação (compreendendo cerca de 55.000 declarações de óbito) (48).

Desde que as tabelas de decisão iniciais do Sistema ACME tiveram como base as informações médicas contidas na amostra de declarações de janeiro de 1968, esperava-se, como na realidade ocorreu, que erros não deveriam ter existido ou seriam mínimos em relação à atribuição da causa básica pelo sistema. Dentre as 18.539 declarações processadas, verificou- 
se que a codificação da causa básica pelo ACME e de forma manual coincidiu em 96,0\% das vezes e foram observados erros manuais de codificação em 469 (2,5\%), rejeições intencionais de declarações pelo sistema em outras 267 (1,5\%) e ausência de erros intrínsecos ao sistema, isso segundo subcategorias de quatro dígitos da Classificação Internacional de Doenças.

Procurou-se, em seguida, medir até que ponto uma nova amostra de declarações de óbito, correspondente a fevereiro de 1968, poderia ser processada com acurácia pelo Sistema ACME sem ajustes prévios das tabelas de decisão, verificando-se que, nessas condições, a concordância de 87,1\% entre a causa básica identificada pelo sistema e aquela de forma manual (49).

O princípio aplicado no desenvolvimento de todas as tabelas de decisão do ACME foi o de incluir somente as relações causais realmente presentes nos atestados médicos, princípio este seguido no processamento da amostra de janeiro de 1968 . Entretanto, antes de processar os dados da amostra de fevereiro de 1968, todas as tabelas correspondentes as regras de modificação foram expandidas a fim de incluir todas as disposições correspondentes previstas na adaptação da Classificação Internacional de Doenças usada nos Estados Unidos. Com essa medida esperava-se que a expansão destas últimas tabelas seria mínima.

Após ajustes nas tabelas de decisão, incluindo-se as novas relações causais encontradas pela primeira vez na amostra de fevereiro de 1968 e aquelas relativas às regras de modificação, descritas no parágrafo anterior, o grau de concordância entre seleção da causa básica pelo sistema ACME e de forma manual passou a ser de 96,0\%. Este aumento da concordância refletia a inclusão de novos dados nas tabelas de decisão (49).

- processamento das declarações de óbito da amostra de março de 1968, realizado com base nas tabelas de decisão construídas a partir das amostras anteriores de janeiro e fevereiro, apresentou 89,7\% de concordância entre os dois métodos de seleção da causa básica, correspondente a um aumento de 2,6\% que refletiria o efeito da expansão das tabelas de decisão. Esses resultados permitiram concluir sobre a viabilidade do Sistema ACME, bem como confirmaram a hipótese de que a necessidade de expansão das tabelas de decisão iria decrescer rapidamente e que a eficácia do sistema iria aumentar proporcionalmente (50). 
Em razão do caráter e da extensão das mudanças entre a Oitava e a Nona Revisões da Classificação Internacional de Doenças, houve a necessidade de, praticamente, desenvolver um "novo" Sistema ACME para a Nona Revisão. Este novo sistema beneficiou-se extremamente da metodologia anteriormente empregada, bem como da experiência acumulada pelo seu uso durante a vigência da Oitava Revisão. Sua introdução seguiuse a realização de testes extensos com aproximadamente 150.000 declarações de óbito codificadas pela Oitava e pela Nona Revisões da CID, ao final dos quais a versão do ACME da Nona Revisão atribuía uma causa básica de forma incondicional em 98,5\% dos casos, uma causa básica condicionada à revisão manual de um codificador em um por cento dos casos e rejeitava 0,5\% das declarações para codificação manual. Desde que o Sistema $\mathrm{ACME}$ recebesse, como dados de entrada, códigos corretos, o grau de acurácia para atribuição da causa básica incondicional seria de $99.5 \%$, fato que representa um decréscimo da rejeição de casos de 5,5\% em relação à versão anterior. Além disso, técnicas especiais foram utilizadas nesta nova versão a fim de diminuir a necessidade de armazenamento de dados para processamento, para reduzir as rejeições e para ampliar a interface com outros programas (17). 
CONTROLE DE QUALIDADE DA CODIFICAÇÃO E DO PROCESSAMENTO DAS CAUSAS DE MORTE

A introdução do Sistema $\mathrm{ACME}$ criou a necessidade paralela de desenvolver-se um controle de qualidade diferente do usado até então para a codificação da causa básica de morte. Dois objetivos foram considerados para tal sistema de controle de qualidade: o desenvolvimento de um sistema que atendesse às necessidades de acurácia de dados para a codificação da causa básica e de causas múltiplas de morte e, de outro lado, fosse capaz de indicar com maior confiança a medida dos erros do que o sistema anteriormente disponível para avaliar a classificação da causa básica (61).

Até então, o controle de qualidade era realizado por codificadores com a característica de supervisores, que, de forma dita dependente, controlavam ou verificavam a atribuição de códigos feita por outros codificadores. Estudos sobre esta forma dependente de verificação usada no National Center for Health Statistics demonstraram que ocorriam fatos semelhantes aos ocorridos em outras instituições. Estes estudos mostravam que o codificador-supervisor tinha a tendência, consciente ou inconsciente, de negligenciar ou tolerar erros feitos pelo codificador inicial e introduzir um elemento de erro no processo de verificação e correção. Isso se dava desde que o verificador dependente tinha acesso aos códigos atribuídos pelo codificador original, e, portanto existia a tendência de ser influenciado pela decisão desse codificador original. Em face de tais limitações, decidiu-se que o controle de qualidade poderia ser mais bem realizado por meio de uma verificação independente, com o uso do computador.

Sob a verificação independente, o codificador original e o codificador-supervisor atuam independentemente um do outro. Este último não tem acesso aos códigos atribuídos pelo codificador original como acontece na verificação dependente e assim não há oportunidade de influências mútuas.

O novo sistema de controle de qualidade foi criado para medir - grau de ocorrência de três tipos de erros e para identificar os registros contendo erros. Em primeiro lugar, mediria erros que poderiam comprometer a atribuição automática da causa básica de morte, em segundo lugar erros comprometendo os dados das causas múltiplas e, em terceiro 
lugar, mediria os erros relativos à causa básica de morte atribuída pelo computador.

Esse sistema de controle de qualidade seria executado em duas etapas. Durante a primeira etapa, a adequação dos dados para processamento pelo ACME e para tabulações de causas múltiplas seria determinada. Esta etapa compreenderia a classificação de todas as declarações de óbito de um determinado lote por um codificador e a codificação de uma amostra sistemática de dez por cento do mesmo lote, de forma independente, por dois outros codificadores. O sistema de controle de qualidade compara os códigos atribuídos pelos três codificadores, código por código, linha por linha e correspondentes posições na linha, em todas as declarações da amostra, e gera uma codificação virtual, dita preferida, que sintetiza a opinião da maioria dentre os codificadores. Se dois codificadores colocam o mesmo código numa mesma posição numa mesma linha, este código é alocado para um conjunto de códigos "correto" ou "preferido" relativo a um determinado atestado médico. Cada registro passa então a ser comparado com as correspondentes codificações preferidas e, dessa forma, os erros são computados ao desempenho do codificador, em termos de erros quanto à atribuição da causa básica pelo ACME e em termos de tabulações de causas múltiplas. Se os erros fossem excessivos em qualquer caso, todo o lote de declarações de óbito seria recodificado por um quarto codificador e comparado novamente com a codificação dos dois codificadores independentes da amostra $(22,46,61)$.

A segunda etapa do controle de qualidade seria destinada a medir os erros relativos à atribuição da causa básica pelo computador. O sistema ACME compara os códigos resultantes do processamento realizado com os códigos de causas básicas codificadas manualmente numa amostra de dez por cento de determinado lote, entretanto não na mesma amostra usada para avaliar a codificação das afecções mencionadas no atestado médico. Este sistema pode trabalhar com amostras de qualquer tamanho, dependendo da necessidade do usuário. Se, para determinado lote, a discordância for maior do que a tolerância permitida, os registros correspondentes serão analisados para determinar o grau de erros atribuíveis à codificação manual da causa básica, às tabelas de decisão do ACME e à codificação de todos os pormenores dos dados médicos. Se os erros combinados desses dois últimos grupos excederem os limites de tolerância, a codificação de todas as afecções será verificada totalmente, as tabelas de decisão serão reavaliadas e o lote será reprocessado pelo sistema ACME. Este reprocessamento limita-se àqueles lotes nos quais não foram observados excessos de erros de codificação na 
primeira etapa do controle de qualidade. Portanto, a rejeição de lotes nesta segunda etapa seria extremamente rara.

Além disso, controles de qualidade ocorrem no Sistema ACME relativos à validação de todos os códigos correspondentes às afecções informadas no atestado médico, à forma de entrada de dados e à validação da causa básica selecionada (44, 45, 61).

Em que pese o engenho deste sistema de controle de qualidade, considerado superior àquele de verificação dependente, não haviam sido realizados estudos preliminares para testar a acurácia das taxas de erro sobre a codificação médica baseada na codificação tripla independente. A acurácia dessas medidas poderia ser questionada dado que: 1) letra ilegível, colocação incorreta ou confusa das afeç̧ões no atestado médico ou má qualidade do microfilme poderia tornar impossível a determinação de um único código para determinadas afeç̧ões; 2) instruções para codificação poderiam ser imprecisas permitindo múltiplas interpretações e dois ou mais códigos aceitáveis para uma causa particular; 3) possibilidade de que um codificador com código válido receba a imputação de erro se os dois outros codificadores coincidentemente colocam código não aceitável, e 4) possibilidade de dois codificadores (terceiro codificador não oferecer códigol ou de todos os três codificadores apresentarem códigos não coincidentes, o que determina a imputação de erro a todos, embora seja plausível que um deles tenha codificado de forma correta (22).

Realizou-se um minucioso estudo metodológico sobre o sistema de controle de qualidade. Os dados para tal estudo provieram de uma subamostra de 30 das 472 amostras utilizadas entre julho de 1974 e março de 1975. Seis codificadores foram utilizados para a codificação de cada uma dessas 30 subamostras. Os primeiros três codificadores foram o codificador responsável pela codificação do lote e os dois codificadores da amostra de dez por cento para a verificação independente durante o processamento de rotina. Três codificadores adicionais foram indicados para este estudo. Um codificador adicional realizava uma verificação dependente, pois lhe foi dado acesso a codificação do codificador original do lote. Os outros dois codificadores adicionais foram escolhidos dentre um seleto grupo de peritos e o trabalho dos mesmos serviu como padrão para o estudo. A um desses peritos foi dado acesso a codificação do codificador original do lote e de um dos codificadores da amostra de controle, atuando, portanto como uma espécie de verificador dependente de uma verificação independente dupla. O último 
perito realizava uma codificação independente da subamostra (22).

Considerando que todos os resultados do estudo foram comparados com a codificação dos dois peritos, torna-se importante verificar que a taxa de concordância entre os mesmos foi de $97,77 \%$ e que as taxas de erro foram de 0,56\% e $1,26 \%$ respectivamente para o perito dependente e perito independente.

Este estudo tinha o objetivo de avaliar as medidas de erro produzidas pelo sistema de controle de qualidade baseado na codificação tripla independente, o que equivale a dizer que importava saber até que ponto as medidas de erro atribuídas ao codificador original do lote estavam corretas. Considerouse que a melhor medida do erro do codificador original correspondeu ao valor de 4,27\%, baseada no trabalho do perito independente e ajustada para os erros deste último. O perito dependente estimou a mesma taxa de erro em 3,05\%, e para o codificador adicional que atuava de forma dependente a estimativa do erro foi de 3,67\%. Note-se que, previamente, durante 0 trabalho de rotina, o sistema de controle de qualidade havia estimado em 3,75\% essa taxa de erro (22).

Além de avaliar as taxas de erro para a codificação de todas as afecções codificadas do atestado médico para servirem de dados de entrada ao Sistema ACME, este estudo também avaliou a influência dos erros sobre a causa básica resultante do processamento. Para tanto, verificou-se que o grau de concordância entre os peritos, segundo subcategorias de quatro dígitos, foi de $98,85 \%$ e que as taxas de erro foram de $1,87 \%, 2,21 \%$ e de 1,89\%, respectivamente para o perito dependente, perito independente e finalmente para o codificador do lote original (22).

O Sistema ACME foi submetido recentemente a outro tipo de avaliação. Uma equipe de médicos, constituída por um patologista e por um clínico, atuando na qualidade de peritos, estudaram a extensão em que o trabalho dos codificadores do "National Center for Health Statistics" traduzia a intenção dos médicos que atestavam os óbitos. Este estudo consistiu na revisão de uma amostra não-casual de Declarações de óbito a fim de identificar a causa básica da morte e avaliar a acurácia e a simplicidade das Regras de Mortalidade e das disposições para a codificação de causas múltiplas de morte (16). 
A conclusão desta avaliação foi a de que, de modo geral, o Sistema ACME funcionava de modo satisfatório e que não eram necessárias ou recomendáveis alterações tendo em vista a conveniência de preservar a continuidade histórica. Concluiuse também que as maiores dificuldades não residiam nas atividades de codificação e de processamento das causas de morte, porém nas deficiências dos médicos no fornecimento de informações na Declaração de óbito (16).

A introdução do Sistema ACME no Estado de São Paulo não foi acompanhada de atividades relacionadas à avaliação da qualidade do trabalho dos codificadores de causas de morte nos moldes aos executados nos Estados Unidos.

- controle da qualidade do processamento das causas de morte pelo Sistema ACME realizava-se por meio da codificação manual de amostra de 10\% das Declarações de óbito e subseqüente análise das discordâncias. A identificação dos problemas mais freqüentes ensejou a elaboração de tabelas de decisão especiais para o processamento de mortes relacionadas à Doença de Chagas e à Esquistossomose mansônica. A codificação manual da causa básica foi feita até o ano de 1990, com Declarações de óbito correspondentes ao ano de 1989. 
JUSTIFICATIVA DO TRABALHO

Alguns estudos têm sido feitos sobre a variabilidade da codificação de causas de morte por diferentes codificadores. LAURENTI (29), estudando óbitos hospitalares em 1973, verificou que, em 1.827 atestados de óbito codificados separadamente por dois peritos, houve a discordância entre as causas selecionadas em $6,73 \%$ das vezes segundo grupos da Classificação Internacional de Doenças. CURB (10), em 1983, ao analisar a codificação por três codificadores de causas de falecidos que participavam de programa de diagnóstico e seguimento de hipertensão, verificou a não concordância em 9,8\% das causas segundo categorias de três algarismos da Classificação Internacional de Doenças. Em 1985, em avaliação coordenada pelo Centro Brasileiro de Classificação de Doenças, com a participação de 20 Unidades da Federação compreendendo 47 codificadores, com a utilização de lote de Declarações de óbito caracterizadas por diferentes tipos de afeç̧ões, verificou-se que o grau de acerto, segundo três algarismos da Classificação Internacional de Doenças, variou do pior resultado de 38,7\% ao melhor de 81,6\% (3).

A experiência de quase 20 anos na formação de pessoal para o trabalho de classificação de causas de morte para o Sistema Nacional de Informações sobre Mortalidade torna consciente a necessidade de avaliar-se o desempenho neste trabalho. Esta preocupação foi expressa ao introduzir uma coletânea de trabalhos nacionais sobre qualidade das estatísticas de mortalidade: "Atualmente, sem dúvida e com isenção de ufanismo, pode-se dizer que as estatísticas de mortalidade no Brasil constituem-se em feliz realidade. A confirmação desta realidade, dentre outras formas, pode ser feita pela observação de trabalhos científicos e práticos que analisam os dados de mortalidade existentes, objetivando verificar o número de óbitos conhecidos, isto é, a assim chamada cobertura dos dados e/ou a qualidade dos mesmos. A contribuição prestada ao aprimoramento do Sistema de Informações sobre Mortalidade pelos trabalhos acima referidos tem sido muito grande e nesse sentido inicia-se a sua divulgação. Espera-se que o exemplo desses trabalhos possa estimular o uso e a critica das estatísticas de mortalidade".

A avaliação da codificação e do processamento das causas de morte pelo Sistema ACME no Estado de São Paulo, com características de avaliação recíproca do trabalho de 
formação de codificadores, insere-se no contexto de aprimoramento das estatísticas de mortalidade. 
OBJETIVOS 
OBJETIVOS GERAIS

Avaliar a qualidade da codificação e do processamento das causas de morte pelo sistema ACME utilizado na Fundação Sistema Estadual de Análise de Dados (SEADE) no Estado de São Paulo.

OBJETIVOS ESPECÍFICOS

Avaliar a qualidade da codificação das causas de morte segundo os requisitos específicos para entrada de dados no Sistema ACME.

Avaliar a qualidade da codificação das causas de morte segundo características circunstânciais do preenchimento e do fluxo da Declaração de óbito.

Avaliar o comprometimento da qualidade da identificação da causa básica e das causas associadas de morte devidas a erros de codificação ou de outros fatores relacionados à entrada de dados no Sistema ACME.

Identificar problemas de processamento de causas de morte informadas no Modelo Internacional de Atestado Médico de Causas de Morte devidos às tabelas de decisão do Sistema ACME . 
MATERIAL E MÉTODOS 
O material de estudo constitui-se de uma amostra sistemática de 3.313 declarações de óbito de residentes no Estado de São Paulo e registrados no ano de 1992. Esta amostra resultou dos 202.141 óbitos correspondentes (1), teve intervalo 61 e início no óbito 38 .

Esta amostra foi retirada do banco de dados final de óbitos da Fundação SEADE, destinado a encaminhamento ao Ministério da Saúde para consolidação com os dados das demais Unidades da Federação. A escolha deste banco de dados e a amostragem sistemática objetivaram a seleção de declarações de óbito ao acaso. Já comentado anteriormente o fato de óbitos de menores de um ano de idade estarem agrupados no início dos lotes mensais recebidos dos cartórios para apuração preliminar dos mesmos. Este banco de dados final contém todos os lotes mensais, por ordem de mês e de cartório no qual a amostragem sistemática contorna o problema citado.

A representatividade desta amostra em relação aos 202.141 óbitos do Estado de São Paulo no ano de 1992 pode ser observada nas tabelas 1 e 2, que apresentam, segundo idade e sexo, a distribuição dos óbitos de residentes, respectivamente no Estado e na amostra. Do mesmo modo, esta representatividade também pode ser vista nas tabelas 3 e 4, que mostram, segundo causas de morte pelos Capítulos da Classificação Internacional de Doenças e por sexo, os respectivos óbitos de residentes para o Estado e para a amostra. Nestas tabelas observa-se que os valores proporcionais correspondentes são muito próximos, fato também verificado para a distribuição dos óbitos segundo os 949 cartórios de registro civil.

Da amostra, os registros das declarações de óbito foram impressos e também copiados em meio eletrônico. As declarações de óbito arquivadas na Fundação SEADE foram identificadas e extraídas das mesmas cópias xerográficas. Não foram encontradas sete declarações.

Não foi possível obter-se o arquivo criado pela entrada inicial de dados no Sistema ACME. Este arquivo, que reproduz os dados codificados originalmente do Atestado Médico, contém as afecções codificadas linha por linha segundo respectivas posições nas linhas. Por meio deste arquivo poderia ser feita a avaliação da transcrição da codificação aposta pelo codificador na Declaração de óbito durante a atividade de digitação. Este arquivo, após o processamento, a identificação da causa básica e a geração do arquivo final ("good file"), é destruído. 
A codificação de todos os itens da Declaração de óbito foi revista. Face aos objetivos do trabalho, apenas os códigos referentes aos dados do Atestado Médico foram verificados para análise critica pormenorizada. No entanto, os demais itens, particularmente aqueles constantes das partes II e III da Declaração de óbito, serão objeto de comentários se a codificação ou outras características dos mesmos tiver influência sobre a qualidade da codificação ou processamento das causas de morte. No mesmo sentido, outros aspectos relacionados ao uso da Declaração de óbito serão comentados.

Foram revistas 3.306 Declarações de óbito, uma a uma, sendo os códigos referentes aos dados do Atestado Médico confrontados com os correspondentes campos dos registros dessas declarações, impressos a partir do arquivo final de óbitos. A critica e a avaliação da forma de entrada de dados e da codificação tiveram como base as disposições dos manuais de instruções para o uso do Sistema ACME publicados pelo National Center for Heath Statistics ("Instructions for Classifying Multiple Causes of Death" e "NCHS Procedures for Mortality Medical Data system File Preparation and Maintenance") (42, 43, 46). Nesta revisão eram observados o código propriamente dito da afecção, sua colocação em relação aos demais códigos e o uso de convenções para a transcrição desses dados. Cópias de 24 Atestados Médicos foram encaminhadas ao National Center for Health Statistics para serem codificados em face de dificuldades específicas de codificação (Anexo 3). Outros 40 diagnósticos de difícil classificação foram codificados independentemente por três peritos do Centro Brasileiro de Classificação de Doenças e pelo autor.

Após o confronto dos códigos da Declaração de óbito e os correspondentes registros impressos, a causa básica obtida pelo processamento pelo Sistema ACME e que constava em campo próprio no registro impresso, era criticada. Buscava-se saber, de um lado, se erros de codificação de afecções mencionadas no Atestado Médico influenciavam ou não a classificação da causa básica processada pelo Sistema ACME, e, de outro lado, desde que as afecções estivessem codificadas corretamente, se a causa básica resultante do processamento pelo Sistema ACME estava corretamente classificada. A análise da classificação e do processamento da causa básica de morte fundamentava-se nas tabelas de decisão publicadas pelo National Center for Health Statistics (ICD-9 ACME Decision Tables for Classifying Underlying Cause of Death, 1984) (44, 45). 
Ressalve-se que a notação a ser usada neste trabalho, para maior clareza, difere ligeiramente da empregada na rotina pelos codificadores da Fundação SEADE. Os códigos da Classificação Internacional de Doenças apresentarão um ponto indicando a subcategoria, espaços entre os códigos e símbolos serão colocados e a letra "b", usada para indicar ausência de código ou espaço entre duas causas, não será cortada.

Ressalve-se também que, em razão de seu processamento em microcomputador, as tabelas de apresentação de dados não atendem rigorosamente às normas de apresentação tabular.

No texto, a expressão "Atestado Médico" refere-se ao "Modelo Internacional de Atestado Médico de Causa de Morte" (31). 
TABELA 1 - Óbitos de residentes, por idade e sexo, Estado de São Paulo, 1992

\begin{tabular}{|c|c|c|c|c|c|c|}
\hline \multirow{2}{*}{$\begin{array}{l}\text { IDADE } \\
\text { (anos) }\end{array}$} & \multirow{2}{*}{$\begin{array}{l}\text { MASCU LINO } \\
\text { número }\end{array}$} & \multirow[b]{2}{*}{$\%$} & \multicolumn{2}{|c|}{ FEMI NINO } & \multicolumn{2}{|c|}{ TO TAL } \\
\hline & & & número & $\%$ & número & $\%$ \\
\hline Menos 1 & 9.762 & 8,1 & 7.447 & 9,2 & 17.209 & 8,5 \\
\hline 1 & 602 & 0,5 & 534 & 0,7 & 1.136 & 0,6 \\
\hline 2 & 312 & 0,3 & 256 & 0,3 & 568 & 0,3 \\
\hline 3 & 209 & 0,2 & 185 & 0,2 & 394 & 0,2 \\
\hline 4 & 165 & 0,1 & 138 & 0,2 & 303 & 0,1 \\
\hline 5 a 9 & 708 & 0,6 & 464 & 0,6 & 1.172 & 0,6 \\
\hline 10 a 14 & 922 & 0,8 & 488 & 0,6 & 1.410 & 0,7 \\
\hline 15 a 10 & 3.233 & 2,7 & 815 & 1,0 & 4.048 & 2,0 \\
\hline 20 a 24 & 4.904 & 4,0 & 1.128 & 1,4 & 6.032 & 3,0 \\
\hline 25 a 29 & 5.278 & 4,4 & 1.469 & 1,8 & 6.747 & 3.3 \\
\hline 30 a 34 & 5.399 & 4,5 & 1.815 & 2,2 & 7.214 & 3,6 \\
\hline 35 a 39 & 5.883 & 4,9 & 2.197 & 2,7 & 8.080 & 4,0 \\
\hline 40 a 44 & 6.135 & 5,1 & 2.580 & 3,2 & 8.715 & 4,3 \\
\hline 45 a 49 & 6.414 & 5,3 & 3.214 & 4,0 & 9.628 & 4,8 \\
\hline 50 a 54 & 7.368 & 6,1 & 3.792 & 4,7 & 11.160 & 5,5 \\
\hline 55 a 59 & 8.629 & 7,1 & 4.928 & 6,1 & 13.557 & 6,7 \\
\hline 60 a 64 & 10.131 & 8,4 & 6.250 & 7,7 & 16.381 & 8,1 \\
\hline 65 a 69 & 10.946 & 9,0 & 7.429 & 9,2 & 18.375 & 9,1 \\
\hline 70 a 74 & 10.346 & 8,5 & 8.292 & 10,3 & 18.638 & 9,2 \\
\hline 75 a 79 & 9.837 & 8,1 & 9.256 & 11,4 & 19.093 & 9,4 \\
\hline 80 e mais & 13.740 & 11,3 & 18.071 & 22,3 & 31.811 & 15,7 \\
\hline ignorado & 334 & 0,3 & 136 & 0.2 & 470 & 0,2 \\
\hline TOTAL & 121.257 & 100,0 & 80.884 & 100,0 & 202.141 & 100,0 \\
\hline
\end{tabular}


TABELA 2 - Óbitos de residentes, por idade e sexo, amostra, Est. S. Paulo, 1992.

\begin{tabular}{|c|c|c|c|c|c|c|}
\hline \multirow{2}{*}{$\begin{array}{l}\text { IDADE } \\
\text { (anos) }\end{array}$} & \multicolumn{2}{|c|}{ MASCU LINO } & \multicolumn{2}{|c|}{ FEMI NINO } & \multicolumn{2}{|c|}{ TO TAL } \\
\hline & número & $\%$ & número & $\%$ & número & $\%$ \\
\hline Menos 1 & 162 & 8,2 & 115 & 8,5 & 277 & 8,4 \\
\hline 1 & 11 & 0,6 & 11 & 0,8 & 22 & 0,7 \\
\hline 2 & 10 & 0,5 & 3 & 0,2 & 13 & 0,4 \\
\hline 3 & 3 & 0,2 & 5 & 0,4 & 8 & 0,2 \\
\hline 4 & 2 & 0,1 & 2 & 0,1 & 4 & 0,1 \\
\hline 5 a 9 & 9 & 0,5 & 6 & 0,4 & 15 & 0,5 \\
\hline 10 a 14 & 14 & 0,7 & 11 & 0,8 & 25 & 0,8 \\
\hline 15 a 10 & 43 & 2,2 & 11 & 0,8 & 54 & 1,6 \\
\hline 20 a 24 & 72 & 3,7 & 24 & 1,8 & 96 & 2,9 \\
\hline 25 a 29 & 88 & 4,5 & 12 & 0,9 & 100 & 3,0 \\
\hline 30 a 34 & 82 & 4,2 & 27 & 2,0 & 109 & 3,3 \\
\hline 35 a 39 & 92 & 4,7 & 38 & 2,8 & 130 & 39 \\
\hline 40 a 44 & 79 & 4,0 & 47 & 3,5 & 126 & 3,8 \\
\hline 45 a 49 & 118 & 6,0 & 46 & 3,4 & 164 & 5,0 \\
\hline 50 a 54 & 112 & 5,7 & 72 & 5,3 & 184 & 5,6 \\
\hline 55 a 59 & 132 & 6,7 & 77 & 5,7 & 209 & 6,3 \\
\hline 60 a 64 & 160 & 8,1 & 112 & 8,3 & 272 & 8,2 \\
\hline 65 a 69 & 189 & 9,6 & 142 & 10,5 & 331 & 10,0 \\
\hline 70 a 74 & 181 & 9,2 & 133 & 9,8 & 314 & 9,5 \\
\hline 75 a 79 & 160 & 8,1 & 167 & 12,4 & 327 & 9,9 \\
\hline 80 e mais & 241 & 12,3 & 286 & 21,2 & 527 & 15,9 \\
\hline ignorado & 4 & 0,2 & 2 & 0,1 & 6 & 0,2 \\
\hline TOTAL. & 1.964 & 100,0 & 1.349 & 100,0 & $3: 313$ & 100,0 \\
\hline
\end{tabular}


TABELA 3 - Óbitos de residentes, por causa e sexo, Estado de São Paulo, 1992.

\begin{tabular}{lrrrrrr}
\hline C.I.D. & \multicolumn{2}{r}{ MASCU LINO } & \multicolumn{2}{c}{ FEMI NINO } & \multicolumn{2}{c}{ TO TAL } \\
& número & $\%$ & número & $\%$ & número & $\%$ \\
\hline Cap. I & 4.569 & 3,8 & 2.837 & 3,5 & 7.406 & 3,7 \\
Cap. II & 15.032 & 12,4 & 12.265 & 15,2 & 27.297 & 13,5 \\
Cap. III & 7.654 & 6,3 & 5340 & 6,6 & 12.994 & 6,4 \\
Cap. IV & 361 & 0,3 & 357 & 0,4 & 718 & 0,4 \\
Cap. V & 1.115 & 0,9 & 214 & 0,3 & 1.329 & 0,7 \\
Cap. VI & 1.442 & 1,2 & 1.086 & 1,3 & 2.528 & 1,3 \\
Cap. VII & 35.307 & 29,1 & 30.298 & 37,5 & 65.605 & 32,5 \\
Cap. VIII & 12.897 & 10,6 & 8.819 & 10,9 & 21.716 & 10,7 \\
Cap. IX & 6.861 & 5,7 & 3.431 & 4,2 & 10.292 & 5,1 \\
Cap. X & 1.792 & 1,5 & 1.479 & 1,8 & 3.271 & 1,6 \\
Cap. XI & 0 & 0,0 & 284 & 0,4 & 284 & 0,1 \\
Cap. XII & 173 & 0,1 & 176 & 0,2 & 349 & 0,2 \\
Cap. XIII & 145 & 0,1 & 296 & 0,4 & 441 & 0,2 \\
Cap. XIV & 1.263 & 1,0 & 1.122 & 1,4 & 2.385 & 1,2 \\
Cap. XV & 4.997 & 4,1 & 3.877 & 4,8 & 8.874 & 4,4 \\
Cap. XVI & 7.346 & 6,1 & 4.929 & 6,1 & 12.275 & 6,1 \\
C. Ext. & 20.303 & 16,7 & 4.074 & 5,0 & 24.377 & 12,1 \\
\hline TOTAL & 121.257 & 100,0 & 80.884 & 100,0 & 202.141 & 100,0 \\
& & & & & & \\
\hline
\end{tabular}


TABELA 4 - Óbitos de residentes, por causa e sexo, amostra, Est. S. Paulo, 1992.

\begin{tabular}{|c|c|c|c|c|c|c|}
\hline \multirow[t]{2}{*}{ C.I.D. } & \multicolumn{2}{|c|}{ MASCU LINO } & \multicolumn{2}{|c|}{ FEMI NINO } & \multicolumn{2}{|c|}{ TO TAL } \\
\hline & número & $\%$ & número & $\%$ & número & $\%$ \\
\hline Cap. I & 79 & 4,0 & 44 & 3,3 & 123 & 3,7 \\
\hline Cap. II & 263 & 13,4 & 230 & 17,0 & 493 & 14,9 \\
\hline Cap. III & 135 & 6,9 & 89 & 6,6 & 224 & 6,8 \\
\hline Cap. IV & 6 & 0,3 & 7 & 0,5 & 13 & 0,4 \\
\hline Cap. V & 20 & 1,0 & 4 & 0,3 & 24 & 0,7 \\
\hline Cap. VI & 16 & 0,8 & 16 & 1,2 & 32 & 1,0 \\
\hline Cap. VII & 568 & 28,9 & 503 & 37,3 & 1.071 & 32,3 \\
\hline Cap. VIII & 208 & 10,6 & 137 & 10,2 & 345 & 10,4 \\
\hline Cap. IX & 106 & 5,4 & 54 & 4,0 & 160 & 4,8 \\
\hline Cap. X & 29 & 1,5 & 24 & 1,8 & 53 & 1,6 \\
\hline Cap. XI & 0 & 0,0 & 8 & 0,6 & 8 & 0,2 \\
\hline Cap. XII & 3 & 0,2 & 3 & 0,2 & 6 & 0,2 \\
\hline Cap. XIII & 2 & 0,1 & 5 & 0,4 & 7 & 0,2 \\
\hline Cap. XIV & 23 & 1,2 & 19 & 1,4 & 42 & 1,3 \\
\hline Cap. XV & 85 & 4,3 & 65 & 4,8 & 150 & 4.5 \\
\hline Cap. XVI & 122 & 6,2 & 73 & 5,4 & 195 & 5,9 \\
\hline C. Ext. & 299 & 15,2 & 68 & 5,0 & 367 & 11,1 \\
\hline TOTAL & 1.964 & 100,0 & 1.349 & 100,0 & 3.313 & 100,0 \\
\hline
\end{tabular}


RESULTADOS E DISCUSSÃO 
ASPECTOS GERAIS

\section{Via encaminhada ao SEADE}

- fluxo da Declaração de óbito prevê o recebimento pelos cartórios de Registro Civil das duas vias do mesmo, arquivamento da segunda e encaminhamento da primeira via a Fundação SEADE. Assinalado anteriormente que quando a escrita na primeira via não é firme e vigorosa, a reprodução na segunda via torna-se fraca, ilegível e de difícil interpretação. Além disso, pode ocorrer o deslocamento de uma via sobre a outra no momento do preenchimento da Declaração de óbito, deslocando também, na segunda via, o item assinalado na primeira via.

A fim de avaliar as distorções devidas ao encaminhamento da segunda via da Declaração de óbito a Fundação SEADE ao invés da primeira, os erros conseqüentes foram assinalados e confrontados com o registro correspondente no arquivo final de óbitos.

A Tabela 5 apresenta o número e percentagem de Declarações de óbito segundo a via encaminhada. Pode-se observar que o modelo antigo da Declaração de óbito, ainda disponível em algumas localidades, foi enviado a Fundação SEADE em 5,8\% das vezes. Neste modelo ainda não era especificada a destinação de cada uma das vias; a observação da cópia xerográfica não permite identificar de qual se trata. Do modelo novo, a primeira via foi encaminhada em 52,9\% e a segunda em 41,0\% das vezes. Das declarações em que se ignora a via encaminhada, sete correspondem àquelas não encontradas e duas apresentavam-se danificadas, prejudicando a identificação por meio da cópia xerográfica.

Os erros mais freqüentes diziam respeito à codificação do local de ocorrência do óbito, previsto no item 10 da Declaração de óbito. Em cinco declarações, este item foi codificado como sendo o domicílio, quando o correto seria o hospital, em uma declaração codificou-se a via publica, sendo - hospital o correto e em outra declaração indicou-se o hospital como local de ocorrência, sendo a via pública o correto. Em todos esses casos, o codificador de dados demográficos poderia ter evitado o erro, pois o nome do hospital ou o endereço do mesmo estava assinalado no item seguinte da Declaração de óbito, de número 11. Em uma destas declarações havia mesmo uma observação neste item, remetendo 
a uma ressalva colocada na parte VII da Declaração de óbito, que dizia "Ressalva item 11 - Pronto Socorro Municipal". Em uma destas declarações, além do local de ocorrência, também o estado civil e o sexo foram codificados incorretamente, sendo o sexo indicado feminino, erro que também poderia ser evitado dado que o nome do falecido era Joaquim. Neste último caso, o uso da segunda via da Declaração de óbito foi, com grande probabilidade, a principal causa do erro. Duas dessas declarações provieram de um mesmo cartório. Assinale-se também que a codificação dos dados demográficos é atividade repetitiva e monótona, feita de maneira mecânica pelos codificadores.

TABELA 5 - Número e percentagem de declarações de óbito, de acordo com a via encaminhada á Fundação SEADE, São Paulo, 1992 .

VIA DA D.O.

Número

PERCENTAGEM

$\begin{array}{lrr}\text { MODELO ANTIGO } & 192 & 5,8 \\ \text { MODELO NOVO-1A VIA } & 1.753 & 58,7 \\ \text { MODELO NOVO-2A VIA } & 1.359 & 41,0 \\ \text { IGNORADA } & 9 & 0,3\end{array}$

TOTAL

3.313

100,0

\section{Declarações de óbito em branco.}

Estranho o encontro de quatro Declarações de óbito praticamente em branco, sem assinatura de médico ou de testemunhas. Todas estas declarações tinham o código 799.9 e como causa básica - 799.7 usado corretamente como código de entrada no Sistema ACME (42, 43) - correspondente a causa mal definida. Duas delas vieram encaminhadas na primeira via e duas restantes, procedentes de um mesmo cartório, na segunda 
via da Declaração de óbito. A codificação de alguns dos itens dessas declarações se deveu ao uso dos dados dos mapas que as acompanhavam.

\section{Declarações registradas por testemunhas}

A Lei dos Registros públicos dispõe que, se houver médico no lugar do falecimento, o sepultamento somente se fará com a apresentação de uma certidão do oficial de registro da localidade, certidão esta condicionada ao atestado do médico (2) . Portanto causa estranheza e reveste-se de anormalidade a existência de Declarações de óbito assinadas apenas por declarantes e testemunhas. No Estado de São Paulo, praticamente todos os municípios dispõe de médico, a quem caberia fornecer a Declaração de óbito.

Na amostra estudada, quatro Declarações de óbito foram encontradas cujo registro se processou a partir de informações de declarantes e testemunhas, duas das quais registradas em um mesmo Cartório de Registro Civil. Como causa de morte, em três dessas Declarações, no Atestado Médico, mencionou-se morte "natural", "sem assistência médica" e "morte natural sem assistência médica", as quais foram codificadas como "morte sem assistência médica" (798.9) e na quarta Declaração nada foi mencionado, tendo sido codificada "causa desconhecida" (799.9).

\section{Carimbos nas Declarações de óbito}

Chama-se a atenção para a colocação de carimbos por uma grande variedade de entidades relacionadas ao fluxo da Declaração de óbito, dentre as quais podem ser citados hospitais, empresas funerárias, Cartórios de Registro Civil, Delegacias de Policia, Institutos Médico-Legais, Serviços de Verificação de óbitos e Centros de Saúde.

Uma determinada Declaração de óbito apresentou três carimbos de entidades diferentes, respectivamente da Delegacia de Policia do Município, atestando a indigência do falecido, da Empresa Funerária e do Centro de Saúde.

Além de carimbos de entidades, observam-se outros em que frases, siglas ou palavras informando determinada característica relacionada ao óbito ou ao falecido são incluídas. Assim, como exemplo, "autorizo o sepultamento 
antes de 24 horas", "indigente", "isento de emolumentos", "D.I.C." .

Aparentemente, na maior parte das vezes, os carimbos ocorrem na primeira via e são colocados na Parte IV, no Atestado Médico da Declaração de óbito. Este fato pode prejudicar a leitura das causas de morte e comprometer sua codificação.

\section{Anotações das empresas funerárias}

O manuseio de Declarações de óbito propicia o encontro de fatos fora do comum. Dentre esses, observa-se a utilização da Declaração de óbito pelas empresas ou serviços funerários para a anotação de particularidades correlatas às atividades das mesmas. Naqueles municípios onde os serviços funerários se encarregam de intermediar o registro em cartório, a família do falecido entrega a Declaração de óbito ao agente funerário. Nessa ocasião, as mais variadas anotações podem ser colocadas, dentre as quais a origem, à hora e o destino do enterro, o local do velório, o tamanho e o tipo da urna funerária, o preço do funeral, a variedade de flores, e outras. Tais anotações são observadas nas margens e aparentemente não prejudicam a qualidade da codificação das variáveis incluídas na Declaração de óbito.

\section{Dados contraditórios assinalados}

A indicação de dados em caselas distintas de um mesmo item da Declaração de óbito, isto é, o fato de assinalar classes contraditórias de uma mesma variável eventualmente pode comprometer a codificação respectiva. Nesses casos, o codificador lança mão dos dados registrados nos mapas encaminhados pelos cartórios para a codificação correta. Em duas vezes no item três, correspondente a caracterização de óbito fetal, assinalou-se "sim" e "não"; no item 6, estado civil, dados contraditórios foram assinalados em 9 vezes, como, por exemplo, "solteiro" e "casado", "solteiro" e "viúvo", "solteiro", "casado" e viúvo" ou "casado" e "viúvo". Em uma vez observou-se que no item 7, sexo, assinalou-se "masculino" e "feminino", tendo sido codificado erradamente o sexo masculino (código 1) dado que a falecida chamava-se "Maria" e tinha como ocupação "doméstica".

Outras contradições foram assinaladas nos iten 11, relativo ao local de ocorrência do óbito, no item 33, relativo à caracterização do médico que assina o atestado e no item 37, relativo ao tipo de violência sofrida pelo falecido. Neste último caso, verifica-se que poderia ter ocorrido um erro de 
codificação, pois foram assinaladas, respectivamente, as caselas relativas a "acidente por queda" e "tipo de violência ignorado". Nesta mesma declaração outro fato pouco comum foi observado, qual seja, o médico refazer as linhas (a) e (b) da Parte I do Atestado Médico.

Além das assinaladas contradições, intrínsecas de um mesmo item, foram observadas contradições entre dados de itens diversos da Declaração de óbito. Neste sentido, embora não se constituindo em exemplo de fatos improváveis, em Declaração de óbito de recém-nascido de 10 horas de vida, no item 27, correspondente a duração da gestação, assinalou-se "de 20 a $27 "$ semanas, no item 31, peso ao nascer de 1.200 gramas e causa básica "imaturidade extrema". A causa básica codificada foi imaturidade extrema (765.0), corretamente, apesar do peso maior que 1.000 gramas.

No entanto, uma da Declaração de óbito muito estranha correspondia a falecido do sexo masculino de 14 anos de idade que, segundo o item 10, teria como local de ocorrência a "via pública", enquanto no item 11 seguinte assinalava-se "lagoa (estrada dos romeiros), tendo por causa declarada por extenso na Parte I do Atestado Médico "asfixia mecânica por afogamento", no item 37, como tipo de violência "demais acidentes de trânsito" e no item 39, como local do acidente, "via pública". Codificou-se como asfixia devida a acidente de trânsito não especificado - )94.1 / \&819.9 - tendo ocorrido ainda um erro de digitação resultando a causa final do arquivo em E814.9. Neste caso, ressalvando que o codificador poderia ter tido esclarecimentos adicionais que justificassem as causas codificadas, considerou-se que o correto seria entender o afogamento acidental (E910.8) como causa básica.

\section{Retificação de dados "demográficos"}

Observou-se que dados demográficos em Declarações de óbito eram retificados em alguma etapa do seu fluxo, aparentemente no momento de seu preenchimento ou por ocasião do registro no cartório. O desenho da Declaração de óbito não prevê local para a colocação de tais retificações, que freqüentemente são datilografadas na Parte VII, reservada para o declarante e testemunhas que registram o óbito. As retificações encontradas foram para nome e idade do falecido e para locais de ocorrência e de residência, respectivamente itens 4, 9, 10 e 11 da Declaração de óbito. Dentre as ressalvas observadas, três delas foram procedentes de um mesmo cartório. 


\section{Erros de grafia}

A maioria dos itens da Declaração de óbito deve ser informada assinalando-se a casela adequada. Portanto, as oportunidades para erros de grafia são poucas e se limitam àquelas variáveis em que há necessidade de informar escrevendo-se por extenso. Quando de palestras sobre a forma de preenchimento da Declaração de óbito, sempre se chama a atenção para o cuidado que o médico dever ter para a grafia correta do nome do falecido e dos seus pais, face aos problemas legais que erros deste tipo podem acarretar à família do falecido. Para este tipo de erro os cartórios geralmente estão atentos e as retificações necessárias são feitas.

Em óbito atestado em Instituto Médico-Legal, como local de sua ocorrência, no item 11 da Declaração de óbito, registrase "Alberto Aisten".

Os erros de grafia observados se referiam, com maior freqüência, às causas de morte. Deste modo, foram observadas as grafias "aspiração macissa". "enfizema pulmonar" (cerca de quatro vezes), "shock endotóxico" e "linfosarcoma". Entretanto, determinando um erro de codificação de causa associada, verificou-se a grafia inusitada e incorreta do diagnóstico "ansiedade (anciã)", ao invés de "ancianidade", com o significado de senilidade, de código 797. Este termo foi interpretado como sendo "ansiedade" e codificado em 300.0, como um transtorno neurótico. 
QUESTÕES DE SINTAXE E DE SÍMBOLOS

A entrada de dados sobre causas de morte no Sistema ACME deve obedecer a uma série de procedimentos para a classificação adequada da causa básica resultante. Em tópico anterior, comentou-se que, na Parte I do Atestado Médico, o codificador faz uso de uma barra (/) para indicar que as causas estão informadas em linhas diferentes, sendo possível o uso até de quatro dessas barras correspondendo a cinco linhas no máximo. A separação das causas mencionadas na Parte I daquelas da Parte II deve ser feita pelo uso de um asterisco (*). Quando mais de uma causa for mencionada numa linha da Parte I ou na Parte II, a separação entre as mesmas se faz por meio de uma letra "b" cortada. O símbolo "ampersand" (\&), dentre outras situações, deve ser usado para marcar o código mais especifico da Classificação Suplementar de Causas Externas de Lesões e Envenenamentos, correspondente a causa básica nas mortes violentas. O símbolo de abertura de parênteses - $($ substitui o dígito "8" da série 800 e 0 de fechamento de parênteses - ) - substitui o dígito "9" da série 900 do Capítulo XVII da Classificação Internacional de Doenças, relativo à natureza de lesões, dado que os mesmos dígitos são usados na Classificação Suplementar de Causas Externas para denotar as circunstâncias da violência (46).

O codificador deve atender às disposições pormenorizadas sobre o uso e colocação ordenada desses símbolos e afecções informadas no Atestado Médico para que o sistema possa aplicar as regras de mortalidade e classificar a causa básica de morte correspondente. A aplicação incorreta dessas disposições implica num erro de sintaxe e pode determinar a classificação de uma causa básica também incorreta.

Erros deste tipo foram observados em cerca de 40 Declarações de óbito, a grande maioria dos quais em óbitos devidos a violência. Freqüentemente, em nosso meio, o médico-legista informa apenas a natureza da lesão no Atestado Médico e indica no item 37 na Parte $V$ da Declaração de óbito o tipo de violência, se homicídio, suicídio, acidente ou ignorado. Nesses casos, o codificador deve colocar o(s) código(s) da natureza da lesão reproduzindo as posições em que estejam informados e colocar o código da causa externa em último lugar na Parte II, após o asterisco. Entretanto, se a causa externa estiver informada corretamente na Parte I do Atestado Médico, o símbolo mais adequado é a barra (/), indicando uma sequiência informada. Exemplificando com o atestado abaixo: 


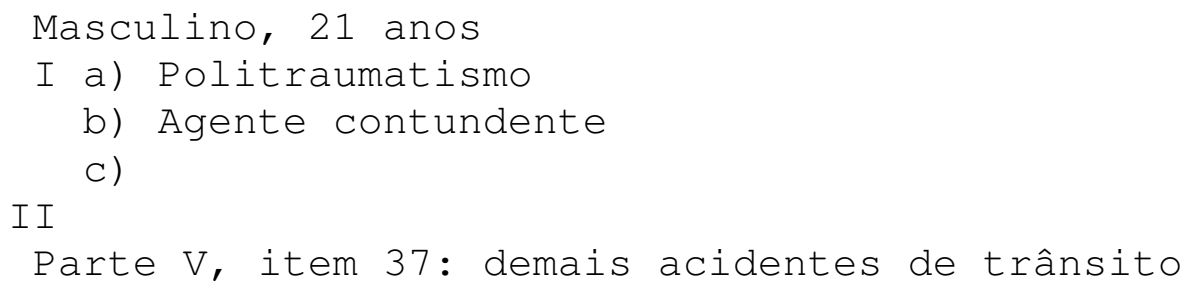

A codificação - 598 * \&8199 - indica que o agente contundente está na Parte II, ao passo que a sintaxe correta seria: ) 598 / \&8199.

Em que pesem tais erros de sintaxe, a causa básica de morte não foi afetada dado que as causas externas são as selecionadas nas mortes violentas.

De modo diverso, a probabilidade de comprometer a classificação da causa básica nas mortes ditas devidas a causas naturais é bem maior, como observado nos atestados que se seguem.

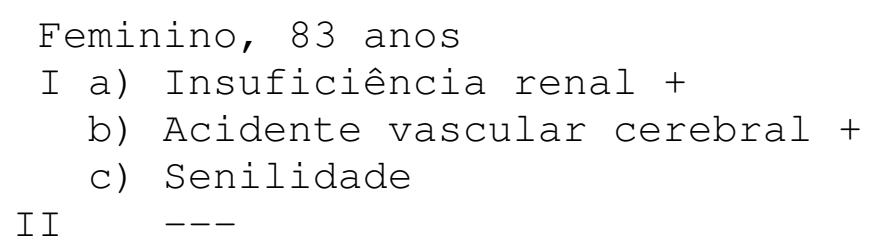

Neste atestado, a codificação - 586 / 436/797 - determinou que o sistema aceitasse a seqüência informada e selecionasse a "senilidade", abandonando-a em seguida e resselecionando o "acidente vascular cerebral" (436). Entretanto, o codificador deveria interpretar todas as causas informadas numa mesma linha dado que as mesmas estão ligadas pelo sinal de adição (+). Esta interpretação produziria a codificação - 586 bo 436 b 797 - que levaria o sistema a selecionar a "insuficiência renal" (586), primeira causa informada, desde que não há seqüência entre as causas.

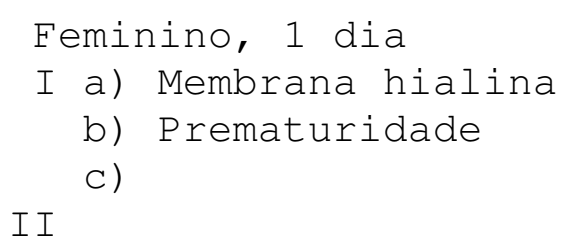

A informação adicional que não venha a modificar uma das causas mencionadas deve ser colocada em último lugar na Parte II. Neste atestado, a codificação - 769 / 765.1 / 761.5 entretanto, colocou a "gemelaridade" (761.5) como causa de 
uma seqüência o que determinou a sua seleção pelo sistema como causa básica. A codificação correta - 769 / 765.1 * 761.5 - determinaria a seleção da "prematuridade" (765.1), seu abandono subseqüente e resseleção da "membrana hialina" (769) como causa básica mais adequada. 
QUESTÕES RELATIVAS A CÓDIGOS ESPECIAIS CRIADOS

Durante o processamento das causas de morte pelo sistema ACME, para a identificação da causa básica, podem ocorrer situações em que a relação entre duas afecções, representadas pelos seus códigos da Classificação Internacional de Doenças, mostra-se ambivalente ou duvidosa. Estas situações ocorrem com maior freqüência quando uma das afecções é representada por um código que é dito residual em determinada partição da Classificação Internacional de Doenças, incluindo várias afeç̧ões que não receberam um código específico. Dessas afecções assim codificadas, algumas podem manter e outras não relação etiológica ou de modificação com as demais informadas num Atestado Médico. Nestes casos, O Sistema ACME não tem possibilidade de decidir por meio das tabelas e rejeita o atestado para decisão manual. A fim de diminuir o número de rejeições, alguns códigos especiais foram criados para representar as afecções que, com maior freqüência, eram causa de rejeições, isolando-as, portanto das demais afecções incluídas naquele código comum original. As decisões para o processamento seriam feitas assim com tais códigos especiais $(42,43)$.

Em apenas três Declarações de óbito foram observados problemas de codificação inadequada de códigos especiais criados, reproduzidas a seguir:

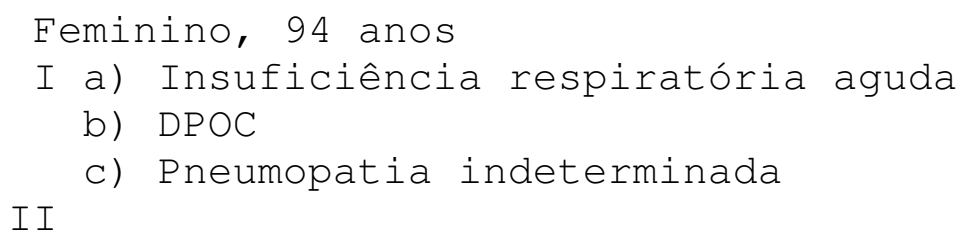

A "doença do pulmão (crônica) SOE" tem código especial, "518.9", que deve ser usado ao invés do original "518.8". A codificação adequada - 518.5 / 496 / 518.9 - selecionaria a "pneumopatia" num primeiro tempo e resselecionaria, especificando, a "doença pulmonar obstrutiva crônica" (496) como causa básica final. Por coincidência, neste atestado, um erro adicional de sintaxe determinou a seleção da mesma causa básica, entretanto com um eventual prejuízo a qualidade de análise de regras de mortalidade. A codificação original 518.5 / 496 * 518.8 - considerou a "pneumopatia" na Parte II e conseqüentemente não foi observada pelo sistema para a seleção direta da "doença pulmonar obstrutiva crônica". Não houve prejuízo para a codificação de causas associadas, pois 
os códigos especiais criados, após o processamento, revertem aos códigos das subcategorias originais de onde provieram as afecções isoladas.

\title{
Feminino, 61 anos
}

I a) Crise hipertensiva, insuf. respiratória

b) Acidente vascular encefálico

c) Crise hipertensiva

II Nefropatia crônica

\begin{abstract}
A "nefropatia crônica SOE" tem código especial criado, "582.7", que deve ser usado em lugar do original, "582.9". Este código criado tem a finalidade de contornar o problema das associações ambivalentes da "hipertensão" (401.-) e de afeç̧ões codificadas entre "580" e "583". Dado estar a "nefropatia crônica" informada na Parte II, a causa básica selecionada, mesmo com erro de sua codificação, será o "acidente vascular encefálico" (436). Por coincidência, também, neste atestado ocorreu um erro de interpretação devido à letra do médico, sendo codificada "hepatopatia crônica" (571.9) ao invés de "nefropatia crônica" (582.7), havendo, portanto um prejuízo para a qualidade das causas associadas.
\end{abstract}
Masculino, anos
I a) Embolia pulmonar
b) Hipertensão arterial
c) Nefropatia crônica

I I

A codificação - 415.1 / 401.9 / 582.9 - não utilizou o código especial criado "582.7" para a "nefropatia crônica". Apesar disso, não houve prejuízo para a causa básica, a própria nefropatia. O prejuízo iria ocorrer se no Atestado Médico a "nefropatia crônica" fosse dita "devida a" "hipertensão arterial" (401.9). 


\section{AFECÇÕES ESPECIFICADAS ENTRE PARÊNTESES}

Ao informar as causas de morte, o médico pode colocar diagnósticos entre parênteses especificando outra afecção mencionada geralmente na mesma linha da Parte I do Atestado Médico. Esta especificação pode ser feita colocando o termo mais específico ao lado do mais genérico.

o processamento adequado dessas informações pelo Sistema ACME demanda a interpretação e respectiva codificação próprias desses diagnósticos $(42,43)$.

Solicita-se ao codificador que, no caso de o termo entre parênteses ou adicional fornecer informação mais precisa e definida sobre a natureza e/ou localização da afecção do que a outra afecção á qual se refere, a afecção entre parênteses deve ser levada em consideração e codificada para o processamento. Essas afeç̧ões, a genérica e a mais específica, não devem ser codificadas separadamente.

Quando a afecção entre parênteses não fornecer informação especificadora sobre a natureza e/ou localização da afecção à qual se refere, ambas as afeç̧ões devem ser codificadas separadamente.

As seguintes Declarações de óbito apresentaram este tipo de especificação e respectivas codificações.

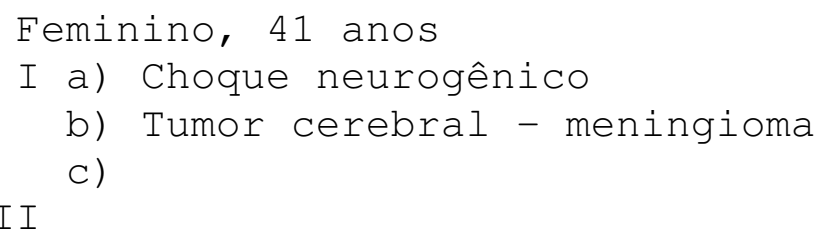

A codificação - 785.8 / 239.6 b 225.2 - de forma incorreta, previu códigos para ambas as causas da linha (b), o que determinou a seleção pelo sistema do código colocado em primeiro lugar, à esquerda. O termo "meningioma" (225.2), mais preciso que "tumor cerebral" e deveria ser codificado isoladamente.

Masculino, 30 anos

I a) AVC (acidente vascular cerebral hemorrágico)

b)

c) 
A codificação - 431 - correta colocou código apenas para o termo entre parênteses, desde que mais preciso que o diagnóstico "AVC" ao qual se referia.

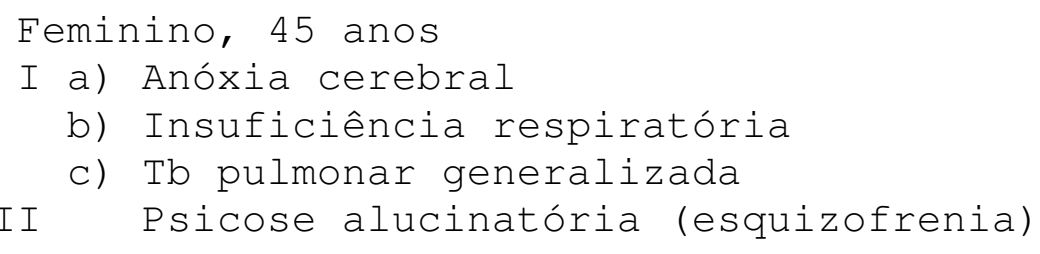

\begin{abstract}
A codificação - 348.1 / 786.0 / 011.9 * 295.9 - correta previu apenas um código para as afecções da Parte II, desde que o termo "esquizofrenia" (295.9) , mais preciso e específico que "psicose alucinatória".
\end{abstract}

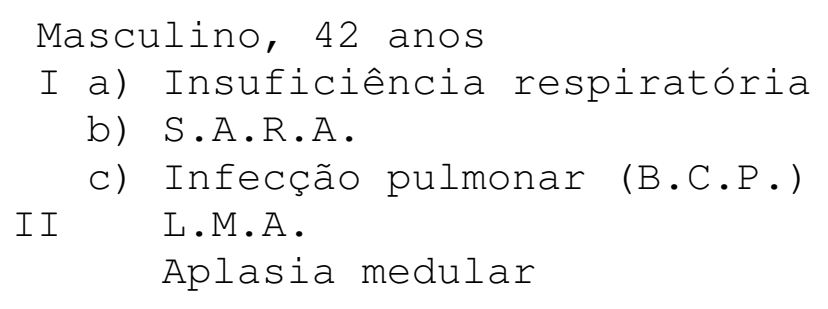

A codificação - 786.0 / 518.5 / 518.8 b 485 * 205.0 b 284.9 incorretamente previu código para a "infecção pulmonar" (518.8), quando fora informado um termo mais específico, a "B.C.P.", sigla de "broncopneumonia" (485), que deveria ser codificada isolada. Não houve prejuízo para a causa básica, pois após seleção da "infecção pulmonar" houve aplicação da regra de modificação para especificidade e resselecionada a "broncopneumonia". Houve um erro para as causa múltiplas.

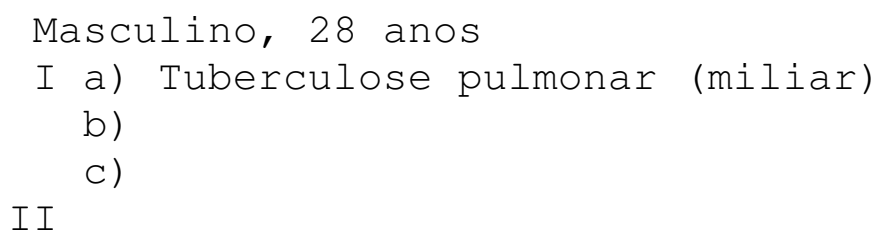

A codificação - 011.9 b 018.9 - incorreta, determinou a seleção da "tuberculose pulmonar" (011.9) como causa básica. A causa mais específica, que deveria ser codificada sómente, seria a "tuberculose miliar", que para qualquer localização tem código "018.9". 
EFEITO DA IDADE DO FALECIDO SOBRE A CODIFICAÇÃO

O codificador deve sempre levar em conta a idade do falecido no momento de atribuir códigos às afecções informadas no Atestado Médico. A Classificação Internacional de Doenças prevê códigos específicos para alguns grupos de idade (31).

$\mathrm{Na}$ amostra de Declarações de óbito estudada verificou-se que a atenção dos codificadores para as categorias destinadas a codificação de afeç̧ões originadas no período perinatal, por exemplo, foi adequada e correta.

No entanto, houve interesse em verificar a forma de codificação de algumas afeç̧ões para as quais o centro Brasileiro de Classificação de Doenças orienta para o uso de códigos adaptados e cujas disposições são apresentadas durante o treinamento dos codificadores. Dentre tais disposições, as que se relacionam com a idade são as pneumonias em menores de 48 horas e a desidratação em menores de cinco anos de idade.

\section{(Bronco) Pneumonias em menores de 48 horas}

A Nona Revisão da Classificação Internacional de Doenças não havia feito distinção específica para as pneumonias não qualificadas quanto à idade do falecido. Talvez por questionamento de codificadores, o Centro de Londres, em publicação destinada a orientar o uso da Classificação para uso em mortalidade, julgou conveniente dispor que as pneumonias, em crianças falecidas com menos de 48 horas de vida, fossem codificadas como congênitas (770.0), com o argumento que após esse período de tempo a probabilidade dessas afecções serem adquiridas seria bem maior.

$\mathrm{Na}$ amostra foram observados dois óbitos em que a broncopneumonia apresentou-se como causa básica, um deles em criança de 14 horas e 960 gramas de peso e outro com um dia de vida. Nesses óbitos, o codificador não atendeu a recomendação de codificar a broncopneumonia como congênita e atribuiu o código "485" à causa básica. Julga-se que este fato se deva a uma falta de divulgação desta norma. 


\section{Desidratação em menores de 5 anos}

Durante os trabalhos da Investigação Interamericana de Mortalidade na Infância (52), notou-se que ocorria um modismo na forma pela qual os médicos informavam as mortes devidas a gastroenterocolite. Era freqüente a menção de "desidratação" isolada ou acompanhada de afeç̧ões correlatas para as mortes nas quais a investigação mostrava ser a gastroenterocolite a causa básica real. Desde então, durante o treinamento para uso da Classificação Internacional de Doenças em mortalidade, os codificadores são orientados para codificar como gastroenterocolite (009.1 na Nona Revisão) aqueles atestados em que "desidratação" ocorre mencionada sozinha ou é selecionada como causa básica em menores de cinco anos de idade.

Foram observados 18 óbitos em menores de cinco anos cuja causa básica foi codificada em "009.1". Destes, em seis, ou um terço dos mesmos, a desidratação foi selecionada como causa básica no Atestado Médico e adequadamente interpretada pelo codificador. 
LIMITAÇÕES DE SEXO

Algumas categorias da Classificação Internacional de Doenças são limitadas a um sexo. Geralmente os problemas devidos a erros de codificação deste tipo são descobertos pelo crivo das tabelas de consistência durante o processamento inicial. Provavelmente isso se verificou em uma declaração de falecido do sexo masculino cuja causa básica, neoplasia maligna de mama, estava codificada em "174.9", código reservado para "neoplasia maligna da mama feminina". No arquivo final este óbito tem código "175", correspondente a "neoplasia maligna da mama masculina".

LOCALIZAÇÃO IMPLÍCITA DE AFECÇÕES.

Algumas afeç̧ões são geralmente codificadas pela Classificação Internacional de Doenças segundo suas localizações. Por exemplo, tal ocorre com atrofia, calcificação, cálculo congestão, degeneração, dilatação, edema, embolia, estenose, fibrose, gangrena, hemorragia, hipertrofia, insuficiência, necrose, obstrução, perfuração, ruptura, etc.. No entanto, por vezes, essas afecções são mencionadas sem a especificação de localização.

Quando isso ocorre, geralmente é possível inferir que a localização dessa afeç̧ão seja a mesma de outra causa mencionada no atestado com localização especificada. Isto, entretanto só é possível desde que haja previsão de classificar a afeç̧ão mencionada isolada segundo a localização informada em relação à outra causa. O manual de instruções extensamente discute os pormenores dessa disposição genérica, por exemplo, considerando estarem as afecções na mesma linha ou em linhas diferentes do Atestado Médico, a existência de uma ou mais localizações ao mesmo tempo, a previsão ou não de códigos para localizações específicas pela Classificação Internacional de Doenças, etc. $(42,43)$.

Observou-se uma Declaração de óbito em que surgiu problema deste tipo. 


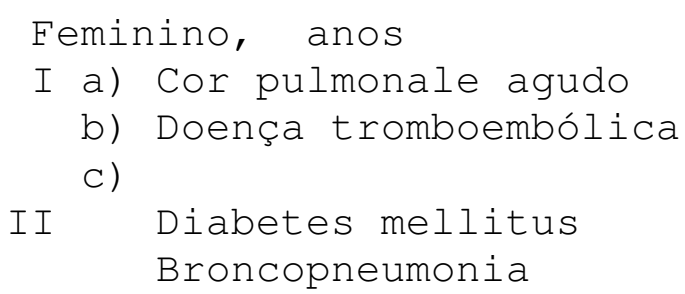

A codificação - 415.0 / 444.9 * 250.0 b 485 - resultou do fato de estar a "doença tromboembólica" (444.9) mencionada sem localização. O processamento não aceitou a seqüência da Parte I, selecionou o "cor pulmonale agudo" (415.0) e em seguida considerou este último como seqüela direta da "broncopneumonia" (485). Trata-se de problema de difícil codificação. A "doença tromboembólica" deveria ter sido interpretada como "pulmonar" (415.1), determinando a codificação seguinte - 415.0 / 415.1 * 250.0 b 485 - que originaria a causa básica "embolia pulmonar" (415.1). 
QUESTÕES DE FORMATO

\section{Afecções entre linhas da Parte I}

Uma Declaração de óbito na qual o médico coloca causas entre linhas da Parte I foi observada, reproduzida a seguir.

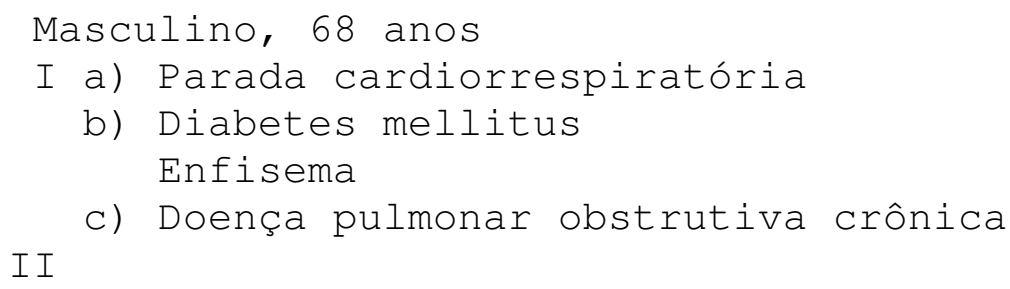

Esta Declaração de óbito foi codificada da seguinte maneira 799.1 / 250.0 / 492 / 496 - , corretamente, desde que intercalou o "enfisema" numa linha virtual entre as linhas (b) e (c) .

\section{Afecções ditas como devidas a I (a), I (b) ou I(c)}

Observou-se uma Declaração de óbito na qual o médico, na Parte I do Atestado Médico, notou haver colocado incorretamente as causas nas linhas (b) e (c) e indicou este fato por meio de uma seta. O codificador interpretou este sinal e codificou de acordo, a saber:

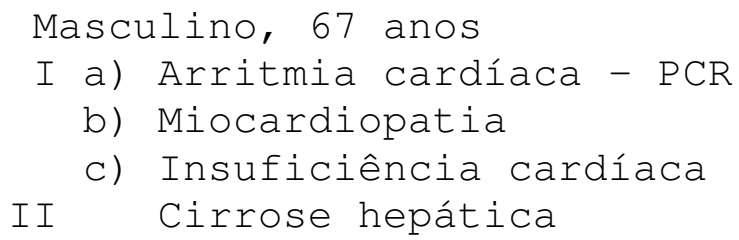

Codificação: 427.9 b 427.5 / 428.9 / 425.4 * 571.5, isto é, colocando a "insuficiência cardíaca" (428.9) devido a "miocardiopatia" (425.4).

No entanto, em outra Declaração de óbito, em que também o médico coloca seta, tal interpretação não se deu

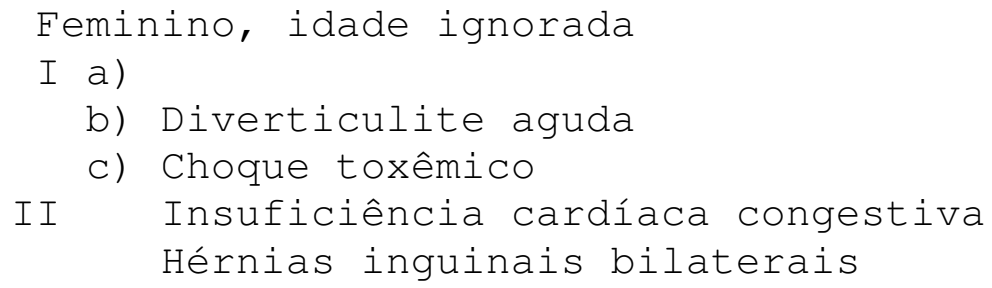

A codificação - 562.1 / 785.5 * 428.0 b 553.9 - não levou em consideração a seta, fato que não comprometeu a causa básica 
"diverticulite aguda" (562.1). Neste caso, ainda ocorreu erro de sintaxe, pois a ausência de afecção na linha (a) deveria ser indicada.

Em outra Declaração de óbito o médico refez na Parte II do Atestado Médico uma seqüência informada incorretamente na Parte I, o que levou a um erro de sintaxe e de interpretação, a saber:

\author{
Masculino, 14 anos \\ I a) Insuficiência cardíaca congestiva \\ b) Troca de válvula mitral \\ c) Edema agudo de pulmão \\ II Edema agudo de pulmão devido a ICC \\ devido a insuficiência da válvula mitral
}

codificado - 428.0/394.9/518.4*518.4 b 428.0 b 424.0 produziu, pelo processamento, a causa básica "insuficiência da válvula mitral" (424.0) corretamente.

\title{
Anulação da frase "devido a" ou das letras da Parte I
}

Algumas vezes o médico anula a frase "devido a ou como conseqüência de" ou anula as letras que identificam as linhas na Parte I do Atestado Médico. Dependendo do modo em que essa anulação é feita, o codificador dever codificar as causas mencionadas, para o que existem normas específicas para cada caso.

Na Declaração de óbito a seguir, o médico recolocou as letras (a) e (b) da Parte I, pois julgou insuficiente o espaço para informar as lesões que produziram a morte, a saber:

\author{
Masculino, anos \\ I a) A) TCE c/ hematomas extra-dural, subdural \\ b) intraparenquimatoso e edema cerebral \\ c) B) Agente contundente \\ II \\ Tipo de violência: queda, ignorado
}

que foi codificado - $(54 \mathrm{~b}(52) /(53 \mathrm{~b}(54)$ / \&888 - quando 0 correto seria - $(54$ b $(52$ b $(53$ b (54 / \&888. Esta Declaração fora discutida no tópico relativo a dados contraditórios. O erro de sintaxe cometido neste caso não compromete a causa básica. 


\section{Numeração de causas}

Foram observadas duas Declarações de óbito nas quais o médico numerou as afecções mencionadas no Atestado Médico. Quando isso ocorre, todas as causas a partir do início da numeração devem ser interpretadas como informadas numa mesma linha. As Declarações de óbito e respectivas codificações são apresentadas a seguir;

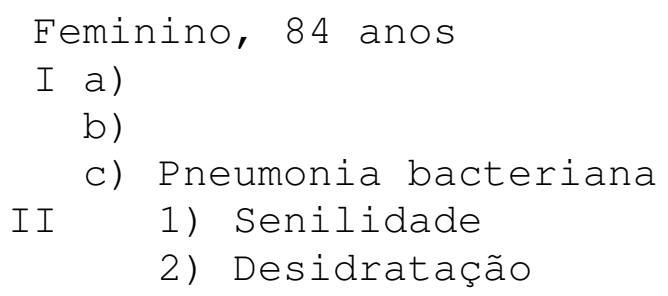

codificado - 428.9 * 797 b 276.5 - tendo a "pneumonia bacteriana" (428.9) como causa básica. Neste caso, a rigor, a codificação deveria ser - / b / 428.9 * 797 b 276.5 - para indicar que as linhas (a) e (b) estavam sem afecções informadas.

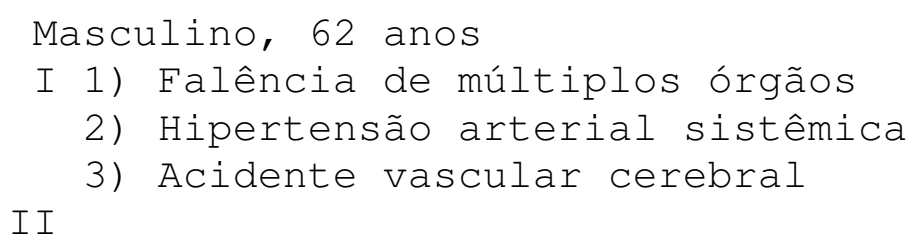

codificado 799.8 / 401.9 / 436 - , quando o correto seria colocar - 799.8 b 401.9 b 436 - erro de sintaxe que entretanto não comprometeu a causa básica "acidente vascular cerebral" (436). 


\begin{abstract}
Ao preencher uma Declaração de óbito o médico pode ter alguma dúvida quanto a causa ou causas de morte e de alguma forma indicar tal dúvida. As expressões mais freqüentes são "provável", "possível", "a esclarecer" ou o sinal de interrogação "?" colocados junto às afecções. O codificador deve ignorar a dúvida e codificar as causas como realmente existentes segundo as disposições da Classificação Internacional de Doenças.
\end{abstract}

Na amostra, oito Declarações de óbito apresentavam indicação de dúvida, apresentadas a seguir com as respectivas codificações de entrada no Sistema ACME.

Feminino, 3 anos

I a) Síndrome de Friderichsen

b) Provável meningococcemia

c)

II

Codificação - $036.3 / 036.2$

Masculino, 76 anos

I a) Morte súbita

b) IAM extenso?

c)

II Hipertensão arterial sistêmica

Codificação $-798.1 / 410 * 401.9$

Feminino, 63 anos

I a) Distúrbio hidroeletrolítico

b) Hemorragia digestiva alta

c) a esclarecer

II

Codificação - 276.9/578.9

Feminino, 40 minutos

I a) Insuficiência respiratória

b) Cardiopatia congênita (?)

c)

II

Codificado - $770.8 / 746.9$ 
Feminino, 22 anos

I a) Choque séptico

b) Endometrite?

c)

II

Codificado $-785.5 / 615.9$

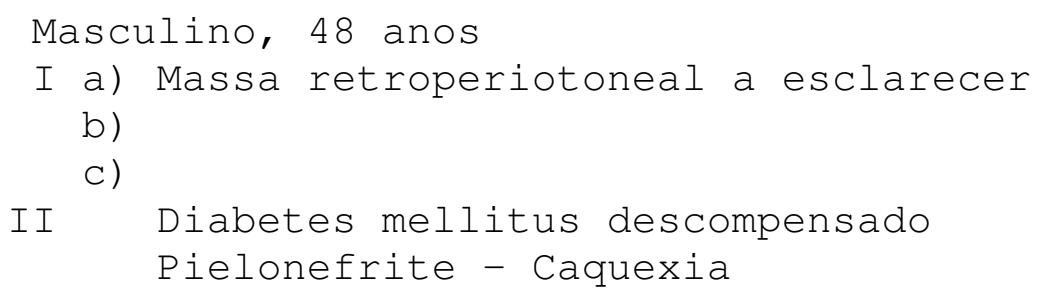

Codificado - 158.9 * 250.0 b 590.8 b 799.4 - atestado este cujo diagnóstico "massa retroperiotoneal a esclarecer" não tem representação definida na Classificação Internacional de Doenças e que, para este trabalho, foi recodificado do seguinte modo - 250.0 b 590.8 b 799.4 - provocando a mudança da causa básica de "158.9" para "diabetes mellitus (250.0).

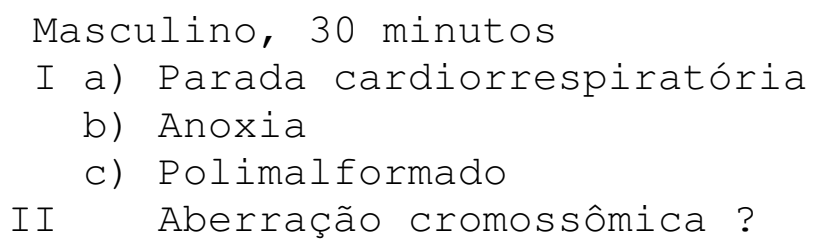

Codificado - 427.4/427.9/086.0 
CODIFICAÇÃO DE MENÇÕES DO TIPO "IDEM", "COMO ACIMA", ETC.

A orientação sobre a codificação de menções do tipo "idem", "como acima", o símbolo de aspas ("), na posição "devido a" em relação a outra afecção, dispõe que tais menções não devem ser codificadas $(42,43)$.

Caso análogo ocorreu em Declaração de óbito na qual, em todas as linhas da Parte I, o médico repete o mesmo diagnóstico, a saber:

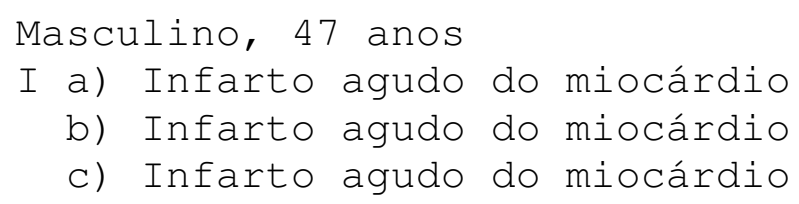

Este atestado recebeu simplesmente a codificação correta 410 - dado que o mesmo diagnóstico foi repetido em todas as linhas.

Na Declaração de óbito abaixo, entretanto, o mesmo código foi usado para causas repetidas.

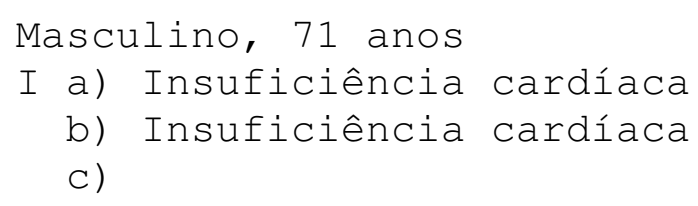

A codificação - 428.9 / 428.9 - não seria necessária. 
TERMOS NÃO INDEXADOS OU ILEGÍVEIS

Um dos problemas mais difíceis com o qual o codificador se depara é o da classificação de diagnósticos que não estão incluídos no Índice da Classificação Internacional de Doenças. Nestes casos, torna-se necessário verificar o significado do termo diagnóstico e encontrar o código mais adequado na Lista Tabular, isto é, no Volume I da Classificação Internacional de Doenças (31) .

A procura do significado desses diagnósticos dever ser feita em dicionários médicos. Neste sentido, é recomendável que todo serviço que faça levantamento de dados de morbidade ou mortalidade a partir de documentos primários disponha de tais publicações. Nesses serviços é usual a manutenção, pelos codificadores, de anotações próprias sobre termos diagnósticos não indexados pela classificação.

O manual de instruções para entrada de dados no Sistema ACME, a respeito deste problema, prevê que "quando for mencionado um termo que não esteja incluído no índice alfabético da Classificação Internacional de Doenças, uma consulta deve ser feita ao supervisor de codificação" (42, 43). Esta orientação procura refletir, pela experiência cotidiana, a referida dificuldade do problema e a necessidade de critérios seguros para a determinação do código mais adequado desses diagnósticos.

Nota-se a dificuldade do problema quando consultas deste tipo são encaminhadas ao Centro Brasileiro de Classificação de Doenças. A busca dos significados dos mesmos, no Centro e na Biblioteca da Faculdade de Saúde Pública, por meio de ampla gama de dicionários de termos médicos, de epônimos, de síndromes diagnostica, de siglas, e de outros, pode não ter sucesso. Nestes casos, procura-se entrar em contacto com o médico que forneceu a Declaração de óbito ou que registrou o diagnóstico para o necessário esclarecimento.

O Centro de São Paulo, pelo seu Boletim, e os demais Centros Colaboradores da Organização Mundial da Saúde, no período entre as revisões da Classificação Internacional de Doenças, publicam atualizações do Índice para orientar os codificadores (47).

Na amostra estudada foram observados cerca de cinqüenta termos diagnósticos cuja codificação não estava prevista pela 
Classificação Internacional de Doenças em seu Índice. Quarenta desses termos foram codificados, separadamente, por três peritos do Centro de São Paulo e pelo autor. Para tanto, estabelecia-se não haver, para a codificação, outras restrições além da proibição do uso de códigos em asterisco. o Quadro 1, a seguir, apresenta os códigos oferecidos aos diagnósticos não indexados.

Observa-se que em apenas quatro vezes houve concordância dos quatro técnicos, o que ocorreu na codificação dos termos "carcinoma espinocelular", "carcinoma metastático em fígado", "convulsão generalizada por hipofluxo" e "miocardiopatia dilatada". Em 18 vezes, houve concordância de códigos atribuídos por três dos técnicos. Em 15 vezes dois dos técnicos concordaram na codificação, e nestes casos, em 10 vezes os outros dois técnicos discordaram e em cinco vezes houve concordância entre os mesmos. Por outro lado, houve atribuição de quatro códigos diferentes em três vezes, respectivamente para os termos "doença neurológica degenerativa", "linfangite carcinomatosa pulmonar" e "síndrome vascular da fossa cerebelar posterior". Ressalve-se que o fato de haver concordância entre os peritos e/ou o autor não significa que o código respectivo reflita a classificação mais adequada e correta.

Algumas Declarações de óbito em que termos não indexados foram mencionados serão comentadas.

\author{
Feminino, 42 anos \\ I a) Arritmia cardíaca \\ b) Hipertireoidismo \\ c) Doença de B. Graves \\ II Insuficiência cardíaca
}

Este óbito, ocorrido em janeiro de 1992, recebeu a seguinte codificação - 427.9 / 246.9 / 799.9 * 428.9 - onde a "Doença de Basedow Graves" foi considerada como ilegível. Esta Declaração de óbito foi encaminhada ao Centro para consulta. Verificou-se que o Índice da Classificação Internacional de Doenças prevê os termos "Doença, Basedow" e "Doença, Grave, de", ambos com código "242.0"; não havia previsão de "Doença, Basedow-Graves", além disso, a grafia "Grave" estava incorreta. Apesar da resposta do Centro ser de julho de 1992, - esclarecimento não foi considerado. A causa básica muda de "246.9" para "242.0".

As Declarações de óbito seguintes incluem o termo "hepatite transinfecciosa". 


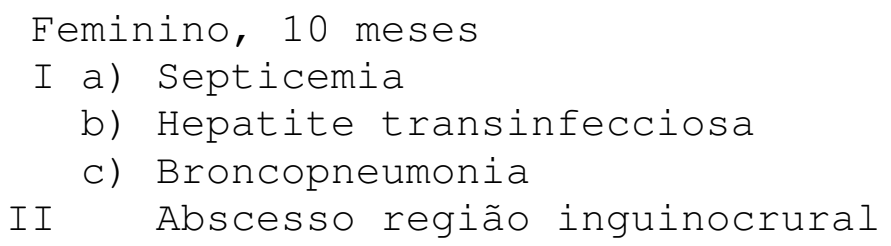

Codificação: 038.9 / $070.1 / 485$ *682.2 - gerando a causa básica "070.1", código de "hepatite por vírus A sem menção de coma hepático", no qual o diagnóstico "hepatite infecciosa" está incluído.

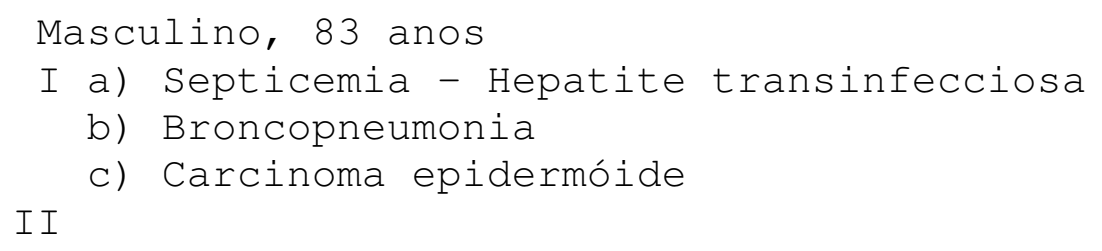

Codificação: 038.9 b 070.1 / 485 / 173.9 - gerando a causa básica "carcinoma epidermóide" (173.9), pois o código correspondente à "hepatite infecciosa" (070.1) estava na segunda posição na linha (a). A par disso, ressalve-se a codificação de "carcinoma epidermóide" que a rigor deveria ser "199.1".

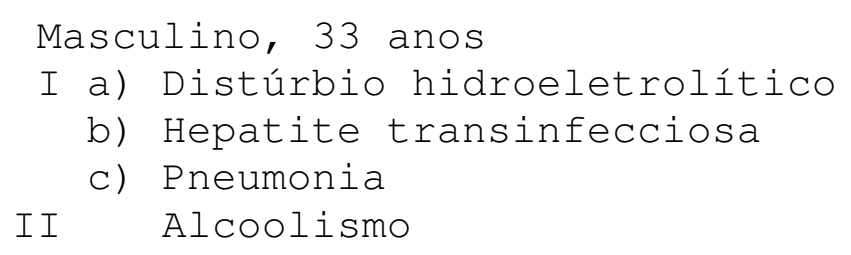

Codificação: 276.9 / 070.9 / 486 *303 - gerando a causa básica incorreta "hepatite viral" (070.9) pelo Sistema ACME.

Há muito tempo procura-se identificar o código adequado para o diagnóstico "hepatite transinfecciosa", tendo sido consultados diversos patologistas e especialistas em moléstias do fígado, entretanto sem uma definição quanto à caracterização precisa do quadro patológico correspondente. Recentemente, durante assessoria prestada à uma aluna de PósGraduação da Faculdade de Saúde Pública que desenvolve trabalho sobre "hepatites infecciosas", esclareceu-se que o termo "hepatite transinfecciosa" é usado para os casos em que ocorre comprometimento hepático, de forma reativa, a um processo infeccioso extra-hepático, generalizado ou em outra localização. Não se trata, portanto de uma infecção do fígado propriamente dito. Em face de tais caracteristicas, considera-se que "573.3" seria o código mais adequado. 
Por conseqüência, dentre as Declarações de óbito anteriores, a primeira e a terceira sofrem mudança da causa básica, respectivamente para "broncopneumonia" (485) e "pneumonia" (486) ao passo que a segunda Declaração de óbito incorre em erro de codificação da causa associada apenas.

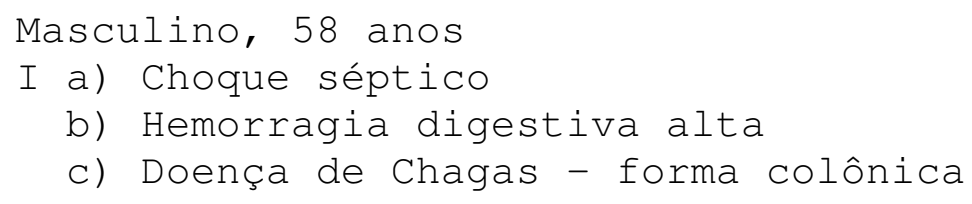

A codificação - $785.5 / 578.9$ / 086.2 - não levou em consideração a localização do comprometimento do cólon e identificou apenas a "Doença de Chagas" (086.2). Embora o Índice não especifique explicitamente tal comprometimento, o código correto (086.1) poderia ter sido obtido a partir do verbete "Tripanossomíase, americana, com, envolvimento de outros órgãos".

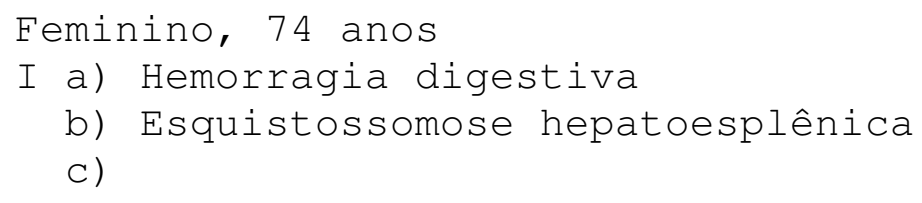

A codificação - 578.9 / 120.8 - não identificou ser a "esquistossomose hepatoesplênica" como devida ao Schistosoma mansoni (120.1). O termo não está previsto nos volumes I e II da Classificação Internacional de Doenças.

Dentre os diagnósticos não indexados na Nona Revisão da Classificação Internacional de Doenças, o de "miocardiopatia dilatada" foi o mais freqüente, tendo sido mencionado cerca de 27 vezes. A interpretação ao mesmo dependeu da localização de sua menção no Atestado Médico. Se o diagnóstico estivesse colocado corretamente na última linha preenchida da Parte I, considera-se a "miocardiopatia dilatada" como primária e codifica-se "425.4". Caso esteja informada como "devida a outra afecção especificada, segue-se a orientação do manual para entrada de dados no Sistema ACME, por analogia com o termo "miocardiopatia", e codifica-se "425.9" para processamento da causa básica (42, 43). Esta interpretação está de acordo com os resultados de estudo clinico-patológico - qual concluiu que em 47\% dos casos, as miocardiopatias dilatadas têm etiologia idiopática, são devidas a miocardites idiopáticas em 12\%, a doenças coronarianas em 11\% e devidas a outras causas identificáveis em 31\% dos casos restantes (27). 


\author{
Masculino, 55 anos \\ I a) Fibrilação ventricular \\ b) Insuficiência cardíaca \\ c) Miocardiopatia dilatada importante
} II

Neste Atestado Médico, a "miocardiopatia dilatada" está colocada na última linha preenchida da Parte I e recebeu código "425.4", corretamente, sendo a causa básica de morte. Codificou-se - 427.4 / 428.9/425.4 - de forma correta.
Masculino, 41 anos
I a) Choque cardiogênico
b) Miocardiopatia dilatada
c) Insuficiência aórtica

II

A codificação - $785.5 / 425.9$ / 424.1 - interpretou a "miocardiopatia dilatada" como secundária (425.9) levando ao processamento da "insuficiência aórtica" (424.1) como causa básica.

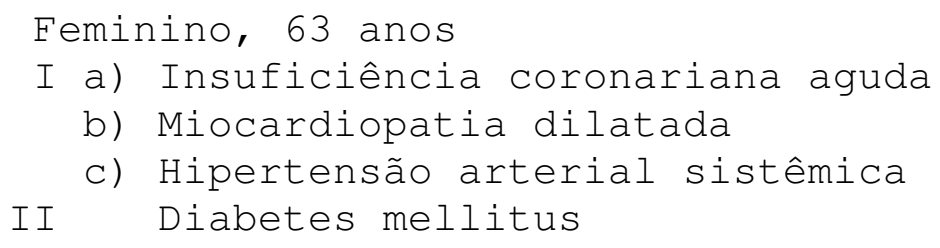

A codificação - 411 / 425.9 / 401.9 * 250.0 - considerou a "miocardiopatia dilatada" como secundária (425.9). Este fato determinou a seleção pela Regra Geral da "hipertensão arterial sistêmica" (401.9), sua associação com a "miocardiopatia dilatada" gerando o diagnóstico intermediário de "doença cardíaca hipertensiva" que finalmente se associa com a "insuficiência coronariana aguda" (411), causa básica final.

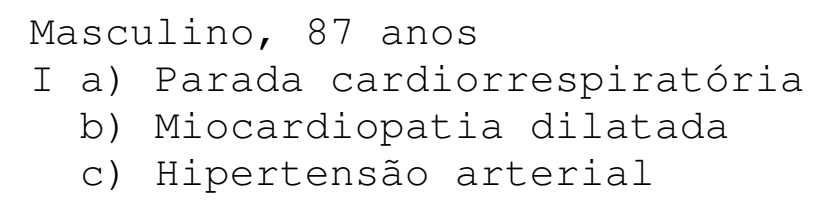

II

A codificação - 427.5 / 425.4 / 401.9 - levou à seleção da "miocardiopatia dilatada" (425.4), inferida como primária, como causa básica. Codificando-se corretamente em "425.9", a seqüência informada teria sido aceita, a "hipertensão" (401.9) selecionada pela Regra Geral e em seguida associada a 
"miocardiopatia", resultando na causa básica final "doença hipertensiva do coração" (402.9). 
Quadro 1 - Diagnósticos codificados por três peritos e pelo autor (A, B, C, D), independentemente

\begin{tabular}{|c|c|c|c|c|}
\hline Diagnóstico & $\mathbf{A}$ & $\mathbf{B}$ & $\mathbf{C}$ & $\mathbf{D}$ \\
\hline Abdome agudo vascular & 789.0 & 789.0 & 789.0 & 557.0 \\
\hline Agente biodinâmico patológico & --.--- & 799.9 & 136.9 & 136.9 \\
\hline Alteração da crase sangüínea & 286.9 & 289.9 & 289.9 & 286.9 \\
\hline Blastoma & 199.1 & 239.9 & 199.1 & 239.9 \\
\hline Carcinoma espinocelular & 199.1 & 199.1 & 199.1 & 199.1 \\
\hline Carcinoma metastático em figado & 197.7 & 197.7 & 197.7 & 197.7 \\
\hline Cardiopatia embolizante & 429.9 & 429.9 & 414.9 & 429.9 \\
\hline Cerclagem pulmonar & E878.8 & 799.9 & 518.8 & 799.9 \\
\hline Contusão em cabeça & 920 & 920 & 920 & E988.9 \\
\hline Convulsão generalizada por hipofluxo & 780.3 & 780.3 & 780.3 & 780.3 \\
\hline Delaminação aórtica & --.-- & 441.0 & 447.9 & 441.0 \\
\hline Diabetes mellitus descompensado & 250.9 & 250.9 & 250.9 & 250.7 \\
\hline Doença neurológica degenerativa & 331.9 & 358.9 & 349.8 & 349.9 \\
\hline Falência de múltiplos órgãos & 799.8 & 799.9 & 799.8 & 799.8 \\
\hline Falta de pré-natal & 779.9 & 799.9 & V22.2 & 799.9 \\
\hline Hepatite transinfecciosa & 573.3 & 573.3 & 070.1 & 070.1 \\
\hline Hepatopatia crônica pelo vírus $\mathrm{C}$ & 070.5 & 571.4 & 070.5 & 139.8 \\
\hline Herniação uncal & 348.4 & 348.4 & 742.0 & 348.4 \\
\hline Hiperfluxo pulmonar & -.-- & 459.9 & 417.9 & 417.9 \\
\hline Hipertensão pulmonar em recém-nascido & 416.0 & 746.9 & 779.8 & 416.0 \\
\hline Homicídio em criança & E967.9 & E968.9 & E968.9 & E968.9 \\
\hline Insuficiência cardíaca descompensada & 428.9 & 428.0 & 428.9 & 428.0 \\
\hline Insuficiência cardiaca refratária & 428.9 & 428.0 & 428.9 & 428.0 \\
\hline Intoxicạaão exógena & $-\cdots---$ & 977.9 & 977.9 & E980.9 \\
\hline Laparatomia & E878.8 & 799.9 & 799.9 & 799.9 \\
\hline Linfangite carcinomatosa pulmonar & 196.1 & 197.0 & 457.2 & 199.1 \\
\hline Meningite por diplococos gram + & 320.9 & 320.5 & 320.9 & 320.9 \\
\hline Mielodisplasia & 742.5 & 742.9 & 742.5 & 336.9 \\
\hline Miocardiopatia aterosclerótica & 414.0 & 414.0 & 425.4 & 414.0 \\
\hline Miocardiopatia congestiva & 425.4 & 428.0 & 425.4 & 425.4 \\
\hline Miocardiopatia descompensada & 425.4 & 428.0 & 425.4 & 425.4 \\
\hline Miocardiopatia dilatada & 425.4 & 425.4 & 425.4 & 425.4 \\
\hline Miocardiopatia hipertensiva & 402.9 & 402.9 & 425.4 & 402.9 \\
\hline Miocardioparia isquêmica & 414.0 & 414.0 & 425.4 & 414.0 \\
\hline Morte natural & 799.9 & 799.0 & 799.9 & 799.9 \\
\hline Síndrome de Klippel-Weber & ----- & ----- & 759.8 & 756.1 \\
\hline \multicolumn{5}{|l|}{ Síndrome vascular da fossa cerebelar } \\
\hline posterior & 437.8 & 434.9 & 436 & 437.9 \\
\hline TBC residual & 137.0 & 137.0 & 011.9 & 017.8 \\
\hline Tumor cerebral/fungos & 239.6 & 117.9 & 239.6 & 239.5 \\
\hline Tumor renal & 189.0 & 239.5 & 239.5 & 239.5 \\
\hline
\end{tabular}


USO DE CÓdIGOS DE REJEIÇÃO OU DE EXCLUSÃO (REJECT CODES)

No Atestado Médico, á direita das linhas tanto da Parte I como da Parte II, reserva-se um espaço para a indicação do "intervalo entre o início da doença e a morte". Considerando que a causa básica deve ser mencionada na última linha usada da Parte I, o tempo indicado para a mesma deve ser maior que os tempos respectivos para as causas conseqüenciais mencionadas nas linhas acima, e destas últimas o tempo menor ser o da causa imediata, direta ou terminal que deve constar na linha (a). Com a informação do tempo de duração das afecções que levaram a morte é possível reconstituir-se a história natural de doenças. Para o codificador, esta informação orienta o raciocínio para a aceitação ou não da seqüência informada pelo médico no processo de seleção da causa básica da morte. Esta orientação reveste-se de tal importância que a Classificação Internacional de Doenças coloca a mesma nas notas para a interpretação do qualificativo "sumamente improvável" (31) .

- processamento das causas de morte pelo sistema ACME pressupõe que os dados sobre duração estejam colocados de modo adequado. Examina, portanto, se a causa da linha (a) é aceita como devida às causas das linhas (b) e (c), e se a causa da linha (b) é devida á causa da linha (c). Na eventualidade de a duração de afeç̧ões entre linha ou linhas não for adequada, o codificador deve indicar essa inconsistência colocando um código especial em um campo do registro correspondente ao atestado médico que está sendo codificado. Este código especial denomina-se código de rejeição ou de exclusão (reject code) (42, 43).

A instrução para uso deste código dispõe que quando a duração de uma afecção na posição "devido a" é menor do que a duração da afeç̧ão mencionada na linha acima e apenas uma afeç̧ão for mencionada nessas linhas, um código de rejeição (1-5) dever ser usado no campo próprio. Quando mais de uma afecção passível de codificação for informada na mesma linha, não levar em consideração a duração naquela linha. Usar o código de rejeição adequado mesmo que existam linhas sem duração ou mesmo que haja mais de uma afeç̧ão passível de codificação entre as durações inconsistentes; neste caso, considerar a inconsistência como ocorrendo entre a linha imediatamente acima e a linha com a duração menor. 
Os códigos de rejeição e os respectivos tipos de inconsistência entre linhas da Parte I são os seguintes:

$\begin{array}{cl}\text { Código de rejeição } & \text { Linhas da Parte I } \\ 1 & \text { I (a) e I (b) } \\ 2 & \text { I (b) e I (c) } \\ 3 & \text { I (c) e I (d) } \\ & \text { I (d) e I (e) } \\ 5 & \text { durações inconsistentes entre mais } \\ & \text { que duas linhas da Parte I ou outra } \\ & \text { situação onde os códigos 1-4 não se } \\ & \text { aplicam. }\end{array}$

$\mathrm{Na}$ amostra estudada foram verificadas oito Declarações de óbito nas quais o código de rejeição deveria ter sido usado. Essas Declarações, nas quais não foram encontradas anotações específicas, são as seguintes com as respectivas codificações:
Masculino, 69 anos
I a) Ins. vascular periférica
10 anos
b) Ins. respiratória
8 anos
c) Ins. cardíaca congestiva
8 anos

II

A codificação - 443.9 / 786.0 / 428.0 - produziu a causa básica "insuficiência vascular periférica" (443.9), por aplicação da Regra 2, isto é, a falta do código de rejeição "1" não comprometeu a sua seleção dado o médico ter informado seqüência sumamente improvável.

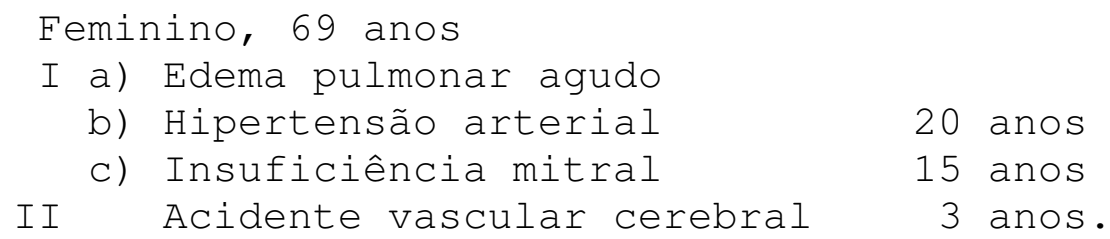

A codificação - 518.4 / 401.9 / 424.0 * 438 - conduziu a causa básica "efeito tardio de acidente vascular cerebral" (438), que não foi comprometida. A hipertensão arterial, selecionada pela Regra 1, não foi aceita como devida a insuficiência mitral. Houve subseqüente associação com o efeito tardio do acidente vascular cerebral. 


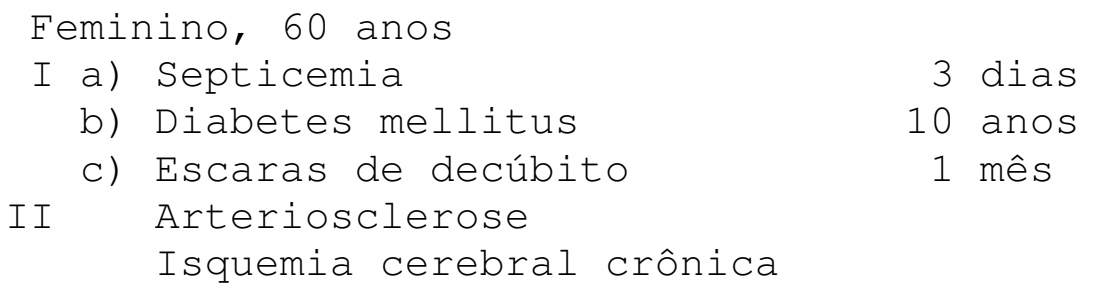

A codificação - 038.9/250.0/707*440.9 b 437.1 - levou à causa básica "diabetes mellitus com outras manifestações especificadas" (250.7), do mesmo modo não comprometendo sua codificação. O sistema, apesar de não ter recebido o código de rejeição, não aceitou "diabetes" devido a "escaras de decúbito". Selecionado o "diabetes" pela Regra 1, houve subseqüente associação com "escaras de decúbito".

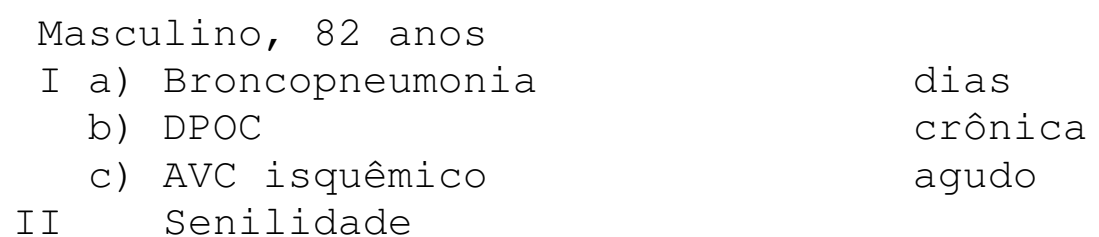

A codificação - 485/496/434.9 * 797 - levou à causa básica "acidente vascular cerebral isquêmico", dado o Sistema não ter sido informado que uma afecção "aguda" não é causa de outra dita "crônica". Neste caso, a causa básica muda para "doença pulmonar obstrutiva crônica" (496). Além disso, levanta-se a questão de o sistema estar aceitando uma "doença pulmonar obstrutiva crônica" como devida Ás "doenças cerebrovasculares" (44, 45).
Feminino, 54 anos
I a) Choque séptico
1 dia
b) Colangite
7 dias
c) Insuficiência renal aguda
1 dia

II

A codificação - $785.5 / 576.1$ / 584.9 - conduziu á identificação da "colangite" (576.1) como causa básica, que não foi comprometida pela falta do código de rejeição. o Sistema não aceitou "colangite" devido a "insuficiência renal aguda" .

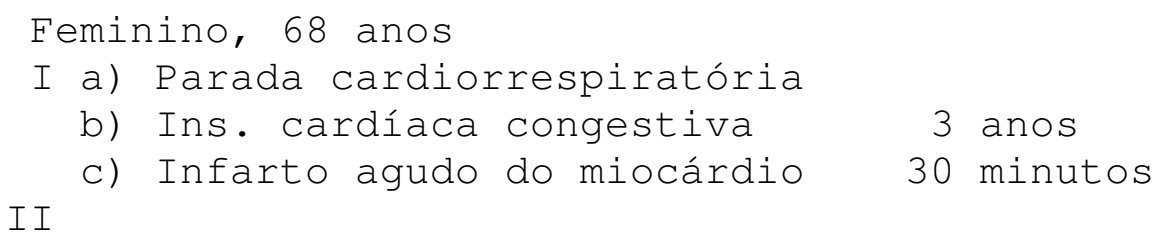


A codificação - 427.5 / 428.0 / 410 - produziu a causa básica "infarto agudo do miocárdio" (410), que não foi comprometida. Neste caso, o Sistema aceitou que o "infarto do miocárdio" tivesse produzido a "insuficiência cardíaca congestiva" e o mesmo foi selecionado pela Regra Geral.

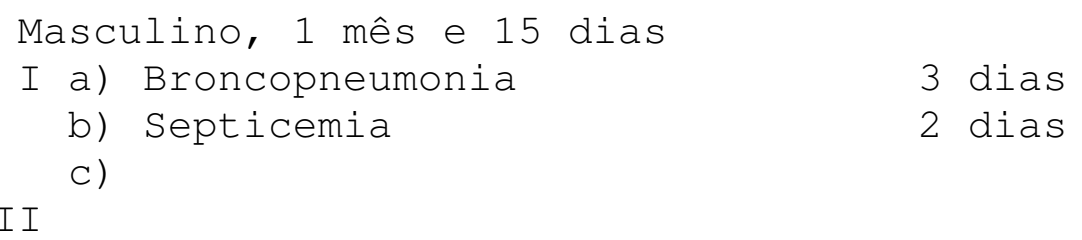

A codificação - 485 / 038.9 - levou a seleção da "septicemia" (038.9) como causa básica, quando o correto seria ter selecionado a "broncopneumonia" (485) se o código de rejeição "1" tivesse sido usado.

$\begin{array}{ll}\text { Masculino, } 63 \text { anos } & \\ \text { I a) Acidente vascular cerebral } & 4 \text { dias } \\ \text { b) Hipertensão arterial } & 1 \text { ano } \\ \text { c) Insuficiência cardíaca } & 7 \text { dias }\end{array}$

II

A codificação - 436/401.9 / 428.0 - conduziu á causa básica "acidente vascular cerebral", que não foi afetada pela falta do código de rejeição "1". Pela Regra 1 o Sistema selecionou a "hipertensão arterial" (401.9) e em seguida procedeu a sua associação com o "acidente vascular cerebral" (436), causa básica final.

Verifica-se que dentre oito Declarações de óbito em que o código de rejeição não foi usado para indicar a inconsistência da duração entre afecções, apenas em duas delas houve mudança da causa básica. Este fato, o restrito comprometimento da causa básica identificada pelo Sistema, deve-se a duas razões. A primeira diz respeito às inconsistências correlatas temporais e etiopatogênicas das afeç̧ões envolvidas, isto é, a uma relação temporal não aceita corresponde geralmente a não aceitação pelo sistema ACME da relação etiopatogênica tal como foi informada pelo médico. A segunda razão refere-se à recuperação da causa básica pelas regras de mortalidade da Classificação Internacional de Doenças.

No entanto, em todas as Declarações de óbito houve prejuízo para o estudo da forma de preenchimento do Atestado Medico quanto ao uso das regras de mortalidade. 
USO DE SIGLAS

Levantamento contínuo realizado junto aos codificadores e usuários da Classificação Internacional de Doenças registra no momento aproximadamente 300 siglas usadas pelos médicos em ambulatórios, hospitais e demais serviços de saúde ou nas Declarações de óbito. O uso de siglas para identificar diagnósticos tem sido censurado considerando os problemas que tal uso acarreta; freqüentemente a dificuldade em interpretar seu significado ou a múltipla interpretação que pode ser dada às mesmas prejudica a correta classificação dos diagnósticos e causas de morte.

No material de estudo foram observadas 40 siglas diferentes usadas cerca de 205 vezes, correspondendo a aproximadamente 6\% de todas as Declarações de óbito da amostra. Poucas declarações apresentavam duas ou mais siglas no Atestado Médico. As siglas usadas com maior freqüência e suas respectivas percentagens em relação ao número de vezes em que aparecem siglas foram: $\operatorname{AVC}(17,6 \%), \operatorname{DOPC}(16,6 \%), \operatorname{ICC}(8,8 \%)$, $\operatorname{SIDA}(8,3 \%), \operatorname{AIDS}(7,3 \%), \operatorname{HAS}(5,4 \%)$ e $\operatorname{BCP}(4,9 \%) . A$ sigla AVC somada às variantes AVCH, AVCI e AVE atinge a cerca de $20 \%$ dentre todas as usadas.

Apenas na Declaração de óbito reproduzida a seguir foi observada interpretação incorreta de sigla.

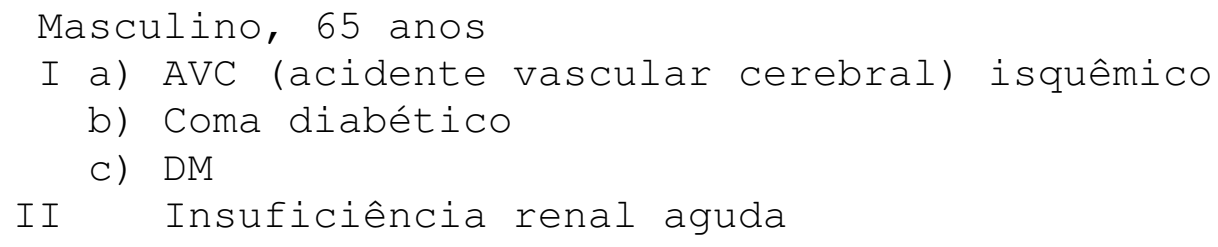

A codificação - 434.9 / 250.2 / 277.9 * 584.9 - mostra que a sigla "DM" foi interpretada como "doença do metabolismo SoE" ao invés de "diabetes mellitus". Apesar da interpretação inadequada, a causa básica apresentou-se correta, isto é, "diabetes mellitus com coma" (250.2). 
COLOCAÇÃO DE CÓDIGOS DA CLASSIFICAÇÃO INTERNACIONAL DE DOENÇAS

De modo análogo ao do uso de siglas, a colocação de códigos da Classificação Internacional de Doenças pelos médicos nas Declarações de óbito também é censurado. Isto porque, argumenta-se, os médicos geralmente não recebem treinamento sobre a maneira de usar a Classificação ensejando, portanto, o encontro de códigos inadequados.

Neste estudo foram observadas cinco Declarações de óbito nas quais os médicos atestantes colocaram códigos da Classificação Internacional de Doenças. Em quatro delas foram usados códigos da adaptação da Classificação que inclui dígito controle, cujo uso dá margem maior a ocorrência de erros ou de codificação inadequada, pois esta classificação não se acompanha de Índice. Três dessas Declarações provieram de um mesmo cartório, correspondentes a falecidos em um mesmo hospital, embora fornecidas por médicos distintos. Foram usados os códigos "428.9", "486.9/0", "798.9/8" e "799.9/5", este ultimo por duas vezes, correspondentes, respectivamente, a "insuficiência cardíaca", "pneumonia", "morte sem assistência médica" e "causa desconhecida". 
CAUSAS DE MORTE CONDICIONADAS A RESULTADOS DE EXAMES

Nove Declarações de óbito foram encontradas nas quais há menção de envio de material para exames complementares a fim de caracterizar a causa da morte. Destas declarações, duas foram fornecidas por Serviços de Verificação de óbitos, ambas sendo assinadas pelo mesmo médico, e sete por Institutos Médico-Legais. Três correspondem a óbitos registrados num mesmo município.

As causas básicas de morte atribuídas nessas Declarações de óbito foram "779.9" (2 vezes), "799.9" (4 vezes), "E928.9" (2 vezes) e "E988.9" (uma vez), correspondentes, respectivamente, a "afecção originada no período perinatal mal definida", "causa desconhecida", "acidente soE" e "lesão em que se ignora se acidental ou intencionalmente infligida por meios não especificados". Todas estas causas permaneceram no arquivo final e não foram modificadas, o que demonstra que eventuais esclarecimentos obtidos a partir dos resultados dos exames complementares não foram comunicados à Fundação SEADE.

A atribuição de código da Classificação suplementar de Causas Externas de Lesões e de Envenenamentos em três dessas declarações, bem como o código "779.9" do Capítulo XV, sobre Algumas Afeç̧ões Originada no Período Perinatal, em duas outras declarações, não parece ser a classificação mais adequada. No caso do código de causas externas, essa atribuição se deveu apenas pelo fato de as declarações terem sido fornecidas em Instituto Médico-Legal, não tendo sido mencionado na Declaração de óbito qualquer evidência de morte violenta. Quanto aos códigos do Capítulo XV, esta classificação pode superestimar as causas perinatais desde que os exames complementares poderiam determinar causas de outros capítulos, como o de anomalias congênitas, por exemplo.

Em relação às quatro Declarações de óbito em que a causa básica teve código "799.9" no arquivo final, houve erro inicial de codificação, embora não comprometendo a causa básica. O codificador atribuiu a essas declarações o código especial criado "799.7", reservado para "causa desconhecida", quando deveria ter usado o código "799.9", destinado a codificar justamente tais declarações em que exames complementares são solicitados. O código "799.9" também deveria ser o usado nas cinco declarações comentadas no 
parágrafo anterior, mudando, nestas declarações, a causa básica final para "799.9". 
LEGISLAÇÃO CITADA NA DECLARAÇÃO DE ÓBITO

Duas Declarações de óbito foram encontradas com a citação seguinte: "Morte súbita - Art. 2, 3, 4 e 5 do Decreto 51.014 de 05/12/68 e da Lei no 10.095 de 03/05/68", ambas de um mesmo médico. Tiveram como causa básica codificada "morte instantânea" (798.1) .

A Lei no 10.095, de 3 de maio de 1968, dispõe sobre o Serviço de Verificação de óbitos do Município de São Paulo e dá outras providências (60). O Decreto no 51.014 , de 5 de dezembro de 1968, regulamenta as disposições da Lei no 10.095 (58).

Aparentemente essas duas Declarações de óbito foram fornecidas a pessoas falecidas sem assistência médica. Dentre os dispositivos legais citados, caberia com maior propriedade apenas o Art. 2 do Decreto n 51.014, que reza "Os óbitos motivados por moléstia mal definida, que ocorrerem nos municípios do Interior do Estado onde não funcionem Serviços de Verificação de óbitos, serão atestados por médicos da Secretaria de saúde Pública, nos termos do artigo 4, item I, da Lei no 10.095". Este fato leva a crer que o médico atestante desconhece a Lei no 5.452, de 22 de dezembro de 1986, mais recente e que reorganiza os serviços de Verificação de óbitos no Estado de São Paulo (59). Esta lei, para situações análogas, no Artigo 2 de suas Disposições Transitórias, dispõe que "nos municípios do Interior do Estado onde não houver SVO, os óbitos de pessoas falecidas de morte natural sem assistência médica deverão ter seus atestados fornecidos por médico da Secretaria da saúde, e, na sua falta, por qualquer outro médico da localidade", especificando no parágrafo 1 o que "em qualquer dos casos deverá constar do atestado que a morte ocorreu sem assistência médica". Tal caracterização dessas mortes, como "sem assistência médica" (798.9) mostra-se mais adequada que a de "morte instantânea" (798.1). 
MENÇÃO DE BOLETIM DE OCORRÊNCIA POLICIAL

O aprimoramento dos dados sobre as mortes violentas têm se constituído numa das principais preocupações daqueles que trabalham com estatísticas de mortalidade no Brasil. Por disposição legal, os falecidos em razão de causas não naturais devem ser submetidos à necropsia em Instituto Médico-Legal, onde a Declaração de óbito será fornecida. O médico-legista, que recebe o cadáver encaminhado pela policia para necropsia, argumenta que não presenciou a ocorrência dos fatos que determinaram a morte, que apenas constata a natureza das lesões produzidas no corpo da vítima, portanto não lhe sendo possível informar sobre as circunstâncias da violência que produziram tais lesões. Isto equivale a dizer que não poderia afirmar que um traumatismo crânioencefálico adveio de um atropelamento acidental, ou que uma perfuração do tórax foi produzida por arma de fogo de forma homicida. Os escrúpulos, hesitações e dúvidas do médico-legista em informar na Declaração de óbito as causas externas de mortes violentas são vinculadas ao caráter e á força legal que possam advir de tal informação, gerando seu comprometimento em face da informação e a responsabilidade correlata.

A menção da causa de morte limitada á natureza da lesão nas mortes violentas compromete sobremaneira a qualidade da informação tendo em vista o conceito de causa básica da morte. A omissão das "circunstâncias do acidente ou violência que produziram a lesão fatal", isto é, da ação externa, prejudica a prevenção dessas mortes.

A importância e necessidade dos dados sobre as causas externas nas mortes violentas têm gerado sugestões para a obtenção dos mesmos. Aos serviços que produzem as estatísticas de mortalidade, em especial aos codificadores de causas de morte, sugestões têm sido feitas para a procura de esclarecimentos complementares que poderiam ser obtidos por meio de noticias sobre mortes violentas em jornais, nas Delegacias de Polícia ou mesmo nos Institutos Médico-Legais. O encaminhamento de cadáver vítima de morte violenta pelos órgãos policiais ao Instituto Médico-Legal se faz por meio de um "boletim de ocorrência", no qual se registra a suposta circunstância que provocou a morte. Os dados do boletim de ocorrência podem ser utilizados para recuperar a causa externa. 
Neste sentido, os médicos-legistas têm sido orientados para informar as causas externas no Atestado Médico reproduzindo as informações do Boletim de Ocorrência policial que encaminhou o cadáver e identificando o mesmo na Declaração de óbito.

Verifica-se que essa orientação tem frutificado com resultados satisfatórios para a melhoria da qualidade da causa externa de mortes violentas. Na amostra estudada, dezenas de Declarações de óbito preenchidas em Institutos Médico-Legais, bem como em Serviços de Verificação de óbito, em mortes de causas naturais, trazem a indicação do Boletim de Ocorrência policial, identificado pelo número, pela Delegacia de Policia e pela data de sua expedição. Freqüentemente esta indicação é feita ao lado da casela relativa ao tipo de violência, incluída no item "37" da Declaração de óbito. 
INTENÇÃO DO MÉDICO ATESTANTE

A fim de obter-se o código mais adequado para um dado diagnóstico, torna-se necessário, às vezes, levar em consideração outros dados informados e a seqüência segundo a qual são colocadas as causas no Atestado Médico. A classificação desses diagnósticos, fora do contexto em que se apresentam, poderia deixar de traduzir o significado pretendido pelo médico atestante. Com tal objetivo, foram estabelecidas instruções específicas para alguns termos diagnósticos cuja codificação para fins de processamento da causa básica pelo sistema ACME depende de tais condições (42, 43).

Foram observadas Declarações de óbito com questões deste tipo em que se mencionavam os diagnósticos relacionados com "microorganismos e infecções" (136.9), "miocardiopatia" (425.4) e "pneumonias" (481, 485, 486). A par destas afecções cuja codificação é prevista em manuais de instrução, discutese a codificação do diagnóstico "neoplasia cervical".

\section{Microorganismos e infecções (136.9)}

Dentre as instruções para a classificação de termos diagnósticos relacionados com microorganismos e infecções, a primeira delas dispõe que "quando um afecção infecciosa ou inflamatória for informada devido a um microorganismo especificado ou a uma infecção não-sistêmica especificada, sendo estes últimos, o microorganismo ou a infecção, os únicos diagnósticos na linha ou a primeira menção na posição "devido a", codifica-se a afecção (onde estiver mencionada no Atestado Médicol modificada pelo microorganismo ou pela infecção. Não devem ser atribuídos códigos separados para o microorganismo ou para a infecção" (42, 43.

Esta situação apresentou-se na Declaração de óbito reproduzida a seguir.
Feminino, 1 ano
I a) Septicemia
b) Stafilococcia
c) Varicela grave

II

A codificação - 038.8 / 052 - levou a seleção correta da "varicela" (052) como causa básica, no entanto com erro de 
codificação da "septicemia" (038.8). Este Atestado Médico foi submetido à análise do "National Center for Health statistics" que interpretou a codificação do seguinte modo 038.1 / b / 052 - , isto é, modificando a "septicemia" para "septicemia estafilocócica" e não indicando código na linha (b) .

\title{
Miocardiopatia (425.4)
}

O termo "miocardiopatia", dentre os que tiveram adaptação de códigos para processamento, é o mencionado com maior freqüência em Declarações de óbito.

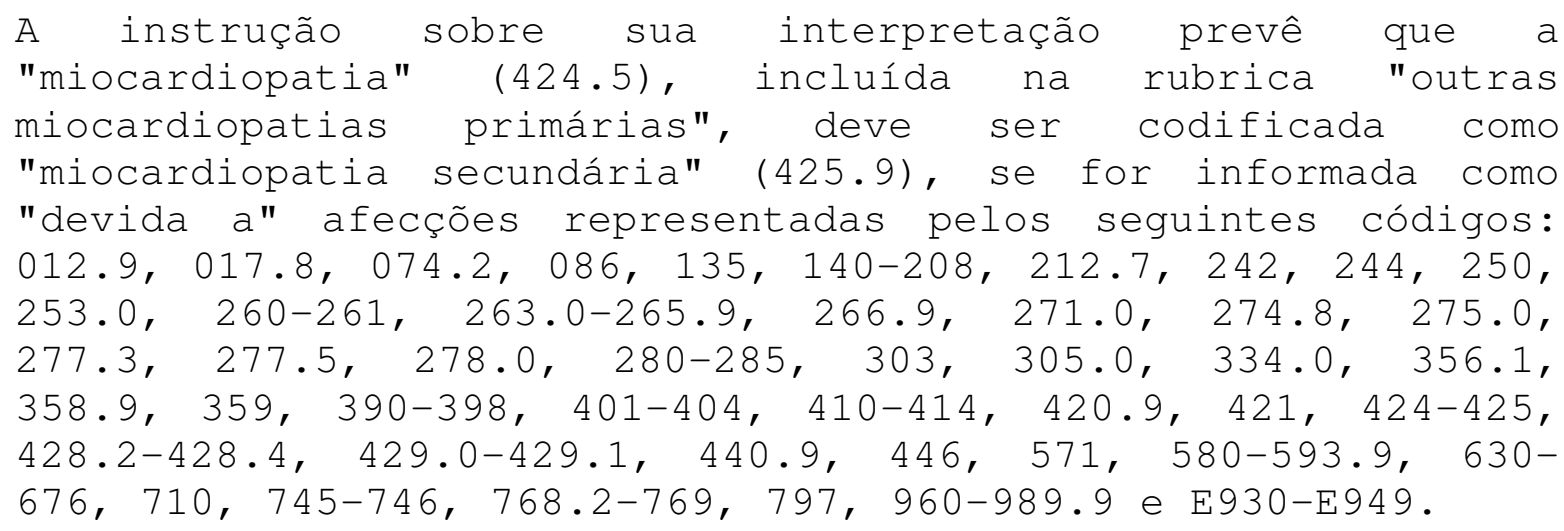

Observou-se que o código "425.9" para "miocardiopatia secundária" foi usado indevidamente nas seguintes Declarações de óbito.
Masculino, 71 anos
I a) Fibrilação ventricular
b) Miocardiopatia
c) Acidente vascular cerebral
II
Hipertensão arterial sistêmica

A codificação - 427.4 / 425.9/436*401.9 - levou à seleção da causa básica "miocardiopatia secundária" (425.9). Neste caso, o código usado deveria ser o original (425.4), desde que não há previsão de mudá-lo quando a "miocardiopatia" é dita "devida a" um "acidente vascular cerebral" (436).

\author{
Feminino, 25 anos \\ I a) Parada cardiorrespiratória \\ b) Miocardiopatia \\ c) Insuficiência cardíaca \\ II \\ Hipertensão arterial
}


A codificação - 427.5 / 425.9 / 428.9 * 401.9 - conduziu á seleção da causa básica representada pelo código "425.9", em lugar do correto "425.4", que deveria ter sido usado, como no caso anterior.

\author{
Feminino, 74 anos \\ I a) Insuficiência respiratória \\ b) Miocardiopatia \\ c) Insuficiência cardíaca congestiva
}

II

A codificação - 786.0 / 425.9 / 428.0 -, é análoga ao do caso anterior. O Sistema selecionou "425.9" em lugar de "425.4" que deveria ter sido usado.
Masculino, 53 anos
I a) Embolia pulmonar
b) Miocardiopatia congestiva
c) Insuficiência cardíaca

II

A codificação - 415.1 / 425.9 / 428.9 - reproduz a forma dos dois últimos atestados discutidos. O código "425.4" deveria ter sido usado desde que não há previsão para usar "425.9" quando a "miocardiopatia" estiver informada como "devida a" "insuficiência cardíaca" (425.9) ou "insuficiência cardíaca congestiva" (425.0).

Por outro lado, nas Declarações de óbito que são apresentadas a seguir, o codificador deixou de atender às instruções para interpretar a miocardiopatia como secundária.

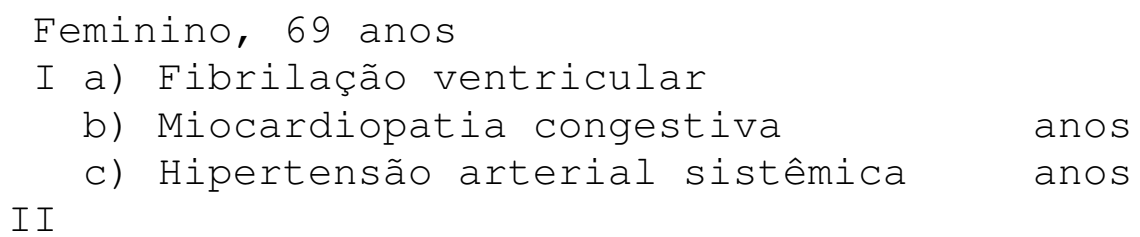

$\mathrm{Na}$ codificação - 427.5 / 425.4 / 401.9 - a "miocardiopatia congestiva" foi interpretada com primária (425.4), fato que resultou sua seleção como causa básica. O correto teria sido codificá-la como secundária (425.9), fato que determinaria a seleção pela Regra Geral da "hipertensão arterial sistêmica" e sua posterior associação com a miocardiopatia resultando na causa básica final "doença cardíaca hipertensiva" (402.9). 


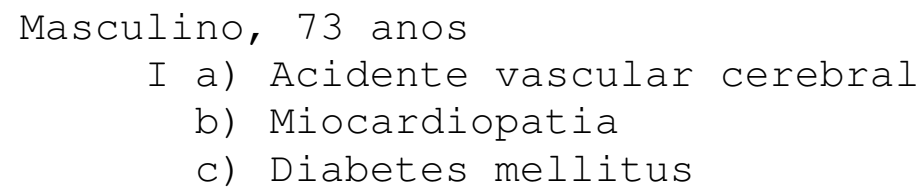

II

A codificação - 436/425.4 / 250.0 - levou a seleção da "miocardiopatia" (425.4), interpretada como primária, como sendo a causa básica. O correto teria sido sua codificação como secundária (425.9), medida que permitiria a seleção, pelo processamento, do "diabetes mellitus" (250.0) como causa básica correta.

$\mathrm{Na}$ Declaração de óbito apresentada a seguir, a "miocardiopatia" é informada como "devida a" "síndrome da imunodeficiência adquirida" (279.1), eventualidade não prevista nos manuais de instrução de 1984 (42).
Masculino, 22 anos
I a) Desconhecida
b) Miocardiopatia
c) SIDA

II

A previsão de codificar a "miocardiopatia" como "425.9" quando "devida a" "síndrome da imunodeficiência adquirida" já se encontra em manuais recentes, de 1992 (43). Neste atestado, embora a codificação - 425.4 / 279.1 - tenha sido incorreta, a causa básica selecionada foi intencionalmente definida pelo codificador como "síndrome da imunodeficiência adquirida".

\title{
Pneumonias $(481,485,486)$
}

A "pneumonia (486), a "broncopneumonia" (485) e a "pneumonia lobar de microorganismo não especificado" (481), devem ser codificadas como "pneumonia hipostática" (514) se estiverem informadas como "devidas a" "estar acamado", "estase", "hipostase", "inatividade", "retido no leito" e expressões equivalentes. Observou-se uma Declaração de óbito com tais diagnósticos, embora com diferenças quanto à forma.

\author{
Feminino, 46 anos \\ I a) Insuficiência respiratória \\ b) Broncopneumonia \\ C) \\ I Paciente acamada de longa data
}


Neste Atestado Médico, a "broncopneumonia" (485) não esta dita "devida a" "estar acamada" e, a rigor, a disposição em tela não se aplicaria. Apesar disso, o fato de o Médico atestante indicar que houve influência da situação da paciente estar acamada na determinação da morte, tal influência se faz por meio da etiopatogenia da "broncopneumonia". Deste modo, optou-se pela codificação 786.0 / 514 - que leva a seleção de "pneumonia hipostática" (514) como causa básica.

\section{Neoplasia cervical no sexo feminino}

O diagnóstico "neoplasia cervical", usado com freqüência, e aqueles de outras afeç̧ões qualificadas como de localização "cervical", ocorrendo em mulheres, geram dúvidas quanto a sua interpretação e codificação. A dúvida consiste em definir a localização entre "pescoço" e "colo do útero". Neste sentido, sugere-se a norma para interpretar o adjetivo "cervical", usado para qualificar "neoplasia" em mulheres, como relativo a "colo do útero" e codificar de forma conseqüente.

Esta interpretação pode ser aplicada na Declaração de óbito seguinte.

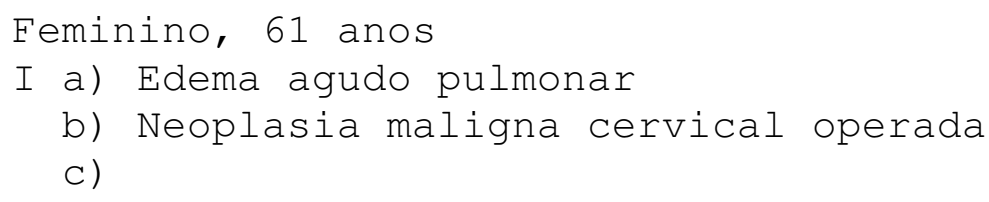

A codificação - 518.4 / 195.0 - interpretou a neoplasia como do "pescoço" (195.0) ao passo que o mais provável seria ter sido "neoplasia maligna do colo do útero" (180.9) a causa básica da morte. 
O processamento correto das causas de morte pelo sistema ACME está condicionado à forma da codificação das afecções mencionadas no Atestado Médico. Esta codificação, por sua vez, subordina-se à seqüência segundo a qual essas afecções são colocadas, à inter-relação entre elas e a pormenores de sua codificação pela Classificação Internacional de Doenças. o manual de instruções, de modo especial, orienta a codificação de atestados em que estejam informadas causas raras de morte, estas incluindo afecções triviais e doenças de notificação compulsória, além de neoplasias, doenças reumáticas do coração, complicações da gravidez, parto e puerpério, afecções congênitas, afecções originadas no período perinatal, e as situações previstas pela Regra de Modificação 10 (efeitos tardios), Regra de Modificação 11 (Pneumonia antiga, gripe e causas maternas) e de causas desconhecidas ou mal definidas $(42,43)$.

De modo geral, problemas não foram observados com a codificação das categorias citadas no parágrafo anterior. No entanto, dadas algumas das peculiaridades da codificação das neoplasias, comentários serão feitos sobre a inferência preconizada pelo Centro Brasileiro de Classificação de Doenças sobre o diagnóstico "neoplasia cerebral" e sobre o uso de uma disposição da Classificação Internacional de Doenças para a codificação de neoplasias de localizações vizinhas.

No decurso de pesquisas sobre a qualidade da informação sobre as causas de morte contidas nas Declarações de óbito, principalmente em pesquisas com emprego da metodologia das chamadas "Investigações Interamericanas de Mortalidade" (51, 52), torna-se possível o conhecimento do significado correto das causas informadas pelo médico atestante do óbito. A busca de esclarecimentos complementares sobre o processo mórbido que produziu a morte por meio de entrevista de familiares do falecido, consulta de prontuários médicos de hospitais onde ocorreu a morte ou o falecido recebera assistência, consulta de resultados de exames complementares, de laudos de autópsia, etc., tudo isso permite a recuperação de dados precisos e valiosos para a reconstituição das reais causas de morte. Em tópico anterior, discutiu-se a interpretação do diagnóstico "desidratação" usada com o significado de "gastroenterocolite". 
Em relação aos termos "neoplasia" e "tumor", verificou-se que poucas vezes são qualificados segundo sua natureza pelos médicos que fornecem a Declaração de óbito. Houve necessidade de considerar este fato para evitar a codificação em excesso desses óbitos como devidos a "neoplasias de natureza não especificada", categoria de caráter residual do Capítulo das Neoplasias.

A orientação específica aos codificadores reza: "quando a causa básica selecionada for identificada pelo termo "neoplasia", sem especificação de ser maligna, benigna, in situ, de comportamento incerto ou de natureza não especificada, o codificador deverá inferir que essa neoplasia seja maligna e assim codificá-la, segundo o tipo morfológico e sua localização. Tal inferência não deve ser feita quando a localização informada for o cérebro, codificando-se neste caso a neoplasia como de natureza não especificada, isto é, $239.6 "$.

A justificativa desta orientação se faz em seguida: "a interpretação de constituir-se em neoplasia maligna aquela mencionada apenas como "neoplasia" decorre da observação, no Brasil, do uso desse termo pelos médicos ao atestarem o óbito. Os médicos usam o termo "neoplasia" como sinônimo de "neoplasia maligna", pois a quase totalidade dos óbitos devidos a tais causas se devem a neoplasias malignas. A menção de uma morte ter como causa básica uma neoplasia benigna é de tal forma rara que o médico chama a atenção para o fato, indicando, explicitamente, a neoplasia como benigna".

Para a codificação da causa básica da morte, esta orientação tem sido observada pelos codificadores. Além disso, verificase também que os médicos já informam com maior freqüência a natureza da neoplasia. No entanto, recentemente, ao realizarse a análise da aplicação do sistema de Seleção de Causa Básica de Morte por Microcomputador (SCB) a óbitos em que todas as causas de morte estavam codificadas e não apenas a causa básica, verificou-se a existência de registros de Atestados Médicos nos quais o código "239.6", que corresponderia a um diagnóstico de "neoplasia cerebral" estava acompanhado a códigos de neoplasias secundárias (196.a 198.-). Este fato fez pensar que os codificadores estivessem sempre usando o código "239.6" para "neoplasia cerebral", mesmo que no Atestado Médico houvesse a indicação de sua malignidade.

Um artigo no Boletim do Centro foi publicado chamando a atenção para este problema. São estas as palavras textuais: 
"os codificadores recebem durante o treinamento no uso da Classificação Internacional de Doenças em mortalidade algumas instruções quanto à interpretação de modismos no Brasil em relação a diagnósticos e causas de morte. Deste modo, aprendem que a desidratação deve ser interpretada como gastroenterocolite em menores de cinco anos de idade quando a mesma for a causa básica, que a parada cardíaca, se estiver sozinha no atestado, dever ser interpretada como causa mal definida e codificada em "799.1", e, além de outras, que os termos "neoplasia" e "tumor" devem ser interpretados como "neoplasia maligna" e "tumor maligno". Esta última inferência, de considerar neoplasia e tumor como malignos, sempre faz a ressalva que, quando forem cerebrais, deverão ser codificados em "239.6", código correspondente a neoplasia do cérebro de natureza não especificada. Esta ressalva se deve ao fato de as neoplasias e tumores cerebrais, mesmo benignos, face à localização, determinarem quadros clínicos de muita gravidade. Esta nota chama a atenção dos codificadores que esta restrição, de interpretar neoplasias cerebrais como de natureza não especificada, será feita somente quando não houver caracterização da natureza da neoplasia, quer por indicação do tipo histológico, quer pela indicação de outros diagnósticos em outra parte do atestado. Assim sendo, se houver informação de que a neoplasia cerebral, selecionada como causa básica, produziu metástases, não dever ser usado o código "239.6", mas sim o código de neoplasia maligna do cérebro. O Boletim coloca esta nota, dado haver encontrado, em revisões de Declarações de óbito de alguns Estados, a codificação de tais casos em "239.6" mesmo com a presença de metástases informadas devidas a neoplasia cerebral" (4).

Na amostra foram observadas 11 Declarações de óbito em que a causa básica de morte recebeu código "239.6", das quais 9 se encontravam codificadas de modo adequado e duas apresentavam erros. Das Declarações de óbito com erros, uma delas foi comentada ao se discutir a codificação de afecções especificadas entre parênteses e formas análogas de especificação de diagnósticos; na última linha da Parte I do Atestado Médico mencionava-se "tumor cerebral - meningiona", tendo ambos diagnósticos sido codificados separadamente, determinando seleção do termo menos específico. A outra Declaração de óbito em que houve erro reproduz-se a seguir.

Feminino, 61 anos

I a) Hipertensão intracraniana (cerebral)

b)

c) Neoplasia maligna intracraniana 
A codificação - 348.2 / b / 239.6 - confirma a suspeita aventada sobre estar havendo confusão a respeito de interpretar "neoplasia cerebral" como de "natureza não especificada". Neste atestado, a natureza da neoplasia foi especificada pelo médico como maligna e o código correto seria "191.9".

Em outras três Declarações de óbito problemas com a interpretação de neoplasias de localização cerebral foram observados.

\author{
Masculino, 62 anos \\ I a) Hipertensão intracraniana aguda \\ b) Neoplasia da fossa posterior \\ c) \\ II \\ Meningite purulenta
}

A codificação - 348.2 / 191.9 * 320.9 - não atendeu a orientação específica. O código adequado seria "239.6", tendo ocorrido erro de codificação da causa básica.
Masculino, 60 anos
I a) Parada cardiorrespiratória
b) Neoplasia pulmonar
c) Tumor cerebral
II Neoplasia pele c/ metástases

A codificação - 799.1 / 197.0 / 239.6 * 198.2 - apresenta erros de interpretação e codificação. A "neoplasia pulmonar", considerada secundária (197.0), não poderia ser devida a um "tumor cerebral", considerado "de natureza não especificada" (239.6). A Nota sobre Neoplasias Malignas da Classificação Internacional de Doenças (31), para Atestados Médicos em que algumas localizações são ditas metastáticas e outras não, orienta para considerar como sendo primária aquela localização que não é tomada com freqüência por metástases. Neste Atestado, atendendo às disposições dessa Nota, a "neoplasia da pele" (173.9) seria considerada primária e selecionada como causa básica. Deste modo, a codificação $799.1 / 197.0$ / $198.3 * 173.9$ b 199.0 - seria a mais adequada.

A outra peculiaridade da codificação de neoplasias refere-se à menção no Atestado Médico de localizações vizinhas e cujo local de origem não possa ser determinado. A disposição específica está colocada na Nota 4, à pagina 103 do Volume 1 da Classificação Internacional de Doenças (31). Nesta eventualidade, de não ser possível identificar o local de origem, existem três subcategorias que devem ser usadas 
quando a neoplasia maligna atingir localizações vizinhas de alguns sistemas ou aparelhos orgânicos, a saber, para "neoplasia maligna de outras localizações e de localizações mal definidas do lábio, da boca e da faringe" (149.8), para "neoplasia maligna de outras localizações e de localizações mal definidas nos órgãos digestivos e no peritônio" (159.8) e para "neoplasia maligna de outras localizações e de localizações mal definidas no aparelho respiratório e órgãos intratorácicos" (165.8).

Em duas Declarações de óbito houve oportunidade de ser aplicada a nota acima.

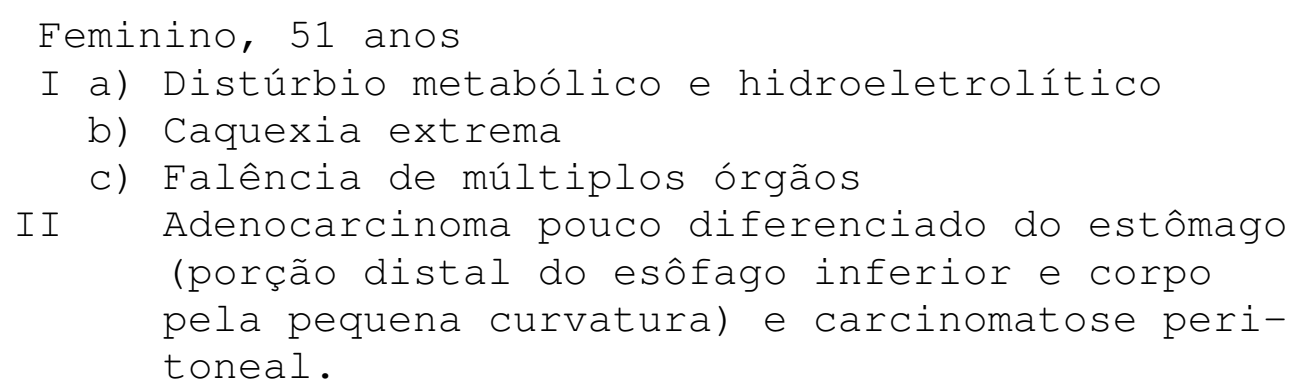

A codificação - 998.9 * \&878.6 b \&151.9 b 197.6 - reflete a grande dificuldade encontrada para interpretar este Atestado Médico. As causas da Parte I foram sintetizadas como "complicações pós-operatórias" [198.9], sendo na Parte II mencionada uma remoção de órgão (\&878.6) e a "neoplasia do estômago operada" (\&151.9). Embora as afecções mencionadas na Parte I não se constituam propriamente em complicações pósoperatórias, o codificador poderia ter tido acesso a esclarecimentos complementares do médico atestante, o que poderia justificar tal codificação. Ressalve-se haver o médico assinalado que o diagnóstico foi confirmado por cirurgia. Entretanto, importa assinalar que a neoplasia, entre parênteses, foi especificada como "da porção distal do esôfago inferior e corpo - do estômago - pela pequena curvatura" descrição que, para fins de classificação, é considerada atingindo localizações vizinhas e cujo local de origem não é determinado. O código "159.8" deve ser usado para caracterizar a causa básica da morte. A codificação 277.9 b $276.9 / 799.4 / 799.8 * 159.8$ b 197.6 - seria a mais adequada.

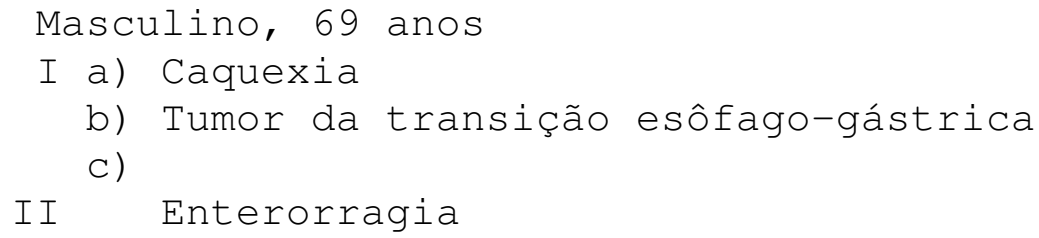


A codificação - 799.4 / 159.8 * 578.9 - corretamente reflete a neoplasia que compromete localizações vizinhas sem possibilidade de identificar sua origem. 
SUMÁRIO DOS ERROS DE CODIFICAÇÃO

A análise crítica da codificação das causas de morte nas 3.306 Declarações de óbito da amostra estudada permitiu a identificação de erros que comprometem a causa básica, as causas associadas ou ambas as causas. Em uma mesma Declaração de óbito poderiam ocorrer vários erros. Para simplificar a apresentação, a Declaração de óbito será considerada como unidade de erro e não o número de códigos incorretos. Do mesmo modo, nas Declarações de óbito em que havia comprometimento de ambas as causas, a causa básica foi considerada como comprometida. A Tabela 6, a seguir, apresenta a distribuição dos erros observados segundo a causa comprometida e o sexo.

Tabela 6 - Declarações de óbito de residentes com erros de codificação, segundo causa de morte comprometida e sexo, amostra, Estado de São Paulo, 1992.

CAUSA

MASCULINO

FEMININO

TOTAL

BASICA

BÁSICA

66

48

114

ASSOCIADA

35

28

63

TOTAL

101

76

177

Foram observados 114 erros que comprometeram a qualidade da causa básica e 63 a causa associada de morte, totalizando 177 Declarações de óbito. Sem dúvida, os erros da causa básica se revestem de maior importância face às distorções que determinam nas estatísticas oficiais de mortalidade.

Pode-se dizer que a taxa de erros da causa básica de morte foi de 3,4\% em relação às Declarações de óbito analisadas da amostra. Verifica-se que este valor é maior que os valores encontrados por HARRIS e FRENCH no estudo metodológico do sistema de controle de qualidade da codificação, de 1,87\%, 
2,21\% e 1,89\%, trabalho este descrito na introdução (22). Estas comparações se fazem considerando a causa básica de morte apresentada segundo subcategorias de quatro algarismos da Classificação Internacional de Doenças. As correspondentes taxas de erro da causa básica, apuradas segundo os 17 Capítulos da Classificação Internacional de Doenças, são de 1, 1\% para a amostra dos óbitos de São Paulo e de 0,79\%, 0.94\% e de $0.77 \%$, respectivamente para os peritos e codificador original estudados por HARRIS e FRENCH (22).

Além de estimar a taxa de erro para a causa básica de morte, interessa também conhecer a taxa de erro para todas as causas, isto é para as causas múltiplas, compreendidas pela soma da causa básica e das causas associadas. Para tanto, torna-se necessário calcular o número de menções de diagnósticos informados. Em trabalho anterior (55), verificou-se, no Estado de São Paulo, a média de 2,55 diagnósticos informados por Declaração de óbito, que, aplicados ás declarações estudas da amostra, resulta em 8.430 diagnósticos estimados. Verifica-se então que a taxa de erros para causas múltiplas correspondente às 177 Declarações de óbito foi de 2,1\%, valor este inferior aos encontrados por HARRIS e FRENCH, que variaram de 3,05\% a 4,27\% (22).

- Anexo 4 apresenta a relação das Declarações de óbito com erro, identificadas pelo número seqüencial, data de registro, distrito de registro, e sexo, código do grupo etário, causa básica identificada pelo Sistema ACME, causa básica corrigida e tipo de erro.

Nas páginas seguintes são apresentadas tabelas que mostram a distribuição dos erros que comprometem a causa básica de morte e, nas duas últimas, respectivamente Tabelas 13 e 14, os erros totais. A análise destas tabelas, associada à identificação dos problemas responsáveis pelos erros em cada Declaração de óbito correspondente, pode oferecer subsídios para orientar medidas visando o aprimoramento da qualidade da codificação das causas de morte.

As Tabelas 7 e 8 apresentam os erros que comprometem a causa básica, de acordo com os Capítulos da Classificação Internacional de Doenças em que se incluíram, respectivamente, a causa básica selecionada pelo Sistema ACME e a causa básica corrigida. A Tabela 9 mostra a distribuição das causas básicas de morte da amostra após a correção dos erros. A Tabela 10 relaciona os erros com a nova distribuição das causas básicas da amostra. Todas essas tabelas apresentam-se segundo o sexo dos falecidos. 
Observa-se certa concentração de erros, em números absolutos e em relação ao número de óbitos incluídos nos respectivos Capítulos, em Declarações de óbito com causas básicas classificadas em "Doenças Infecciosas e Parasitárias" (Capítulo I), "Neoplasias" (Capítulo II), "Algumas Afecções Originadas no Período Perinatal" (Capítulo XV), "Sintomas, Sinais e Afecções Mal Definidas" (Capítulo XVI) e na "Classificação Suplementar de Causas Externas de Lesões e Envenenamentos" (Causas Externas).

A Tabela 11 mostra os erros da causa básica segundo grupos etários e sexo e a Tabela 12 relacionam tais erros com os respectivos óbitos da amostra. A distribuição dos erros segundo a idade conduz a hipóteses coincidentes com a sua distribuição pelos Capítulos da Classificação Internacional de Doenças. Do mesmo modo, em números absolutos e em relação ao número de óbitos por grupo etário, nota-se certa concentração de erros em menores de 1 ano de idade, onde predominam as "Doenças Infecciosas e Parasitárias" e principalmente causas de morte incluídas no capítulo "Algumas Afecções Originadas no Período Perinatal". Além disso, notase também ligeira convergência de erros nas idades mais avançadas, nas quais predominam as "Neoplasias" e são mais comuns as afecções "Mal Definidas".

Estes achados podem reorientar, por exemplo, os temas e a parcela de tempo reservados ao treinamento de codificadores. Críticas têm sido feitas sobre as características dos Atestados Médicos utilizados como exercícios práticos para aplicação das Regras de Mortalidade. Em que pese sua padronização internacional pela Organização Mundial da Saúde, argumenta-se que tais exercícios não refletem de modo adequado a forma de atestar e as doenças mais freqüentes em nosso meio como causa de morte. A observação derivada das tabelas comentadas sugere, por exemplo, maior atenção ao ensino da codificação de óbitos infantis e em especial os óbitos perinatais.

As Tabelas 13 e 14 mostram, segundo idade e sexo, a soma dos erros que comprometem, além da causa básica, também as causas associadas de morte, bem como confirmam as observações derivadas das tabelas anteriores. 
TABELA 7 - Erros da causa básica, segundo causa básica original e sexo. Amostra. Estado de São Paulo, 1992.

\begin{tabular}{lrrrrrr}
\hline C.I.D. & \multicolumn{2}{r}{$\begin{array}{l}\text { MASCU LINO } \\
\text { número }\end{array}$} & $\begin{array}{r}\text { FEMI NINO } \\
\text { número }\end{array}$ & $\%$ & \multicolumn{2}{c}{ TO TAL } \\
\hline Cap. I & 7 & 10,6 & 4 & 8,3 & 11 & 9,6 \\
Cap. II & 8 & 12,1 & 10 & 20,8 & 18 & 15,8 \\
Cap. III & 2 & 3,0 & 3 & 6,3 & 5 & 4,4 \\
Cap. IV & 1 & 1,5 & 2 & 4,2 & 3 & 2,6 \\
Cap. V & 0 & 0,0 & 1 & 2,1 & 1 & 0,9 \\
Cap. VI & 1 & 1,5 & 1 & 2,1 & 2 & 1,8 \\
Cap. VII & 11 & 16,7 & 8 & 16,7 & 19 & 16,7 \\
Cap. VIII & 10 & 15,2 & 4 & 8,3 & 14 & 12,3 \\
Cap. IX & 0 & 0,0 & 2 & 4,2 & 2 & 1,8 \\
Cap. X & 4 & 6,1 & 2 & 4,2 & 6 & 5,3 \\
Cap. XI & 0 & 0,0 & 0 & 0,0 & 0 & 0,0 \\
Cap. XII & 0 & 0,0 & 0 & 0,0 & 0 & 0,0 \\
Cap. XIII & 0 & 0,0 & 0 & 0,0 & 0 & 0,0 \\
Cap. XIV & 0 & 0,0 & 2 & 4,2 & 2 & 1,8 \\
Cap. XV & 4 & 6,1 & 4 & 8,3 & 8 & 7,0 \\
Cap. XVI & 1 & 1,5 & 1 & 2,1 & 2 & 1,8 \\
C. EXt. & 17 & 25,8 & 4 & 8,3 & 21 & 18,4 \\
\hline TOTAL & 66 & 100,0 & 48 & 100,0 & 114 & 100,0 \\
& & & & & & \\
\hline & & & & & & \\
\hline
\end{tabular}




\section{\#}

TABELA 8 - Erros da causa básica, segundo causa básica corrigida e sexo. Amostra. Estado de São Paulo, 1992.

\begin{tabular}{|c|c|c|c|c|c|c|}
\hline \multirow[t]{2}{*}{ C.I.D. } & \multicolumn{2}{|c|}{ MASCU LINO } & \multicolumn{2}{|c|}{ FEMI NINO } & \multicolumn{2}{|c|}{ TO TAL } \\
\hline & número & $\%$ & número & $\%$ & número & $\%$ \\
\hline Cap. I & 7 & 10,6 & 3 & 6,3 & 10 & 8,8 \\
\hline Cap. II & 11 & 16,7 & 12 & 25,0 & 23 & 20,2 \\
\hline Cap. III & 4 & 6,1 & 4 & 8,3 & 8 & 7,0 \\
\hline Cap. IV & 1 & 1,5 & 0 & 0,0 & 1 & 0,9 \\
\hline Cap. V & 0 & 0,0 & 0 & 0,0 & 0 & 0,0 \\
\hline Cap. VI & 1 & 1,5 & 1 & 2,1 & 2 & 1,8 \\
\hline Cap. VII & 9 & 13,6 & 11 & 22,9 & 20 & 17,5 \\
\hline Cap. VIII & 5 & 7,6 & 3 & 6,3 & 8 & 7,0 \\
\hline Cap. IX & 1 & 1,5 & 1 & 2,1 & 2 & 1,8 \\
\hline Cap. X & 1 & 1,5 & 2 & 4,2 & 3 & 2,6 \\
\hline Cap. XI & 0 & 0,0 & 0 & 0,0 & 0 & 0,0 \\
\hline Cap. XII & 0 & 0,0 & 0 & 0,0 & 0 & 0,0 \\
\hline Cap. XIII & 0 & 0,0 & 0 & 0,0 & 0 & 0,0 \\
\hline Cap. XIV & 0 & 0,0 & 0 & 0,0 & 0 & 0,0 \\
\hline Cap. XV & 5 & 7,6 & 3 & 6,3 & 8 & 7,0 \\
\hline Cap. XVI & 7 & 10,6 & 4 & 8,3 & 11 & 9,6 \\
\hline C. Ext. & 14 & 21,2 & 4 & 8,3 & 18 & 15,8 \\
\hline TOTAL & 66 & 100,0 & 48 & 100,0 & 114 & 100,0 \\
\hline
\end{tabular}


TABELA 9 - Óbitos por causa corrigida e sexo. Amostra. Est. S. Paulo, 1992.

\begin{tabular}{lrrrrrr}
\hline C.I.D. & \multicolumn{2}{r}{$\begin{array}{l}\text { MASCU LINO } \\
\text { número }\end{array}$} & $\begin{array}{c}\text { FEMI NINO } \\
\text { número }\end{array}$ & $\%$ & número & $\%$ \\
\hline Cap. I & 79 & 4,0 & 43 & 3,2 & 122 & 3,7 \\
Cap. II & 266 & 13,5 & 232 & 17,2 & 498 & 15,0 \\
Cap. III & 137 & 7,0 & 90 & 6,7 & 227 & 6,9 \\
Cap. IV & 6 & 0,3 & 5 & 0,4 & 11 & 0,3 \\
Cap. V & 20 & 1,0 & 3 & 0,2 & 23 & 0,7 \\
Cap. VI & 16 & 0,8 & 16 & 1,2 & 32 & 1,0 \\
Cap. VII & 566 & 28,8 & 506 & 37,5 & 1.072 & 32,4 \\
Cap. VIII & 203 & 10,3 & 136 & 10,1 & 339 & 10,2 \\
Cap. IX & 107 & 5,4 & 53 & 3,9 & 160 & 4,8 \\
Cap. X & 26 & 1,3 & 24 & 1,8 & 50 & 1,5 \\
Cap. XI & 0 & 0,0 & 8 & 0,6 & 8 & 0,2 \\
Cap. XII & 3 & 0,2 & 3 & 0,2 & 6 & 0,2 \\
Cap. XIII & 2 & 0,1 & 5 & 0,4 & 7 & 0,2 \\
Cap. XIV & 23 & 1,2 & 17 & 1,3 & 40 & 1,2 \\
Cap. XV & 86 & 4,4 & 64 & 4,7 & 150 & 4,5 \\
Cap. XVI & 128 & 6,5 & 76 & 5,6 & 204 & 6,2 \\
C. EXt. & 296 & 15,1 & 68 & 5,0 & 364 & 11,0 \\
\hline TOTAL & 1.964 & 100,0 & 1.349 & 100,0 & 3.313 & 100,0 \\
\hline & & & & & & \\
\hline & & & & & &
\end{tabular}


TABELA 10 - Óbitos por causa corrigida e erros relacionados, segundo sexo. Amostra , Estado de São Paulo, 1992.

\begin{tabular}{|c|c|c|c|c|c|c|}
\hline \multirow[t]{2}{*}{ C.I.D. } & \multicolumn{4}{|c|}{ MASCU LINO } & \multicolumn{2}{|c|}{ FEMI NINO } \\
\hline & óbitos & erros & $\%$ & óbitos & erros & $\%$ \\
\hline Cap. I & 79 & 7 & 8,9 & 43 & 3 & 7,0 \\
\hline Cap. II & 266 & 11 & 4,1 & 232 & 12 & 5,2 \\
\hline Cap. III & 137 & 4 & 2,9 & 90 & 4 & 4,4 \\
\hline Cap. IV & 6 & 1 & 16,7 & 5 & 0 & 0,0 \\
\hline Cap. V & 20 & 0 & 0,0 & 3 & 0 & 0,0 \\
\hline Cap. VI & 16 & 1 & 6,3 & 16 & 1 & 6,3 \\
\hline Cap. VII & 566 & 9 & 1,6 & 506 & 11 & 2,2 \\
\hline Cap. YIII & 203 & 5 & 2,5 & 136 & 3 & 2,2 \\
\hline Cap. IX & 107 & 1 & 0,9 & 53 & 1 & 1,9 \\
\hline Cap. $X$ & 26 & 1 & 3,8 & 24 & 2 & 8,3 \\
\hline Cap. XI & 0 & 0 & 0,0 & 8 & 0 & 0,0 \\
\hline Cap. XII & 3 & 0 & 0,0 & 3 & 0 & 0,0 \\
\hline Cap. XIII & 2 & 0 & 0,0 & 5 & 0 & 0,0 \\
\hline Cap. XIV & 23 & 0 & 0,0 & 17 & 0 & 0,0 \\
\hline Cap. XV & 86 & 5 & 5,8 & 64 & 3 & 4,7 \\
\hline Cap. XVI & 128 & 7 & 5,5 & 76 & 4 & 5,3 \\
\hline C. Ext. & 296 & 14 & 4,7 & 68 & 4 & 5,9 \\
\hline TOTAL & 1.964 & 66 & 3,4 & 1.349 & 48 & 3,6 \\
\hline
\end{tabular}


TABELA 11 - Erros da causa básica, segundo idade e sexo. Amostra. Estado de São Paulo, 1992.

\begin{tabular}{|c|c|c|c|c|c|c|}
\hline \multirow{2}{*}{$\begin{array}{l}\text { IDADE } \\
\text { (anos) }\end{array}$} & \multicolumn{2}{|c|}{ MASCU LINO } & \multicolumn{2}{|c|}{ FEMI NINO } & \multicolumn{2}{|c|}{ TO TAL } \\
\hline & número & $\%$ & número & $\%$ & número & $\%$ \\
\hline Menos 1 & 9 & 13,6 & 8 & 16,7 & 17 & 14,9 \\
\hline 1 & 1 & 1,5 & 0 & 0,0 & 1 & 0,9 \\
\hline 2 & 2 & 3,0 & 0 & 0,0 & 2 & 1,8 \\
\hline 3 & 0 & 0,0 & 0 & 0,0 & 0 & 0,0 \\
\hline 4 & 0 & 0,0 & 0 & 0,0 & 0 & 0,0 \\
\hline 5 a 9 & 0 & 0,0 & 0 & 0,0 & 0 & 0,0 \\
\hline 10 a 14 & 2 & 3,0 & 0 & 0,0 & 2 & 1,8 \\
\hline 15 a 19 & 1 & 1,5 & 1 & 2,1 & 2 & 1,8 \\
\hline 20 a 24 & 2 & 3,0 & 0 & 0,0 & 2 & 1,8 \\
\hline 25 a 29 & 4 & 6,1 & 1 & 2,1 & 5 & 4,4 \\
\hline 30 a 34 & 5 & 7,6 & 2 & 4,2 & 7 & 6,1 \\
\hline 35 a 39 & 0 & 0,0 & 1 & 2,1 & 1 & 0,9 \\
\hline 40 a 44 & 2 & 3,0 & 3 & 6,3 & 5 & 4,4 \\
\hline 45 a 49 & 2 & 3,0 & 4 & 8,3 & 6 & 5,3 \\
\hline 50 a 54 & 3 & 4,5 & 2 & 4,2 & 5 & 4,4 \\
\hline 55 a 59 & 5 & 7,6 & 4 & 8,3 & 9 & 7,9 \\
\hline 60 a 64 & 9 & 13,6 & 4 & 8,3 & 13 & 11,4 \\
\hline 65 a 69 & 7 & 10,6 & 9 & 18,8 & 16 & 14,0 \\
\hline 70 a 74 & 5 & 7,6 & 3 & 6,3 & 8 & 7,0 \\
\hline 75 a 79 & 2 & 3,0 & 4 & 8,3 & 6 & 5,3 \\
\hline 80 e mais & 5 & 7,6 & 2 & 4,2 & 7 & 6,1 \\
\hline ignorado & 0 & 0,0 & 0 & 0,0 & 0 & 0,0 \\
\hline TOTAL & 66 & 100,0 & 48 & 100,0 & 114 & 100,0 \\
\hline
\end{tabular}


TABELA 12 - Óbitos segundo idade e sexo e erros correspondentes da seleção da causa básica de morte. Amostra. Est. S. Paulo, 1992.

\begin{tabular}{|c|c|c|c|c|c|c|}
\hline \multirow{2}{*}{$\begin{array}{l}\text { IDADE } \\
\text { (anos) }\end{array}$} & \multicolumn{4}{|c|}{ MASCU LINO } & \multicolumn{2}{|c|}{ FEMI NINO } \\
\hline & óbitos & erros & $\%$ & óbitos & erros & $\%$ \\
\hline & & & & 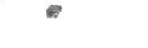 & & \\
\hline Menos 1 & 162 & 9 & 5,6 & 115 & 8 & 7,0 \\
\hline 1 & 11 & 1 & 9,1 & 11 & 0 & 0,0 \\
\hline 2 & 10 & 2 & 20,0 & 3 & 0 & 0,0 \\
\hline 3 & 3 & 0 & 0,0 & 5 & 0 & 0,0 \\
\hline 4 & 2 & 0 & 0,0 & 2 & 0 & 0,0 \\
\hline 5 a 9 & 9 & 0 & 0,0 & 6 & 0 & 0,0 \\
\hline 10 a 14 & 14 & 2 & 14,3 & 11 & 0 & 0,0 \\
\hline 15 a 10 & 43 & 1 & 2,3 & 11 & 1 & 9,1 \\
\hline 20 a 24 & 72 & 2 & 2,8 & 24 & 0 & 0,0 \\
\hline 25 a 29 & 88 & 4 & 4,5 & 12 & 1 & 8,3 \\
\hline 30 a 34 & 82 & 5 & 6,1 & 27 & 2 & 7,4 \\
\hline 35 a 39 & 92 & 0 & 0,0 & 38 & 1 & 2,6 \\
\hline 40 a 44 & 79 & 2 & 2,5 & 47 & 3 & 6,4 \\
\hline 45 a 49 & 118 & 2 & 1,7 & 46 & 4 & 8,7 \\
\hline 50 a 54 & 112 & 3 & 2,7 & 72 & 2 & 2,8 \\
\hline 55 a 59 & 132 & 5 & 3,8 & 77 & 4 & 5,2 \\
\hline 60 a 64 & 160 & 9 & 5,6 & 112 & 4 & 3,6 \\
\hline 65 a 69 & 189 & 7 & 3,7 & 142 & 9 & 6,3 \\
\hline 70 a 74 & 181 & 5 & 2,8 & 133 & 3 & 2,3 \\
\hline 75 a 79 & 160 & 2 & 1,3 & 167 & 4 & 2,4 \\
\hline 80 e mais & 241 & 5 & 2,1 & 286 & 2 & 0,7 \\
\hline ignorado & 4 & 0 & 0,0 & 2 & 0 & 0,0 \\
\hline TOTAL & 1.964 & 66 & 3,4 & 1.349 & 48 & 3,6 \\
\hline
\end{tabular}


TABELA 13 - Erros totais de codificação, segundo idade e sexo.

Amostra. Estado de São Paulo, 1992.

\begin{tabular}{crrrrrr}
\hline $\begin{array}{c}\text { IDADE } \\
\text { (anos) }\end{array}$ & $\begin{array}{r}\text { MASCU LINO } \\
\text { número }\end{array}$ & $\begin{array}{c}\text { FEMI NINO } \\
\text { número }\end{array}$ & $\%$ & \multicolumn{2}{c}{ TO TAL } \\
\hline Menos 1 & 12 & 11,9 & 12 & 15,8 & 24 & 13,6 \\
1 & 1 & 1,0 & 1 & 1,3 & 2 & 1,1 \\
2 & 2 & 2,0 & 0 & 0,0 & 2 & 1,1 \\
3 & 0 & 0,0 & 1 & 1,3 & 1 & 0,6 \\
4 & 0 & 0,0 & 0 & 0,0 & 0 & 0,0 \\
5 a 9 & 1 & 1,0 & 0 & 0,0 & 1 & 0,6 \\
10 a 14 & 2 & 2,0 & 0 & 0,0 & 2 & 1,1 \\
15 a 19 & 2 & 2,0 & 1 & 1,3 & 3 & 1,7 \\
20 a 24 & 3 & 3,0 & 1 & 1,3 & 4 & 2,3 \\
25 a 29 & 6 & 5,9 & 1 & 1,3 & 7 & 4,0 \\
30 a 34 & 8 & 7,9 & 2 & 2,6 & 10 & 5,6 \\
35 a 39 & 2 & 2,0 & 4 & 5,3 & 6 & 3,4 \\
40 a 44 & 4 & 4,0 & 4 & 5,3 & 8 & 4,5 \\
45 a 49 & 4 & 4,0 & 5 & 6,6 & 9 & 5,1 \\
50 a 54 & 3 & 3,0 & 3 & 3,9 & 6 & 3,4 \\
55 a 59 & 7 & 6,9 & 6 & 7,9 & 13 & 7,3 \\
60 a 64 & 12 & 11,9 & 7 & 9,2 & 19 & 10,7 \\
65 a 69 & 12 & 11,9 & 11 & 14,5 & 23 & 13,0 \\
70 a 74 & 9 & 8,9 & 4 & 5,3 & 13 & 7,3 \\
75 a 79 & 2 & 2,0 & 9 & 11,8 & 11 & 6,2 \\
80 e mais & 9 & 8,9 & 4 & 5,3 & 13 & 7,3 \\
ignorado & 0 & 0,0 & 0 & 0,0 & 0 & 0,0 \\
\hline TOTAL & 101 & 100,0 & 76 & 100,0 & 177 & 100,0 \\
\hline & & & & & & \\
\hline
\end{tabular}


TABELA 14 - Óbitos segundo idade e sexo e erros totais correspondentes. Amostra. Estado de São Paulo, 1992.

\begin{tabular}{|c|c|c|c|c|c|c|}
\hline $\begin{array}{l}\text { IDADE } \\
\text { (anos) }\end{array}$ & óbitos & \multicolumn{3}{|c|}{ MASCU LINO } & \multicolumn{2}{|c|}{ FEMI NINO } \\
\hline & & & & 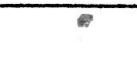 & & \\
\hline Menos 1 & 162 & 12 & 7,4 & 115 & 12 & 10,4 \\
\hline 1 & 11 & 1 & 9,1 & 11 & 1 & 9,1 \\
\hline 2 & 10 & 2 & 20,0 & 3 & 0 & 0,0 \\
\hline 3 & 3 & 0 & 0,0 & 5 & 1 & 20,0 \\
\hline 4 & 2 & 0 & 0,0 & 2 & 0 & 0,0 \\
\hline 5 a 9 & 9 & 1 & 11,1 & 6 & 0 & 0,0 \\
\hline 10 a 14 & 14 & 2 & 14,3 & 11 & 0 & 0,0 \\
\hline 15 a 10 & 43 & 2 & 4,7 & 11 & 1 & 9,1 \\
\hline 20 a 24 & 72 & 3 & 4,2 & 24 & 1 & 4,2 \\
\hline 25 a 29 & 88 & 6 & 6,8 & 12 & 1 & 8,3 \\
\hline 30 a 34 & 82 & 8 & 9,8 & 27 & 2 & 7,4 \\
\hline 35 a 39 & 92 & 2 & 2,2 & 38 & 4 & 10,5 \\
\hline 40 a 44 & 79 & 4 & 5,1 & 47 & 4 & 8,5 \\
\hline 45 a 49 & 118 & 4 & 3,4 & 46 & 5 & 10,9 \\
\hline 50 a 54 & 112 & 3 & 2,7 & 72 & 3 & 4,2 \\
\hline 55 a 59 & 132 & 7 & 5,3 & 77 & 6 & 7,8 \\
\hline 60 a 64 & 160 & 12 & 7,5 & 112 & 7 & 6,3 \\
\hline 65 a 69 & 189 & 12 & 6,3 & 142 & 11 & 7,7 \\
\hline 70 a 74 & 181 & 9 & 5,0 & 133 & 4 & 3,0 \\
\hline 75 a 79 & 160 & 2 & 1,3 & 167 & 9 & 5,4 \\
\hline 80 e mais & 241 & 9 & 3,7 & 286 & 4 & 1,4 \\
\hline ignorado & 4 & 0 & 0,0 & 2 & 0 & 0,0 \\
\hline TOTAL & 1.964 & 101 & 5,1 & 1.349 & 76 & 5,6 \\
\hline
\end{tabular}




\section{AVALIAÇÃO DO PROCESSAMENTO DAS CAUSAS DE MORTE}

Sob a rubrica "avaliação do processamento" pretendia-se discutir, de modo geral, se as disposições das chamadas Regras de Mortalidade da Classificação Internacional de Doenças (31) se refletiam na identificação correta da causa básica de morte pelo Sistema ACME. Em outras palavras, pretendia-se verificar se, primeiro, os preceitos das Regras de Seleção eram atendidos pela Tabela de Decisão $C$ e, segundo, se as previsões das Regras de Modificação eram realizadas por aplicação da Tabela de Decisão D (44, 45) .

Quanto às Regras de Seleção, o ponto crítico consistiria em analisar a probabilidade da seqüência patológica informada na Parte I do Atestado Médico estar correta ou não, neste último caso configurando a situação qualificada pela classificação Internacional de Doenças como "seqüência sumamente improvável". Esta seqüência pressupõe uma relação causal entre as afecções informadas respectivamente nas linhas (a), (b) e (c) da Parte I do Atestado Médico. De modo geral, as relações causais previstas e existentes na Tabela de Decisão C vêm sendo criticadas há anos e poucas são motivo de contestação e discordância. A dificuldade maior reside na avaliação de seqüências com probabilidade de serem aceitas, mas que, no entanto, não foram previstas em razão de sua ocorrência rara ou de ser afecção incomum nos Estados Unidos. Cabe a lembrança que as Tabelas de Decisão foram construídas a partir de amostras de Declarações de óbito.

Identificada a relação causal, se possível ou não, selecionase uma causa básica de morte preliminar. No Sistema ACME esta causa é chamada de causa básica temporária (Temporary underlying cause - TUC). Esta causa temporária pode tornar-se definitiva ou ser substituida por outra em virtude de disposições das Regras de Modificação as quais, para processamento pelo Sistema ACME, encontram-se consolidadas na Tabela de Decisão D. Ressalve-se, também, que a Regra de Seleção 3 é considerada, pelas suas características, como modificadora da causa básica temporária e integrada na Tabela de Decisão D. Os procedimentos para a modificação da causa preliminar envolvem busca de previsão específica na Lista Tabular ou no Índice da Classificação Internacional de Doenças.

Encontrada a afeç̧ão que implique em problema de processamento, procura-se esgotar todas as nuances de sua 
classificação e correspondente representação nas tabelas de decisão. Realiza-se levantamento completo da história natural da afecção, definindo-se a etiopatogenia e relacionando-se as complicações de sua evolução clínica. Consiste em exaustivo trabalho de pesquisa bibliográfica e por vezes de consulta a especialistas. Tem como corolário existir disponibilidade de tempo. Tais foram as características e circunstâncias em que se realizaram as adaptações das tabelas de decisão para a Doença de Chagas e para a Esquistossomose mansônica.

Frustrada a pretensão inicial, pelas razões acima expostas, resta o consolo de terem sido identificados vários problemas de processamento. As características desses problemas serão apresentadas a seguir e colocadas as dúvidas que os cercam.

Imaturidade pulmonar devida a insuficiência cardiorrespiratória

Esta seqüência, aceita pelo Sistema ACME, foi mencionada em óbito de menor com 2 dias de vida no seguinte Atestado Médico.

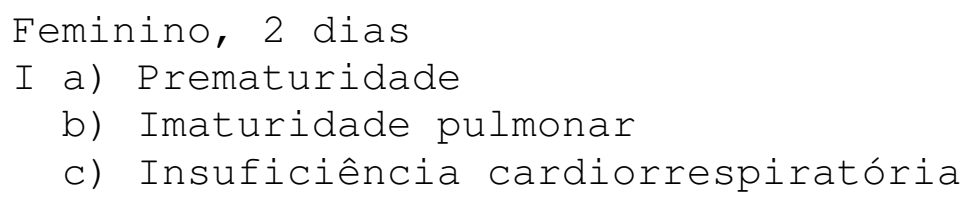

- problema pode ser devido ao código que está sendo atribuído à "insuficiência cardiorrespiratória neonatal" (779.8), equivalente às "outras afecções mal definidas" no adulto.

Parada cardiorrespiratória (neonatal) devida a cisto em plexo coróide.

Análogo o problema ao atestado anterior. A Declaração de óbito em que ocorre apresenta-se a seguir.

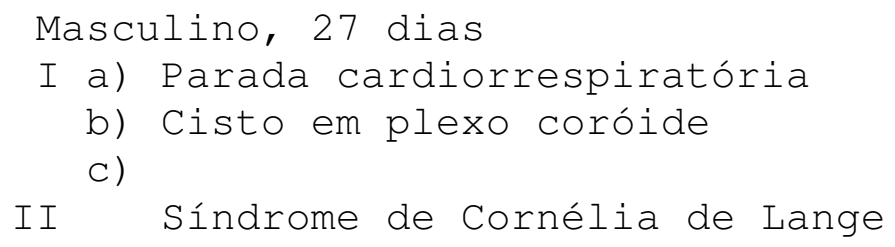


A codificação - 779.8 / 348.0 * 742.8 - levou à seleção da

"parada cardiorrespiratória neonatal" (779.8), cuja codificação deve ser revista.

\section{Doença pulmonar obstrutiva crônica devida a isquemia cerebral}

A "doença pulmonar obstrutiva crônica" (496) é condicionalmente aceita como devida ás "Doenças cerebrovasculares" (430-438), relação esta prevista como ambivalente, ocorrendo uma mensagem de erro que obriga o codificador a uma decisão a respeito do atestado. Na Declaração de óbito em que o problema surgiu, considerou-se como errada a aceitação da seqüência.

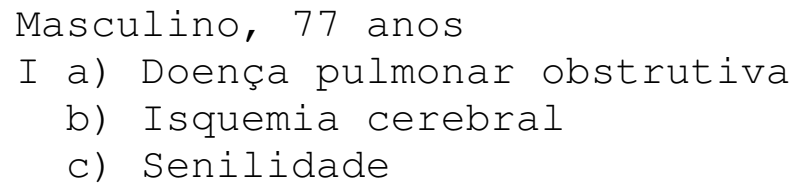

Houve seleção da "isquemia cerebral" (437.1) como causa básica. Julga-se ser a "doença pulmonar obstrutiva" (496) a causa básica correta.

\section{Doença pulmonar obstrutiva crônica devida a miocardiopatia}

Esta seqüência é aceita pelo Sistema ACME. A Declaração de óbito em que a mesma foi mencionada reproduz-se abaixo.

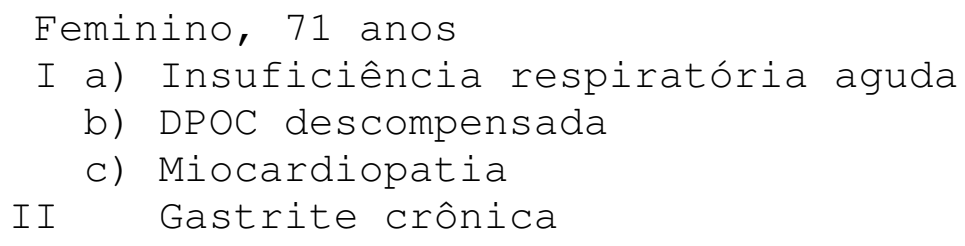

A codificação - 518.5 / $496 / 425.4$ * 535.1 - conduziu à seleção da "miocardiopatia" (425.4) como causa básica.

Doença pulmonar obstrutiva crônica devida a insuficiência cardíaca congestiva

A seqüência acima é aceita, tendo aparecido na Declaração de óbito que se segue. 
Masculino, 100 anos

I a) Parada cardiorrespiratória

b) DPOC

c) ICC

II

A codificação - 427.5/496/428.0 - resultou na seleção da "insuficiência cardíaca congestiva" (428.0) como causa básica.

Escaras de decúbito seqüela direta de "seqüela de acidente vascular cerebral"

Não ha tal previsão na Tabela de Decisão D para processamento das causas de morte pelo sistema ACME. A Declaração de óbito correspondente apresenta-se a seguir.

Feminino, 66 anos

I a) Choque toxiinfeccioso

b) Septicemia

c) Escaras de decúbito infectadas

II Seqüela de AVC

Insuficiência arterial periférica

A causa básica "escaras de decúbito" (707.0) resultou da codificação - 785.5/ $038.9 / 707.0$ * 438 b 443.9 - que se mostra correta.

Esquizofrenia, infarto do miocárdio e parada cardiorrespiratória

Estas afecções, informadas na Declaração de óbito abaixo

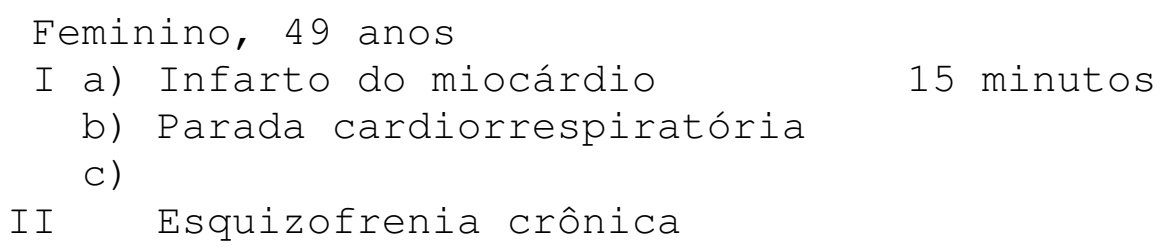

assim codificada - 410 / 799.1 * 295.6 - resultou na causa básica "esquizofrenia crônica" (295.6) por motivos não apurados. O registro impresso da Declaração de óbito reproduz a codificação acima. Pode ter ocorrido erro de digitação no arquivo intermediário para entrada inicial de dados no Sistema ACME. 
Broncopneumonia aspirativa seqüela direta de encefalopatia anóxica

Não está prevista na Tabela D constituir a "broncopneumonia aspirativa" uma seqüela direta de "encefalopatia atóxica", menções essas registradas na Declaração de óbito seguinte. Masculino, 51 anos

I a) Insuficiência respiratória

b) Síndrome da angústia respiratória do adulto

c) Broncopneumonia aspirativa

II Encefalopatia anóxica. Hemorragia digestiva

alta

A codificação - 786.0 / 518.5 / 507.0 * 348.1 b 578.9 - levou á seleção da "broncopneumonia aspirativa" (507.0) como causa básica.

\section{Vasculopatia periférica seqüela direta de diabetes mellitus}

Não há previsão de ser uma "vasculopatia periférica" seqüela direta de "diabetes mellitus". A seguir a Declaração de óbito em que se encontram tais afecções.

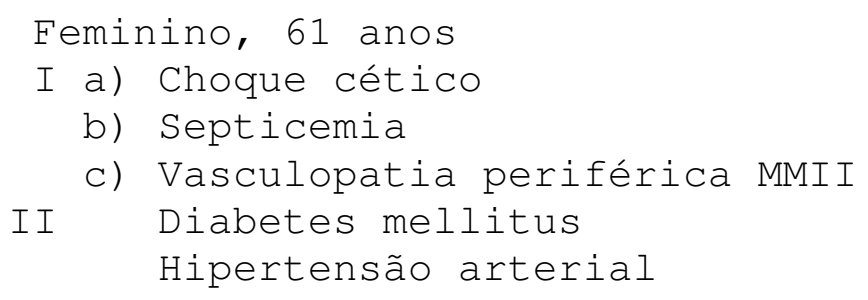

A codificação - $785.5 / 038.9$ / 443.9 * 250.0 b 401.9 produziu a causa básica "vasculopatia periférica" (443.9). A interpretação de ser a mesma seqüela direta de "diabetes mellitus" deve ser estudada.

\section{Síndrome de Fournier seqüela direta de diabetes mellitus}

Não prevista na Tabela $D$ ser a "síndrome de Fournier" uma seqüela direta de "diabetes mellitus". A Declaração de óbito correspondente é a seguinte.

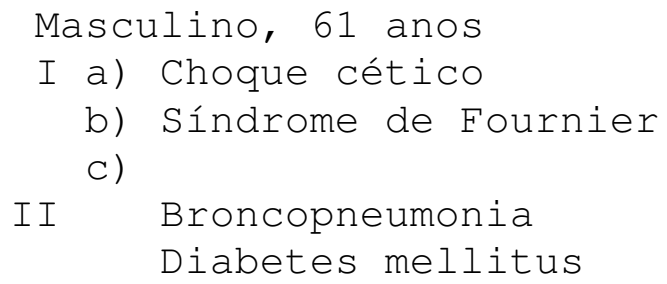


A codificação - 785.5 / 608.8 * 485 b 250.0 - resultou na seleção da "síndrome de Fournier" (608.8) como causa básica. Considerou-se ser a mesma seqüela direta de "diabetes mellitus", com o qual se associa resultando a causa básica "diabetes mellitus com outras manifestações especificadas" $(250.7)$.

Síndrome de Fournier devida a carcinoma de células transicionais da bexiga

Esta seqüência não é aceita pelo Sistema ACME. A Declaração de óbito correspondente apresenta-se abaixo.

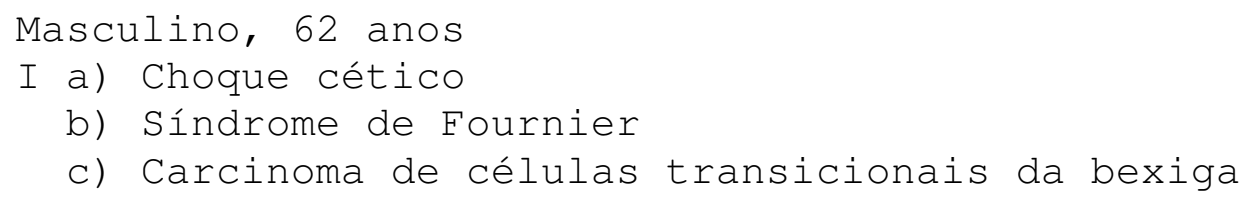

A codificação - 785.5 / 608.8 / 188.9 - conduziu á seleção da "síndrome de Fournier" (608.8), não aceitando a seqüência informada. O "carcinoma de células transicionais da bexiga" (188.9) foi considerado como causa básica correta.

\section{Fibrose pulmonar devida a blastomicose pulmonar}

Esta seqüência não está prevista na Tabela C para interpretação das Regras de Seleção. A Declaração de óbito que a apresentou, a seguinte.

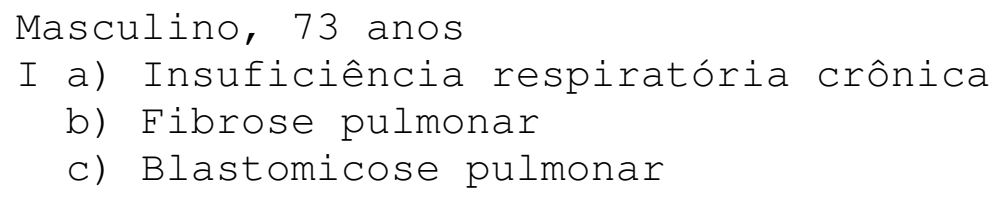

A codificação - 496/515/116.0 - resultou na causa básica "fibrose pulmonar" (515), que foi considerada incorreta e alterada para "blastomicose pulmonar" (116.0).

\section{Insuficiência vascular periférica devida a hanseníase}

O Sistema ACME não aceita esta seqüência que foi informada na Declaração de óbito a seguir. 


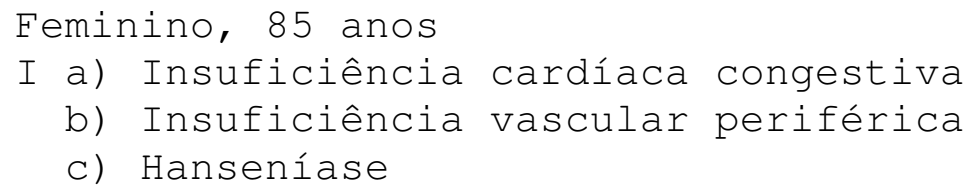

A codificação - 428.0 / 443.9 / 030.9 - resultou na seleção da "insuficiência vascular periférica" (443.9) como causa básica.

\section{Hipertensão pulmonar devida a miocardiopatia dilatada devida} a Doença de Paget

Estas seqüências não são aceitas pelo Sistema $A C M E$, reproduzidas da seguinte Declaração de óbito.

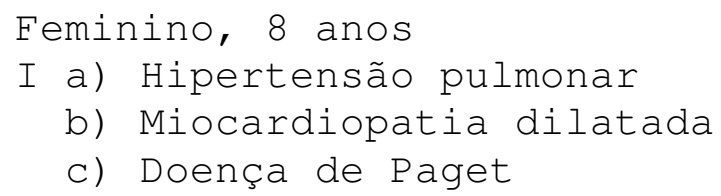

A codificação - 416.0 / 425.9 / 731.0 - correta em princípio, levou á seleção da causa básica "hipertensão pulmonar" (416.0). Verificou-se que é possível a "miocardiopatia dilatada" ser aceita como devida a "Doença de Paget". Outro problema neste atestado é o da interpretação do diagnóstico "Doença de Paget", se afecção neoplásica mamária ou se afecção óssea.

\section{Miocardiopatia devido a enfisema pulmonar}

Seqüência não prevista pela Tabela C. Além disso, ocorre o termo "miocardiopatia", que para determinadas seqüências, como visto em outro tópico, tem código alterado. A Declaração de óbito correspondente apresenta-se a seguir.

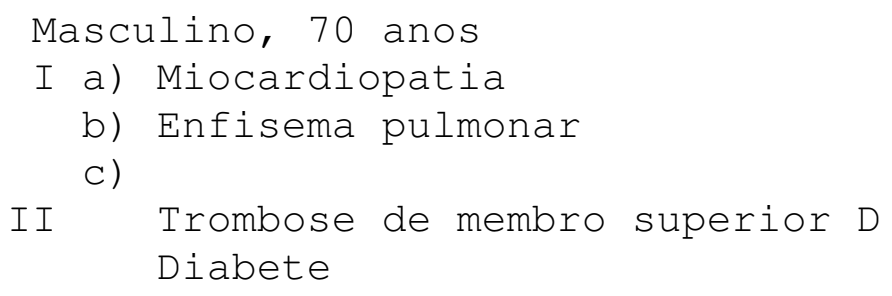

A codificação - 425.9 / 492 * 451.2 b 250.0 - levou á seleção da causa básica "miocardiopatia secundária" (425.9), desde que assim interpretada pelo codificador. 
Insuficiência renal crônica seqüela direta de infecção do trato urinário

A Tabela de Decisão D, versão 1984 (44) prevê a "insuficiência renal crônica" (585) como seqüela direta, sem restrições, de todas as afecções codificadas no intervalo "587-602.9" ao passo que a versão de 1992 (45) considera tal relação condicional, isto é, dependente da confirmação do codificador. A Declaração de óbito em que este fato ocorreu apresenta-se a seguir.

\author{
Masculino, 63 anos \\ I a) Insuficiência respiratória aguda \\ b) Tromboembolismo pulmonar \\ c) Insuficiência renal crônica \\ I Acidente vascular cerebral \\ Infecção do trato urinário
}

A codificação - 518.5 / 415.1 / 585 * 436 b 599.0 selecionou a "insuficiência renal crônica" (585) pela Regra Geral e considerou-a seqüela direta da "infecção do trato urinário" (599.0) que restou como causa básica final. A versão do Sistema ACME em uso na Fundação SEADE desde 1983 não sofreu atualizações. Deste modo, este Atestado Médico não foi rejeitado para revisão manual. Considerou-se ser a "insuficiência renal crônica" a causa básica correta.

Insuficiência renal crônica seqüela direta de amiloidose renal

Esta relação não está prevista na Tabela D. A Declaração de óbito em que estas afecções são mencionadas conjuntamente é a seguinte.

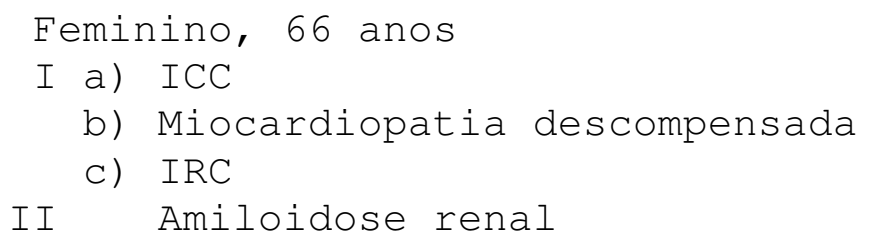

A codificação - 428.0 / 425.9 / 585*277.3 - determinou a seleção como causa básica da "insuficiência renal crônica" (585). O fato de aceitar-se a mesma como seqüela direta de "amiloidose renal" deve ser considerado. 


\section{Cirrose hepática seqüela direta de Hepatite pelo vírus C}

A "cirrose hepática" (571.5) não é prevista como seqüela direta de "hepatite viral" (070.-). A Declaração de óbito em que o problema surge é a seguinte.

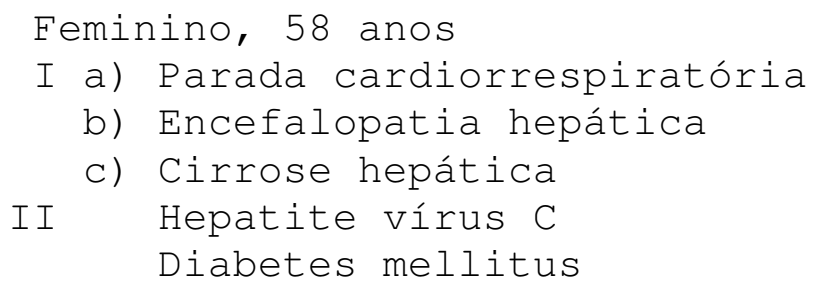

A codificação - 799.1 / 572.2 / 571.5 * 070.3 b 250.0 resultou na seleção da "cirrose hepática" (571.5) como causa básica. Trata-se de avaliar a possibilidade de considerar a mesma como seqüela direta das hepatites virais. Ademais, neste atestado, considera-se ser "070.5" o código mais adequado para a "hepatite por vírus C".

\section{Fibrotórax seqüela direta de tuberculose pulmonar residual}

A Declaração de óbito em que surge o problema é a seguinte.

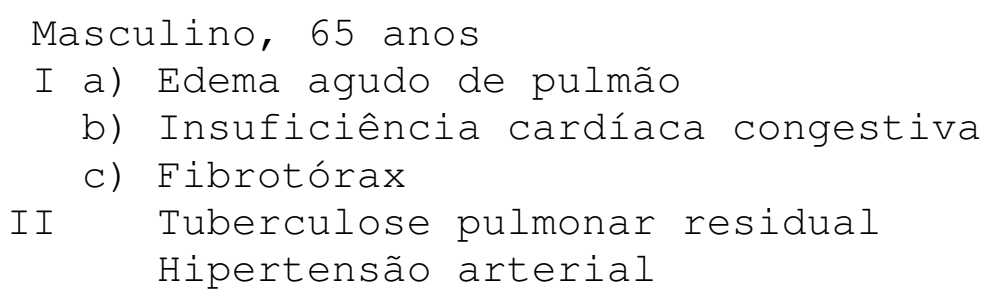

A codificação - 518.4 / 428.0 / 511.0 * 011.9 b 401.9 - levou à seleção do "fibrotórax" (511.0) pela Regra Geral e a sua associação com a "tuberculose pulmonar" (011.9) resultando no diagnóstico de combinação "pleuris tuberculoso" (012.0). Neste Atestado Médico, são discutidos os códigos mais adequados para "fibrotórax" e "tuberculose pulmonar residual", considerados, respectivamente "515" e "137.0" em lugar de "511.0" e "011.9" que foram codificados. Neste caso, não há previsão de o código "515" ser seqüela direta de "efeito tardio de tuberculose pulmonar" (137.0). 
COMENTÁRIOS E RECOMENDAÇÕES 
Realizado um estudo para avaliar a qualidade da codificação e do processamento das causas de morte pelo Sistema ACME para elaboração das estatísticas de mortalidade no Estado de São Paulo. Para avaliar a qualidade da codificação, o trabalho correspondeu ao de um perito dependente, isto é, tendo conhecimento da codificação original realizada pelos codificadores da Fundação SEADE. São lembradas, no momento, as limitações do trabalho condicionado à verificação dependente em face da possibilidade de ser influenciado pelo trabalho do codificador original.

A amostra estudada de 3.313 Declarações de óbito correspondeu a 1,6\% dos 202.141 óbitos de residentes no Estado de São Paulo e registrados no ano de 1992. Verificou-se que, com a mesma, foi possível a identificação de numerosos problemas de codificação e de processamento de causas de morte pelo Sistema ACME.

Os erros de codificação, dos quais muitos podem ser assinalados como simples, teriam condições de ser prevenidos caso um controle da qualidade da codificação fosse introduzido. Ressalvada a integridade profissional da equipe de codificadores da Fundação SEADE, O conhecimento da inexistência de controle sobre a codificação dá margem a que, premidas pelo acúmulo de trabalho, menores esforços sejam dedicados à resolução das Declarações de óbito mais difíceis e complicadas.

As questões de processamento que foram registradas apontam para a necessidade de um acompanhamento contínuo das características de identificação das causas básicas de morte. Para tanto, a retomada da codificação manual de amostra de Declarações de óbito para confronto com a causa básica selecionada pelo Sistema ACME é recomendável. Talvez essa prática tenha sido interrompida face a observação de que, nos casos de discordância entre a causa manual e a processada pelo Sistema ACME, sempre a decisão se dava a favor da causa do Sistema. Ressalvada a colaboração mútua entre a Fundação SEADE e o Centro Brasileiro de Classificação de Doenças, que não necessita de outros adjetivos, evidencia-se justamente na questão do processamento das causas de morte que tal colaboração deve ser intensificada e reforçada. Tal colaboração, de um lado, favorecerá o aprimoramento da Classificação Internacional de Doenças, por exemplo, por meio da melhor caracterização de afecções não incluídas no Índice, e de outro lado, permitirá que as tabelas de decisão para processamento sejam atualizadas para, com maior adequação, selecionar a causa básica de morte. 
As características e os resultados deste trabalho, de modo particular o uso de uma amostra de menos de $2 \%$ das Declarações de óbito e a medida dos erros de codificação evidenciados, estendem a recomendação para ser introduzido um sistema de controle de qualidade análogo no Sistema Nacional de Informações sobre Mortalidade, abrangendo todas as Unidades da Federação, sob a coordenação do Ministério da Saúde.

A entrada em vigor, no Brasil, da Décima Revisão da Classificação Internacional de Doenças em 1995 e o advento do Sistema de Seleção de Causa Básica de Morte por Microcomputador (SCB), realçam a oportunidade de considerarse a introdução de tal controle de qualidade. 
REFERÊNCIAS BIBLIOGRÁFICAS 
01 - ANUÁRIO ESTATístiCO DO ESTADO DE SÃO PAULO: 1992. São Paulo, Fundação Sistema Estadual de Análise de Dados - SEADE, 1993. V. 1 .

02 - BRASIL. Leis, etc. Registros públicos. Lei n 6.015 de 31 de dezembro de 1973: dispõe sobre registros de pessoas naturais e jurídicas, de títulos e documentos e de imóveis. Republicada de acordo com o artigo 20 da Lei no 6.216/75, com as alterações advindas das Leis nos 6.140, de 28 de novembro de 1974 e 6.216, de 30 de junho de 1975. São Paulo, Imprensa Oficial do Estado, 1975.

03 - CENTRO DA OMS PARA A CLASSIFICAÇÃO DE DOENÇAS EM PORTUGUÊS Avaliação de codificadores. Bol. Centro OMS Clas. Doenças Português, 6 (n. esp.), nov. 1985.

04 - CENTRO DA OMS PARA A CLASSIFICAÇÃO DE DOENÇAS EM PORTUGUÊS Codificação de neoplasias em mortalidade. Bol. Centro OMS Clas. Doenças Português, 14 (3): 4-5, set./dez. 1993.

05 - CHAMBLEE, R,F, \& EVANS, M.C. New dimensions in cause of death statistics. Amer. J. publ. Hlth, 72: 1265-70, 1982.

06 - CHAMBLEE, R.F. et al. A national multiple cause of death statistical system. Proceedings of the American Statistical Association. Washington D.C., 1979. [mimeografado].

07 - COHEN, J. \& STEINITZ, R. Underlying and contributory causes of death of adult males in two districts. J. chron. Dis., 22: 17-24, 1969.

08 - COMMITTEE ON MEDICAL CERTIFICATION OF CAUSES OF DEATH. Statistics section - Problems in the medical certification of causes of death. Amer. J. publ. Hlth.,48: 71-80, 1958.

09 - CONTRIBUtORY causes of death. Amer. J. publ. Hlth., 15: $122-4,1925$.

10 - CURB, J.D. et al. Nosological coding of cause of death. Amer. J. Epidemiol., 118: 122-8, 1983.

11 - DORN, H.F. Some considerations in the revision of the International Statistical Classification. Publ. Hlth., 79: $175-9,1964$.

12 - DORN, H.F. Underlying and contributory causes of death. In HAENZEL, W., ed. - Epidemiological approaches to the study 
of cancer and other chronic diseases. Bethesda, Md., National Cancer Institute, 1966. p. 421-30.

13 - DORN, H.F. \& MORIYAMA, I.M. Uses and significance of multiple cause tabulations for mortality statistics. Amer. J. publ. Hlth, 54: 400-6, 1964.

14 - DUBLIN, L.I. \& VAN BUREN, G.H. Contributory causes of death: their importance and suggestions for their classification. Amer. J. publ. Hlth., 14: 100-5,1924.

15 - ERHARDT, C.L. The underutilization of vital statistics. Amer. J. publ. Hlth., 67: 325-6, 1977.

16 - EVALUATION of the multiple cause of death classification system: final report. Bethesda, Md., Moshman Associates Inc., 1989. [Submitted to the National Center for Health Statistics, Centers for Disease Control].

17 - EVANS, M.C. Overview of the ICD-9 mortality data system. Research Triangle Park, N.C.. National Center for Health Statistics, 1981. [Mimeografado].

18 - FUNDAÇÃO SEADE. The present situation of the ACME system in the State of São Paulo. São Paulo, 1985. [Apresentado ao Meeting of Heads of WHO Collaborating Centres for the Classification of Diseases, São Paulo, 1985].

19 - GIRALDELLI, B.W. \& SAAD, P.M. Considerações sobre a implantação no Estado de São Paulo do sistema automático de classificação de causas de morte. Inf. demogr., S. Paulo, (13) : 137-59, 1984 .

20 - GOODMAN, R.A. et al. Mortality data analysis using a multiple-cause approach. J. Amer. med. Ass., 247: 793-6, 1982 .

21 - GURALNICK, L. Some problems in the use of multiple causes of death. J. chron. Dis., 19: 979-90, 1966.

22 - HARRIS, K.W. \& FRENCH, D.K. A methodological study of quality control procedures for mortality medical coding. Vital Health Stat.: Ser. 2, (81), 1980.

23 - ISRAEL, R.A. Analytic potential for multiple cause-ofdeath data. [Apresentado a IX Scientific Meeting of the International Epidemiological Association, Edimburgh, Scotland, 1981]. 
24 - ISRAEL, R.A. \& ARMSTRONG, R.J. An alternative procedure for classifying and analysing mortality data. In: International Population Conference, Liege, 1973. Liege, Belgium, International Union for the Scientific Study of Population, 1973. p. 231-42.

25 - ISRAEL, R.A. et al. New approaches to coding and analysing mortality data. Proceedings of the American Statistical Association, 1972, Washington, D.C., 1972, p. 2024 [separata].

26 - ISRAEL, R.A. et. al. Analytical potential for multiple cause-of-death data. Amer. J. Epidem., 174: 161-79, 1986.

27 - KASPER, E.K. et al. The causes of dilated cardiomyopathy: a clinicopathologic review of 673 consecutive patients. J. Am. Coll. Cardiol., 23: 586-590, 1994.

28 - KRUEGER, D.E. New numerators for old denominators multiple cause of death. In HAENZEL, W., ed. Epidemiological approaches to the study of cancer and other chronic diseases. Bethesda, Md. National Cancer Institute, 1966. p. 431-43.

29 - LAURENTI, R. Causas múltiplas de morte. São Paulo, 1973. [Tese de Livre-Docência - Faculdade de Saúde Pública da USP].

30 - MACMAHON, B. \& PUGH, T.F. Epidemiology: principles and methods. Boston, Little, Brown and Company, 1970.

31 - MANUAL da Classificação Estatística Internacional de Doenças, Lesões e Causa de óbito, baseada nas Recomendações da Nona Conferência de Revisão. São Paulo. Centro da OMS para a Classificação de Doenças em Português, 1980. v. 1.

32 - MANUAL of the international statistical classification of diseases, injuries and causes of death. 6th revision. Geneve, World Heath Organization, 1948.

33 - MARQUES, R.M. et al. Technical report on the feasibility testing of "ACME" system. São Paulo, 1978. [Apresentado ao Meeting of Heads of WHO Centres for Classification of Diseases, São Paulo, 1978 - mimeografado].

34 - MINISTÉRIO DA SAÚDE. Fundação Nacional de Saúde. Centro Nacional de Epidemiologia. Coordenação de Informações em Saúde. Estatísticas de Mortalidade, Brasil, 1988. Brasilia, 
Centro de Documentação do Ministério da Saúde, 1993, 375 p. (Série G: Estatística e Informação em Saúde, 19).

35 - MINISTÉRIO DA SAÚDE. Fundação Nacional de Saúde. Centro Nacional de Epidemiologia. Coordenadoria de Informações Epidemiológicas. Sistema de informações sobre mortalidade para microcomputadores; versão 1.0; manual do usuário. 1991. [Mimeografado].

36 - MINISTÉRIO DA SAÚDE. Núcleo de Informática da Secretaria Geral. Primeira reunião nacional sobre sistemas de informação de saúde. Brasília, 1975.

37 - MINISTÉRIO DA SAÚDE. Secretaria Nacional de Informações Básicas de Saúde. Divisão Nacional de Epidemiologia. Classificação brasileira de ocupações para o subsistema de informações sobre mortalidade/Ministério da Saúde, Divisão Nacional de Epidemiologia. Brasilia, Centro de Documentação do Ministério da Saúde, 1987. 103 p. (Serie G: Estatística e informação em saúde, 11).

38 - MINISTÉRIO DA SAÚDE. Secretaria Nacional de Informações Básicas de Saúde. Divisão Nacional de Epidemiologia. Manual de Instruções para o preenchimento da declaração de óbito. 2 . ed.. Brasília, Centro de Documentação do Ministério da Saúde, 1985.31 p. (Serie A: Normas e manuais técnicos; 24).

39 - MINISTÉRIO DA SAÚDE. Secretaria Nacional de Informações Básicas de Saúde. Divisão Nacional de Epidemiologia. Manual de Instruções de preenchimento da planilha para codificação de declaração de óbito. Brasília, Centro de Documentação do Ministério da Saúde, 1987. 24 p. (Serie A: Normas e manuais técnicos; 37).

40 - MinistéRio DA SAÚde. Sistema de informação de saúde; subsistema de informações sobre mortalidade; manual de procedimentos e operações. Brasília, 1976. 31 p.

41 - MORIYAMA, I.M. Development of the present concept of cause of death. Amer. J. publ. Hlth., 46: 436-41, 1956.

42 - NATIONAL CENTER FOR HEALTH STATISTICS Instruction manual. Part 2b: instructions for classifying multiple causes of death. 1984. Hyattsville, Md. 1983.

43 - NATIONAL CENTER FOR HEALTH STATISTICS Instruction manual. Part 2b: instructions for classifying multiple causes of death. 1992. Hyattsville, Md. 1992. 
44 - NATIONAL CENTER FOR HEALTH STATISTICS Instruction manual. Part 2c: ICD-9 ACME decision tables for classifying underlying causes of death. 1984. Hyattsville, Md. 1983.

45 - NATIONAL CENTER FOR HEALTH STATISTICS Instruction manual. Part 2c: ICD-9 ACME decision tables for classifying underlying causes of death. 1992. Hyattsville, Md. 1992.

46 - NATIONAL CENTER FOR HEALTH STATISTICS Instruction manual. Part 2d: NCHS procedures for mortality medical data system file preparation and maintenance, effective 1979. Hyattsville, Md. 1979.

47 - NATIONAL CENTER FOR HEALTH STATISTICS Instruction manual. Part 2e: Nonindexed terms, standard abbreviations, and state geographic codes used in mortality data classification, 1984. Hyattsville, Md. 1983.

48 - NATIONAL CENTER FOR HEALTH STATISTICS. Division of Data Processing. First progress report on final testing of system for Automated Classification of Medical Entiies (ACME) for selection of underlying cause of death: 1968. Research Triangle Park, N.C., 1969. [mimeografado].

49 - NATIONAL CENTER FOR HEALTH STATISTICS. Division of Data Processing. Second progress report on final testing of system for Automated Classification of Medical Entiies (ACME) for selection of underlying cause of death: 1968. Research Triangle Park, N.C., 1969. [mimeografado].

50 - NATIONAL CENTER FOR HEALTH STATISTICS. Division of Data Processing. Third progress report on final testing of system for Automated Classification of Medical Entiies (ACME) for selection of underlying cause of death: 1968. Research Triangle Park, N.C., 1969. [mimeografado].

51 - PUFFER, R.R. \& GRIfFITH, G.W. Caracteristicas de La mortalidad urbana. Washington, D.C., Organización Panamericana de la Salud, 1968. (OPAS - Publ. cient. 151).

52 - PUFFER, R.R. \& SERRANO, C.V. Caracteristicas de la mortalidad en la nidez. Washington, D.C., Organización Panamericana de la Salud, 1973. (OPAS - Publ. cient. 262).

53 - SANTO, A.H. Estudo crítico das estatísticas de causa de morte em doentes portadores de transtornos mentais. São Paulo, 1980 [Dissertação de Mestrado - Faculdade de Saúde Pública da USP]. 
54 - SANTO, A.H. Importância das estatísticas de mortalidade na organização do sistema de informações em saúde. [Apresentado ao Primeiro Seminário Estadual de Epidemiologia e Estatística de Mortalidade, Teresina, 1984].

55 - SANTO, A.H. Causas múltiplas de morte: formas de apresentação e métodos de análise. São Paulo, 1988. [Tese de Doutoramento - Faculdade de Saúde Pública da USP].

56 - SANTO, A.H. \& LAURENTI, R. General review on mortality coding rules. Geneve. World Health Organization, 1983. (DES/ICD-10/83.15) [Apresentado ao Preparatory Meeting on ICD-10, Geneve, 1983].

57 - SANTO, A.H. \& LAURENTI, R. Estatísticas de mortalidade por causas múltiplas: novas perspectivas com o sistema ACME. Rev. Saúde publ., São Paulo, 20: 397-400, 1986.

58 - SÃO PAULO (Estado) Leis, etc. Decreto no 51.014, de 5 de dezembro de 1968: regulamenta as disposições da Lei no 10.095, de 3 de maio de 1968. In: Coleção de Leis e Decretos do Estado de São Paulo, 1968-4o trimestre. São Paulo, Imprensa Oficial do Estado, 1968, v. 78, p. 957-958.

59 - SÃO PAULO (Estado) Leis, etc. Lei no 5.452, de 22 de dezembro de 1986: reorganiza os Serviços de Verificação de óbitos no Estado de São Paulo. São Paulo Legislação, 4: 36-8, nov. 1986.

60 - SÃO PAULO (Estado) Leis, etc. Lei no 10.095, de 3 de maio de 1968: dispõe sobre o Serviço de Verificação de óbitos do Município de São Paulo e dá outras providências. In: Coleção de Leis e Decretos do Estado de São Paulo, 1968-2으 trimestre. São Paulo, Imprensa Oficial do Estado, 1968, v. $78, \mathrm{p} .33-36$.

61 - TEMPLETON, M.C. \& EVANS, M.C. Automated Classification of Medical Entities (ACME) for Selection of Causes of Death. [Apresentado ao 98th Annual Meeting of the American Public Health Association, Houston, Texas, U.S.A., 1970].

62 - TREOLAR, A.B. The enigma of cause of death. J. Amer. med. Ass., 162: 1376-9, 1956.

63 - UNITED NATIONS. Department of International and Economic Affairs. Levels and trends of mortality since 1950; a joint study by the United Nations and the World Health Organization. New York, 1982. 
ANEXOS 


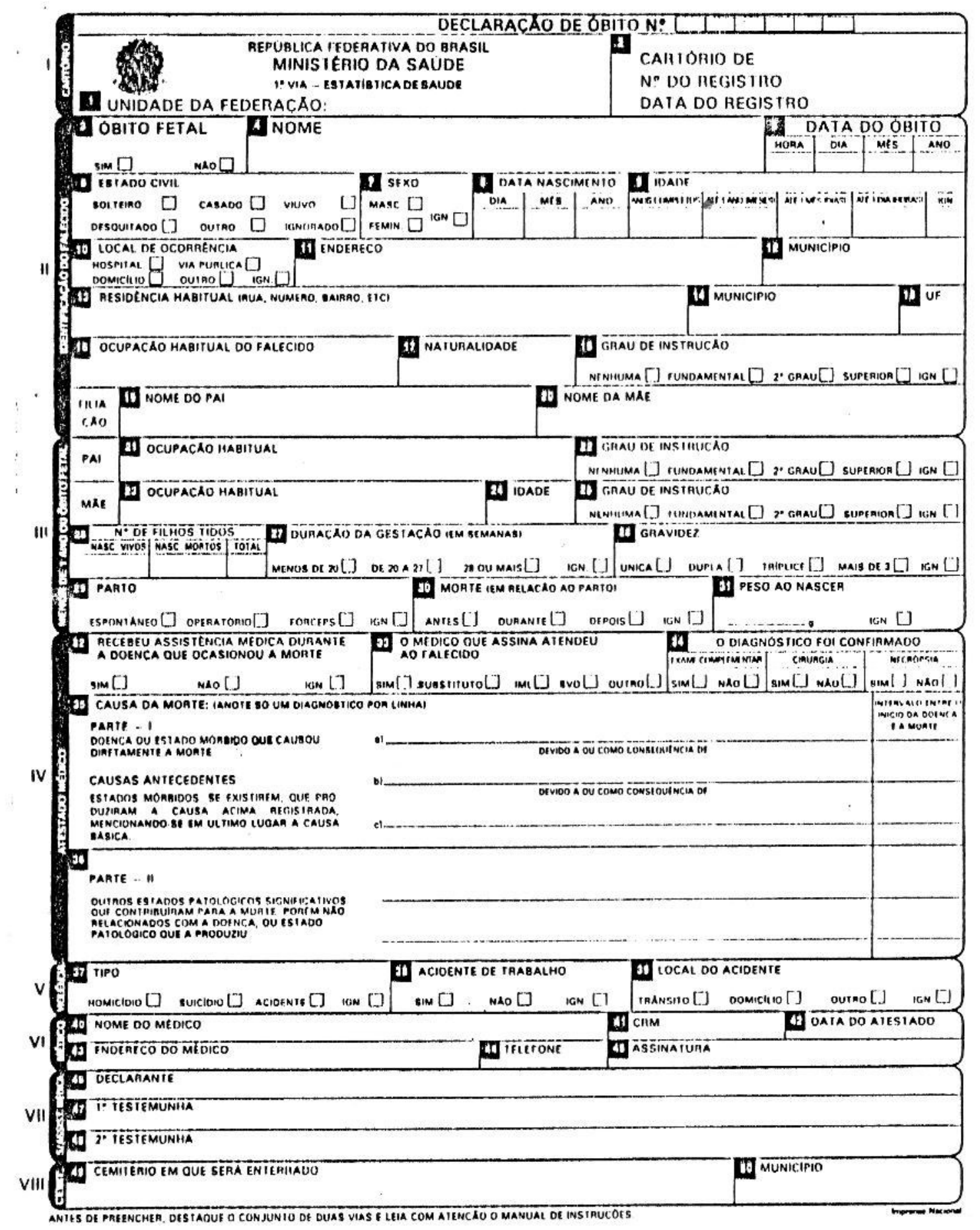


ANEXO 2 


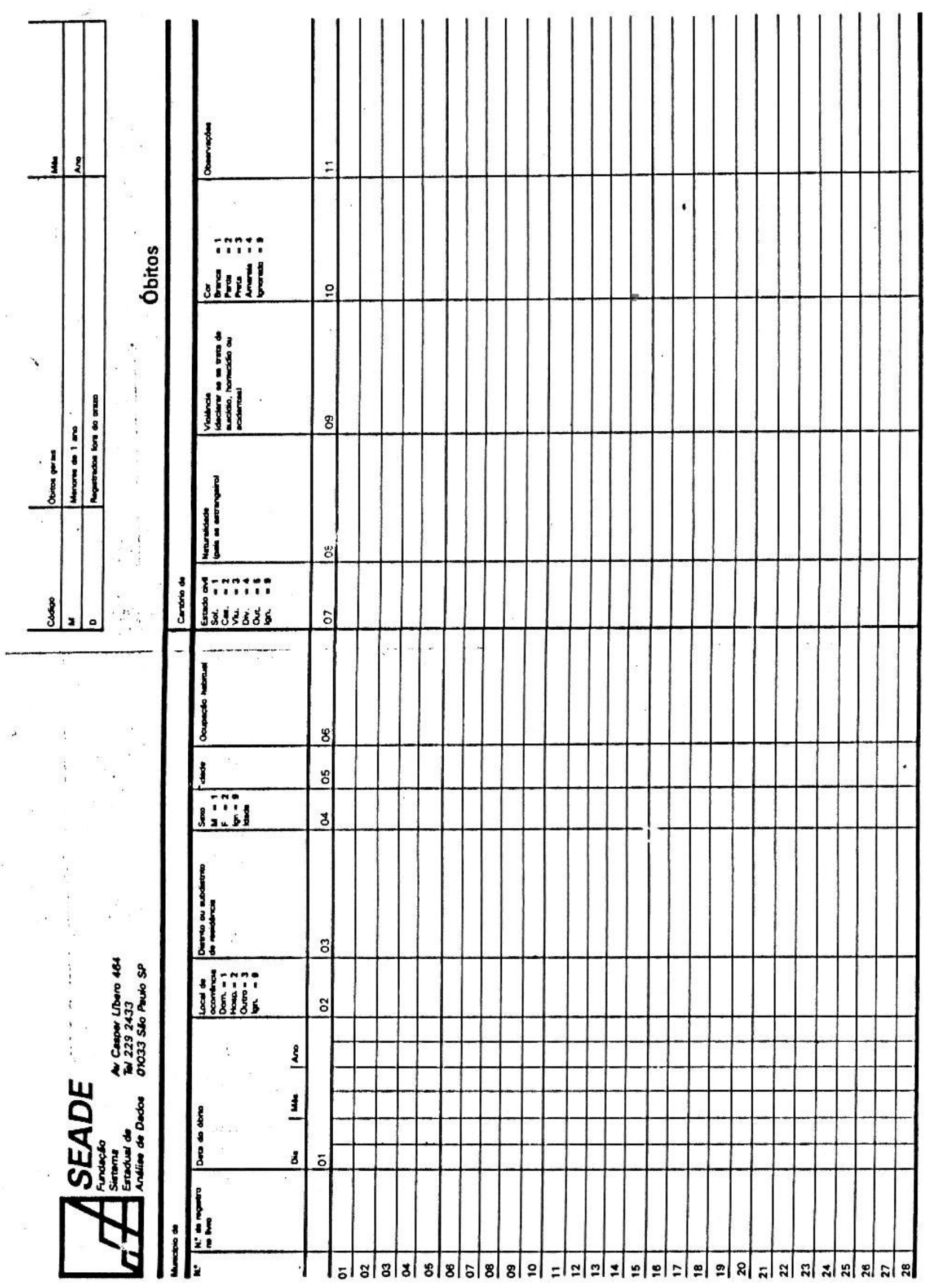


DECLARAÇÕES DE ÓBITO ENCAMINHADAS AO "NATIONAL CENTER FOR HEALTH STATISTICS" PARA CODIFICAÇÃO

Feminino, 36 anos

I a) Insuficiência respiratória

b) Aspiração maciça de vômitos

II Carcinoma uterino disseminado

c) Uremia

SEADE: $786.0 / 507.0 / 586 * 179$ b $199.0-\mathrm{CB}=586$

NCHS : $786.0 / /) 33 \mathrm{~b} \& 911 / 586 * 179-\mathrm{UC}=586$

Masculino, 62 anos

I a) Encefalopatia aguda

b) Estrongiloidíase disseminada

c) Imunodeficiência por corticóide

II Adenocarcinoma de próstata metastático Pênfigo vulgar + Diabetes mellitus

SEADE: $348.3 / 127.2 / 279.3 * 185$ b 6944 b 250.0 $\mathrm{CB}=127.2$

NCHS : $348.3 / 127.2 / 279.3 / 932.0 * \& 185$ b 6944 b 250.0 $\mathrm{UC}=127.2$
Masculino, 3 dias
I a) Aspiração de sangue
b) Síndrome hemorrágica pós-anoxia
c) Anoxia perinatal grave

II

SEADE: $770.1 / 772.0 / 768.5-\mathrm{CB}=768.5$

NCHS : $770.1 / 768.9 / 768.5-\mathrm{UC}=768.5$

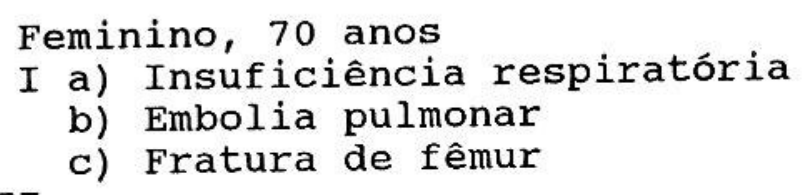

II

SEADE: $786.0 / 415.1 /(21 \mathrm{~b} \& 887-\mathrm{CB}=\mathrm{E} 887$

NCHS : $786.0 / 415.1 /(21 \mathrm{~b} \& 887-\mathrm{UC}=\mathrm{E} 887$

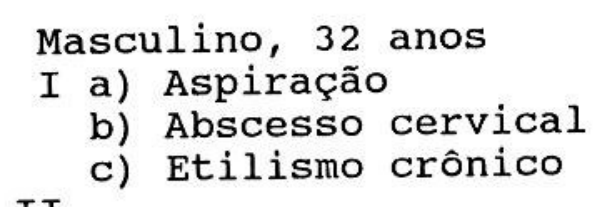

SEADE: $799.0 / 682.1 / 303-\mathrm{CB}=303$

NCHS : ) $33 \mathrm{~b} \& 912 / 682.1 / 303-\mathrm{UC}=303$ 
Masculino, 28 anos

I a) Aspiração de conteúdo gástrico

b) Epilepsia

II

c)

SEADE: $507.0 / 345.9-\mathrm{CB}=345.9$

NCHS : ) 33 b \&911/345.9 - UC $=345.9$

Feminino, 77 anos

I a) Insuficiência cardiocirculatória

b) Doença degenerativa progressiva

II Aci

c) Doença de Alzheimer

SEADE: $799.1 / 797 / 331.0 * 438$ b $401.9-\mathrm{CB}=331.0$

NCHS : $428.0 / \mathrm{b} / 331.0 * 438 \mathrm{~b} 401.9-\mathrm{UC}=331.0$

\author{
Feminino, 46 anos \\ I a) Coagulopatia \\ b) Troca de prótese mitral \\ c) Endomiocardiofibrose
}

II

SEADE: $286.9 / 394.9 / 425.0-\mathrm{CB}=286.9$

NCHS : ) 96.7 b \&878.1/\&425.0 - UC $=425.0$

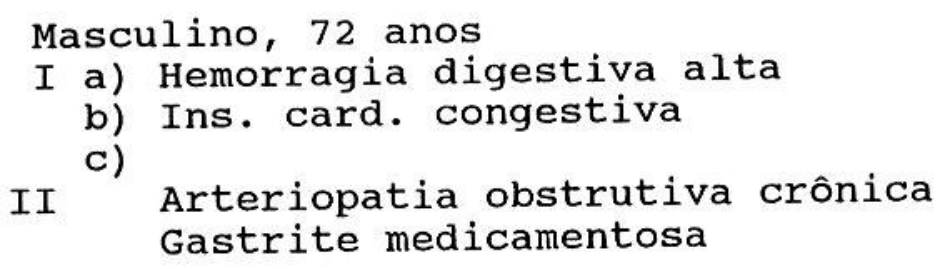

SEADE: $578.9 / 428.0 * 447.9$ b $535.4-\mathrm{CB}=428.0$

NCHS : $578.9 / 428.0 * 447.9$ b 947.9 b $\& 535.4-\mathrm{UC}=428.0$

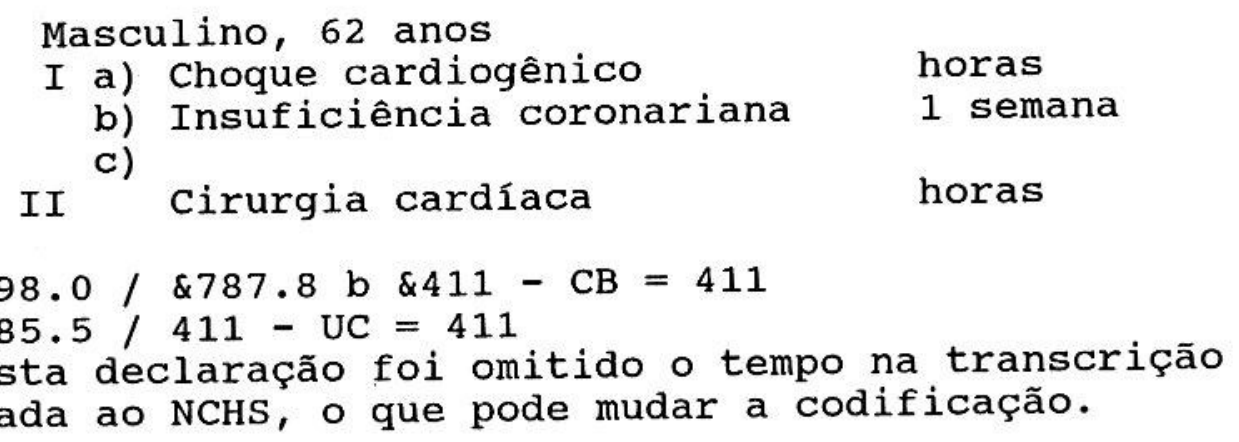

Nota: Nesta declaração foi omitido o tempo na transcrição

encaminhada ao NCHS, o que pode mudar a codificação.

SEADE: ) $98.0 / \& 787.8$ b $\& 411-\mathrm{CB}=411$

NCHS : $785.5 / 411-\mathrm{UC}=411$ 
Masculino, 81 anos

I a) Peritonite fibrinopurulenta

b) Esplenectomia

c) Linfoma de Hodgkin

II

Cirrose hepática portal

SEADE: ) $98.5 / \& 878.6$ b $\& 201.9 * 571.5-\mathrm{CB}=201.9$

NCHS : ) $98.5 / \& 878.6$ b \&201.9*571.5 - UC $=201.9$

Feminino, 81 anos

I a) Insúficiência respiratória aguda

b) Septicemia

c) Peritonite

II

$\mathrm{Tu}$ de ceco perfurado

SEADE: $518.5 / 038.9 / 567.9 * 153.4$ b $540.0-\mathrm{CB}=153.4$

NCHS : $786.0 / 038.9 / 567.9 * 239.0-\mathrm{UC}=239.0$

Masculino, 75 anos

I a) Insuficiência respiratória aguda

b) Choque séptico

II

c) Gangrena MID

Pós-operatório amputação MID

SEADE: $518.5 / 785.5 / 785.4 * 878.5-\mathrm{CB}=518.5$

NCHS : $786.0 / / 98.0 / \& 785.4 * \& 878.5-\mathrm{UC}=\mathrm{E} 878.5$

Masculino, 69 anos

I a) Insuficiência respiratória

b) Septicemia

c) Insuficiência de múltiplos órgãos

II Osteomielite

Fratura transtrocantérica

SEADE: $786.0 / 038.9 / 799.8 * 730.2$ b $733.1-\mathrm{CB}=038.9$

NCHS : $786.0 / 038.9 * 730.3$ b $(20$ b \&887 - UC $=038.9$

Masculino, 34 anos

I a) Amolecimento cerebral

b) Perda de substância encefálica frontal D

c) Hematoma subdural por TCE

II

Informação adicional: Acidente de trânsito

SEADE : $(51 /(54 * \& 819.9-\mathrm{CB}=819.9$

NCHS : $434.9 /(54 /(52 /(54 * \& 819.9-\mathrm{UC}=819.9$

Masculino, 1 ano

I a) Insuficiência respiratória grave
b) Aspiração de vômitos após mamada
c)

SEADE: $786.0 / 507.0-\mathrm{CB}=507.0$

NCHS : $786.0 /) 33 \mathrm{~b} \& 911-\mathrm{UC}=\mathrm{E} 911$ 


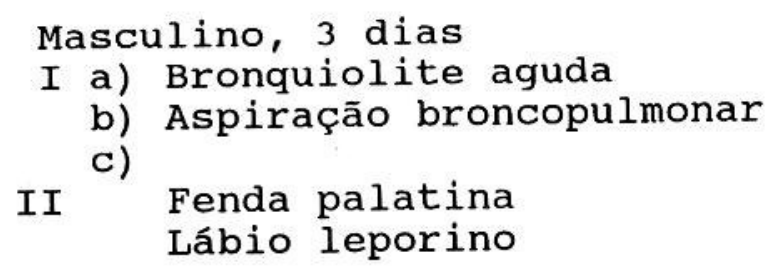

SEADE: $466.1 / 770.1 * 749.0$ b $749.1-\mathrm{CB}=466.1$

NCHS : $466.1 / 770.1 * 749.0$ b $749.1-\mathrm{UC}=770.1$

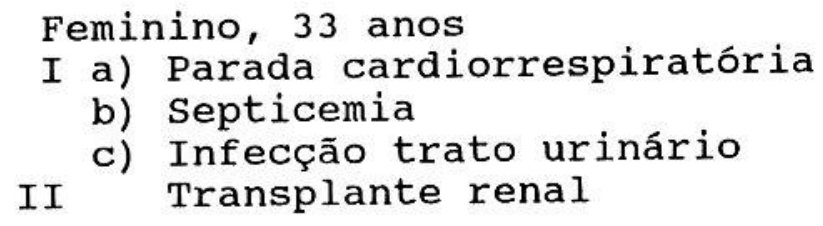

SEADE: $799.1 / 038.9 / 599.0 * 878.0-\mathrm{CB}=599.0$ NCHS : $799.1 / 038.9 / 599.0 * 593.9-\mathrm{UC}=593.9$

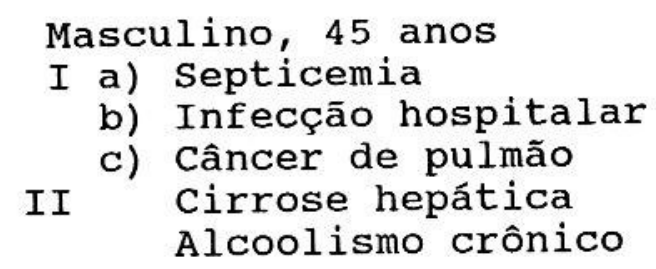

SEADE : $038.9 / 136.9 / 162.9 * 571.5$ b $303-\mathrm{CB}=162.9$

NCHS : $038.9 / \mathrm{b} / 162.9 * 571.5 \mathrm{~b} 303-\mathrm{UC}=162.9$

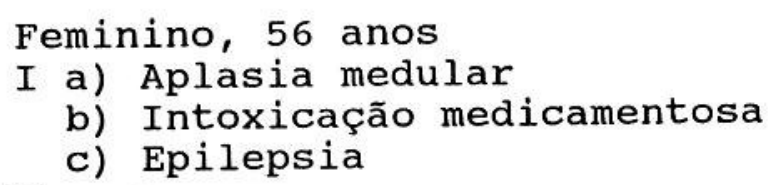

SEADE: $415.1 / 785.4 / 250.0-\mathrm{CB}=250.6$

NCHS : ) $97.3 / \& 878.9$ b $785.4 / \& 250.0-U C=250.6$ 


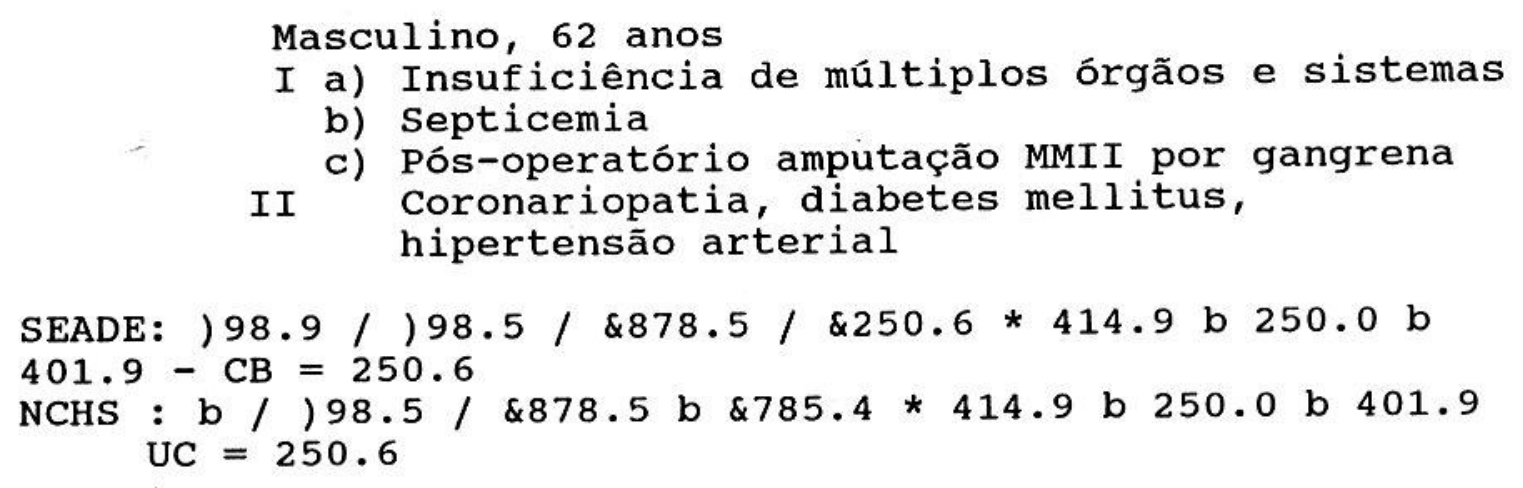


ANEXO 4 
REGISTROS CUJAS DECLARACOES DE OBITO

APRESENTARAM ERRO DE CODIFICACAO DA

CAUSA BASICA (1) OU DE CAUSAS ASSOCIADAS (2) DE MORTE, AMOSTRA, ESTADO DE SAO PAULO, 1992.

NUMERO

DATA

DISTRITO SEXO

GRUPO CAUSA CAUSA

TIPO

SEQUENCIAL REGISTRO REGISTRO

IDADE BASICA CORRIGIDA ERRO

\begin{tabular}{|c|c|c|c|c|c|c|}
\hline 000197 & 140192 & 0024 & 2 & 35 & 5720 & 5720 \\
\hline 000325 & 280192 & 0024 & 2 & 65 & 4140 & 4140 \\
\hline 000121 & 210192 & 0073 & 1 & 70 & 1739 & 1739 \\
\hline 000473 & 310192 & 0206 & 2 & 55 & 5355 & 4449 \\
\hline 000128 & 100192 & 0243 & 1 & 25 & 4416 & 4416 \\
\hline 000029 & 030192 & 0279 & 2 & 75 & 1209 & 1201 \\
\hline 000061 & 290192 & 0310 & 2 & 40 & 2469 & 2420 \\
\hline 000033 & 020192 & 0425 & 2 & 35 & 586 & 586 \\
\hline 000352 & 300192 & 0516 & 1 & 50 & 2500 & 2505 \\
\hline 000108 & 300192 & 1867 & 1 & 75 & 4371 & 496 \\
\hline 000034 & 210192 & 2331 & 1 & 20 & 9889 & 9289 \\
\hline 000040 & 220192 & 3309 & 2 & 45 & 485 & 514 \\
\hline 000033 & 230192 & 3712 & 1 & 65 & 4280 & 4280 \\
\hline 000235 & 310192 & 3724 & 2 & 45 & 2956 & 410 \\
\hline 000079 & 270192 & 5319 & 1 & 15 & 9289 & 9889 \\
\hline 000001 & 300192 & 7029 & 2 & 00 & 7799 & 7999 \\
\hline 000006 & 060192 & 7286 & 2 & 00 & 7485 & 769 \\
\hline 000005 & 060192 & 8060 & 1 & 00 & 7689 & 7684 \\
\hline 000189 & 180292 & 0024 & 2 & 65 & 2780 & 2788 \\
\hline 000320 & 270292 & 0024 & 2 & 75 & 1991 & 2028 \\
\hline 000064 & 110292 & 0085 & 1 & 55 & 4019 & 4378 \\
\hline 000005 & 180292 & 0103 & 2 & 00 & 7611 & 7611 \\
\hline 000001 & 200292 & 0139 & 2 & 00 & 7702 & 7702 \\
\hline 000011 & 050292 & 0140 & 2 & 80 & 485 & 485 \\
\hline 000006 & 210292 & 0590 & 1 & 70 & 4259 & 4254 \\
\hline 000018 & 130292 & 1508 & 1 & 02 & 3209 & 1890 \\
\hline 000012 & 280292 & 1867 & 2 & 65 & 1919 & 2252 \\
\hline 000013 & 270292 & 3712 & 1 & 30 & 515 & 0114 \\
\hline 000007 & 060292 & 3888 & 2 & 45 & 8199 & 8199 \\
\hline 000002 & 210292 & 4182 & 2 & 65 & 5751 & 5759 \\
\hline 000003 & 280292 & 4236 & 2 & 50 & 7998 & 7999 \\
\hline 000003 & 190292 & 4248 & 1 & 00 & 7708 & 7708 \\
\hline 000069 & 140292 & 5319 & 1 & 40 & 1519 & 1519 \\
\hline 000060 & 100292 & 7274 & 1 & 60 & 1272 & 1272 \\
\hline 000057 & 140292 & 8084 & 2 & 80 & 1519 & 1952 \\
\hline 000005 & 140292 & 8515 & 1 & 50 & 436 & 438 \\
\hline 000053 & 100292 & 8629 & 2 & 60 & 1519 & 1598 \\
\hline 000265 & 180392 & 0024 & 1 & 55 & 411 & 411 \\
\hline 000332 & 250392 & 0024 & 2 & 40 & 2396 & 2252 \\
\hline 000132 & 180392 & 0097 & 1 & 65 & 5849 & 4299 \\
\hline 000014 & 090392 & 0139 & 1 & 70 & 888 & 5715 \\
\hline 000123 & 100392 & 0206 & 1 & 65 & 4410 & 4410 \\
\hline 000188 & 140392 & 0206 & 1 & 30 & 0855 & 0855 \\
\hline 000315 & 250392 & 0206 & 2 & 70 & 4249 & 4249 \\
\hline 000111 & 230392 & 0322 & 1 & 60 & 1991 & 1739 \\
\hline 000001 & 040392 & 0486 & 1 & 00 & 7799 & 7999 \\
\hline 000062 & 170392 & 0498 & 2 & 35 & 1208 & 1201 \\
\hline 000020 & 160392 & 2008 & 1 & 60 & 6088 & 2507 \\
\hline 000040 & 160392 & 3724 & 1 & 00 & 0091 & 0091 \\
\hline 000013 & 160392 & 4601 & 2 & 80 & 436 & 586 \\
\hline 000020 & 090392 & 7456 & 1 & 20 & 9889 & 9289 \\
\hline 000186 & 300392 & 7912 & 1 & 65 & 4140 & 4148 \\
\hline 000039 & 190392 & 8096 & 1 & 70 & 515 & 1160 \\
\hline
\end{tabular}


REGISTROS CUJAS DECLARACOES DE OBITO

APRESENTARAM ERRO DE CODIFICACAO DA

CAUSA BASICA (1) OU DE CAUSAS ASSOCIADAS (2) DE MORTE, AMOSTRA, ESTADO DE SAO PAULO, 1992.

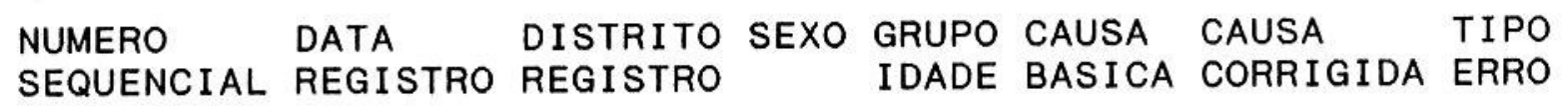

\begin{tabular}{|c|c|c|c|c|c|c|}
\hline 000055 & 090392 & 8629 & 1 & 15 & 5829 & 5829 \\
\hline 000260 & 230492 & 0024 & 2 & 60 & 4140 & 4140 \\
\hline 000082 & 010492 & 0292 & 1 & 00 & 7670 & 7685 \\
\hline 000003 & 140492 & 0462 & 2 & 00 & 9139 & 9839 \\
\hline 000037 & 080492 & 1039 & 1 & 25 & 9889 & 9289 \\
\hline 000066 & 200492 & 1582 & 2 & 25 & 4259 & 4254 \\
\hline 000163 & 280492 & 2215 & 1 & 45 & 7999 & 7999 \\
\hline 000083 & 130492 & 2719 & 2 & 75 & - 4349 & 4349 \\
\hline 000006 & 290492 & 2720 & 1 & 55 & 1160 & 1733 \\
\hline 000007 & 270492 & 3712 & 1 & 00 & 485 & 7700 \\
\hline 000006 & 230492 & 4790 & 1 & 00 & 485 & 7700 \\
\hline 000067 & 130492 & 4790 & 2 & 70 & 1991 & 2028 \\
\hline 000029 & 130492 & 7298 & 2 & 55 & 410 & 410 \\
\hline 000002 & 230492 & 7833 & 1 & 10 & 8149 & 9108 \\
\hline 000030 & 280492 & 8011 & 2 & 00 & 0701 & 485 \\
\hline 000224 & 290592 & 0097 & 1 & 80 & 1619 & 1619 \\
\hline 000244 & 200592 & 0206 & 1 & 30 & 303 & 303 \\
\hline 000483 & 020592 & 0292 & 2 & 60 & 1950 & 1809 \\
\hline 000185 & 200592 & 0516 & 1 & 30 & 9289 & 7999 \\
\hline 000308 & 280592 & 0516 & 1 & 25 & 3459 & 3459 \\
\hline 000001 & 040592 & 0989 & 2 & 75 & 1519 & 1519 \\
\hline 000001 & 070592 & 6713 & 2 & 60 & 1529 & 1539 \\
\hline 000011 & 030592 & 7649 & 1 & 55 & 9889 & 9289 \\
\hline 000062 & 090592 & 8266 & 2 & 70 & 4259 & 2500 \\
\hline 000021 & 120592 & 8278 & 1 & 70 & 4254 & 2500 \\
\hline 000008 & 050592 & 9489 & 2 & 00 & 7689 & 7683 \\
\hline 000192 & 110692 & 0024 & 1 & 70 & 4140 & 4140 \\
\hline 000013 & 050692 & 0127 & 2 & 75 & 3310 & 3310 \\
\hline 000094 & 010692 & 0206 & 2 & 45 & 2869 & 4250 \\
\hline 000158 & 090692 & 0206 & 2 & 20 & 7101 & 7101 \\
\hline 000003 & 220692 & 1843 & 1 & 70 & 0091 & 0091 \\
\hline 000053 & 190692 & 3712 & 2 & 65 & 9889 & 9289 \\
\hline 000082 & 150692 & 5319 & 2 & 75 & 1629 & 1629 \\
\hline 000083 & 070692 & 5502 & 1 & 70 & 4280 & 4280 \\
\hline 000018 & 030692 & 6087 & 1 & 65 & 2502 & 2502 \\
\hline 000022 & 030692 & 7018 & 1 & 80 & 5602 & 5602 \\
\hline 000194 & 220692 & 7912 & 1 & 60 & 6088 & 1889 \\
\hline 000001 & 230692 & 9374 & 2 & 00 & 5070 & 911 \\
\hline 000074 & 010792 & 0292 & 2 & 00 & 769 & 769 \\
\hline 000154 & 280792 & 1429 & 1 & 55 & 0862 & 0861 \\
\hline 000064 & 200792 & 2197 & 2 & 40 & 4210 & 4241 \\
\hline 000002 & 010792 & 2203 & 1 & 00 & 7799 & 7999 \\
\hline 000006 & 100792 & 2513 & 1 & 80 & 4349 & 496 \\
\hline 000220 & 150792 & 3724 & 2 & 70 & 4259 & 4254 \\
\hline 000024 & 210792 & 5046 & 1 & 60 & 485 & 3319 \\
\hline 000033 & 020792 & 7912 & 1 & 60 & 1629 & 1519 \\
\hline 000014 & 090792 & 7924 & 1 & 80 & 431 & 436 \\
\hline 000166 & 310792 & 8291 & 1 & 80 & 0119 & 1370 \\
\hline 000011 & 240792 & 9003 & 1 & 50 & 4259 & 4254 \\
\hline 000231 & 260892 & 0188 & 1 & 60 & 1552 & 1991 \\
\hline 000033 & 170892 & 0199 & 1 & 80 & 1552 & 1991 \\
\hline 000041 & 040892 & 0206 & 1 & 05 & 2396 & 2396 \\
\hline 000056 & 070892 & 0243 & 2 & 65 & 585 & 4280 \\
\hline
\end{tabular}


REGISTROS CUJAS DECLARACOES DE OBITO

APRESENTARAM ERRO DE CODIFICACAO DA

CAUSA BASICA (1) OU DE CAUSAS ASSOCIADAS (2) DE MORTE, AMOSTRA, ESTADO DE SAO PAULO, 1992.

\begin{tabular}{|c|c|c|c|c|}
\hline $\begin{array}{l}\text { NUMERO } \\
\text { SEQUENCI AL }\end{array}$ & STRO & D & & \\
\hline
\end{tabular}

\begin{tabular}{|c|c|c|c|c|c|c|}
\hline 000132 & 110892 & 0516 & 1 & 65 & 5185 & 5188 \\
\hline 000039 & 310892 & 1612 & 1 & 40 & 9889 & 9289 \\
\hline 000011 & 100892 & 1831 & 2 & 65 & 4029 & 4029 \\
\hline 000006 & 300892 & 2094 & 1 & 65 & 280 & 2851 \\
\hline 000002 & 030892 & 4224 & 1 & 55 & 9889 & 9289 \\
\hline 000001 & 020892 & 6506 & 1 & 30 & 9889 & 9289 \\
\hline 000028 & 280892 & 6658 & 2 & 30 & 9889 & 9289 \\
\hline 000004 & 010892 & 7079 & 1 & 80 & .4254 & 4029 \\
\hline 000017 & 050892 & 7456 & 1 & 65 & 9889 & 9289 \\
\hline 000164 & 130892 & 8011 & 2 & 80 & 1534 & 1534 \\
\hline 000027 & 010992 & 0206 & 2 & 65 & 485 & 486 \\
\hline 000049 & 030992 & 0218 & 1 & 40 & 485 & 485 \\
\hline 000178 & 210992 & 0218 & 1 & 65 & 5849 & 5849 \\
\hline 000073 & 180992 & 0243 & 2 & 60 & 1550 & 1550 \\
\hline 000004 & 150992 & 0309 & 2 & 00 & 7567 & 7567 \\
\hline 000069 & 030992 & 0516 & 1 & 60 & 5990 & 585 \\
\hline 000111 & 170992 & 1429 & 2 & 75 & 410 & 4299 \\
\hline 000059 & 090992 & 2215 & 1 & 75 & 1629 & 2028 \\
\hline 000014 & 150992 & 2938 & 1 & 10 & 9889 & 7999 \\
\hline 000095 & 030992 & 3724 & 2 & 60 & 436 & 436 \\
\hline 000020 & 170992 & 6968 & 2 & 03 & 7999 & 7999 \\
\hline 000092 & 290992 & 7298 & 2 & 65 & 2510 & 2502 \\
\hline 000066 & 240992 & 8278 & 1 & 01 & 5070 & 911 \\
\hline 000005 & 040992 & 8862 & 2 & 55 & 0859 & 1749 \\
\hline 000039 & 061092 & 0097 & 2 & 50 & 1749 & 1749 \\
\hline 000057 & 241092 & 0103 & 2 & 45 & 7474 & 193 \\
\hline 000181 & 141092 & 0188 & 1 & 60 & 1919 & 2396 \\
\hline 000074 & 081092 & 0243 & 2 & 35 & 1749 & 1749 \\
\hline 000004 & 311092 & 0279 & 1 & 00 & 4661 & 7701 \\
\hline 000080 & 291092 & 0346 & 1 & 25 & 9289 & 7999 \\
\hline 000126 & 261092 & 1429 & 1 & 20 & 2791 & 2791 \\
\hline 000108 & 301092 & 2197 & 2 & 30 & 5990 & 5939 \\
\hline 000020 & 191092 & 3311 & 2 & 55 & 3311 & 0860 \\
\hline 000010 & 061092 & 4996 & 1 & 80 & 1739 & 1739 \\
\hline 000082 & 301092 & 8680 & 2 & 15 & 9889 & 7999 \\
\hline 000006 & 041192 & 0061 & 1 & 65 & 2500 & 2500 \\
\hline 000062 & 051192 & 0243 & 2 & 55 & 5715 & 5715 \\
\hline 000132 & 181192 & 0279 & 1 & 30 & 9889 & 7999 \\
\hline 000041 & 011192 & 0474 & 1 & 25 & 0119 & 0189 \\
\hline 000195 & 171192 & 0516 & 1 & 45 & 485 & 485 \\
\hline 000051 & 201192 & 2458 & 1 & 35 & 2791 & 2791 \\
\hline 000326 & 301192 & 3724 & 2 & 65 & 4254 & 4029 \\
\hline 000140 & 261192 & 4790 & 2 & 40 & 1749 & 1749 \\
\hline 000018 & 271192 & 5551 & 1 & 35 & 7999 & 7999 \\
\hline 000002 & 121192 & 6051 & 2 & 75 & 436 & 436 \\
\hline 000028 & 181192 & 6555 & 2 & 55 & 2849 & 3459 \\
\hline 000003 & 051192 & 6669 & 2 & 00 & 7799 & 7999 \\
\hline 000064 & 141192 & 6669 & 1 & 25 & 9889 & 9289 \\
\hline 000006 & 241192 & 8667 & 1 & 30 & 0709 & 486 \\
\hline 000038 & 161192 & 8939 & 1 & 45 & 1589 & 2500 \\
\hline 000003 & 171192 & 9441 & 2 & 75 & 1561 & 1552 \\
\hline 000021 & 011292 & 0085 & 1 & 65 & 0120 & 1370 \\
\hline 000152 & 151292 & 0085 & 1 & 55 & 485 & 485 \\
\hline
\end{tabular}


Page No.

4

$08 / 09 / 94$

REGISTROS CUJAS DECLARACOES DE OBITO

APRESENTARAM ERRO DE CODIFICACAO DA

CAUSA BASICA (1) OU DE CAUSAS ASSOCIADAS (2) DE MORTE, AMOSTRA, ESTADO DE SAO PAULO, 1992.

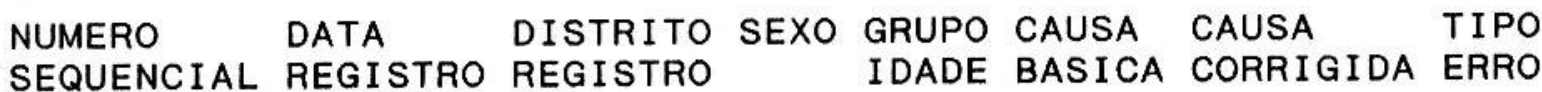

$\begin{array}{llllllll}000048 & 231292 & 0097 & 1 & 65 & 4409 & 4149 & 1 \\ 000043 & 011292 & 0103 & 2 & 65 & 485 & 4151 & 1 \\ 000220 & 211292 & 0206 & 1 & 60 & 2506 & 2506 & 2 \\ 000013 & 021292 & 0243 & 1 & 00 & 7708 & 7708 & 2 \\ 000033 & 141292 & 0279 & 1 & 60 & 2506 & 2506 & 2 \\ 000258 & 271292 & 0292 & 1 & 45 & 5182 & 1552 & 1 \\ 000034 & 291292 & 0371 & 1 & 70 & 1639 & 1991 & 1 \\ 000061 & 101292 & 0425 & 2 & 60 & 2396 & 1919 & 1 \\ 000034 & 151292 & 0504 & 2 & 50 & 4254 & 4140 & 1 \\ 000018 & 151292 & 1612 & 2 & 01 & 052 & 052 & 2 \\ 000007 & 041292 & 1831 & 1 & 60 & 7999 & 7989 & 1 \\ 000050 & 091292 & 2215 & 1 & 30 & 7999 & 7999 & 2 \\ 000004 & 301292 & 3207 & 1 & 00 & 261 & 0090 & 1 \\ 000120 & 071292 & 3724 & 1 & 80 & 1519 & 1519 & 2 \\ 000007 & 121292 & 5502 & 1 & 00 & 0389 & 485 & 1 \\ 000001 & 221292 & 7201 & 2 & 00 & 7615 & 769 & 1 \\ 000149 & 281292 & 7274 & 1 & 02 & 5070 & 911 & 1 \\ 000094 & 131292 & 8266 & 1 & 40 & 9854 & 9229 & 1\end{array}$


ANEXO 4 - Grupos etários e códigos correspondentes.

\begin{tabular}{cc}
\hline $\begin{array}{c}\text { IDADE } \\
\text { (anos) }\end{array}$ & $\begin{array}{c}\text { GRUPOS } \\
\text { (códigos) }\end{array}$ \\
\hline Menos 1 & 00 \\
1 & 01 \\
2 & 02 \\
3 & 03 \\
4 & 04 \\
5 a 9 & 05 \\
10 a 14 & 10 \\
15 a 10 & 15 \\
20 a 24 & 20 \\
25 a 29 & 25 \\
30 a 34 & 30 \\
35 a 39 & 35 \\
40 a 44 & 40 \\
45 a 49 & 45 \\
50 a 54 & 50 \\
55 a 59 & 55 \\
60 a 64 & 60 \\
65 a 69 & 65 \\
70 a 74 & 70 \\
75 a 79 & 75 \\
80 e mais & 80 \\
ignorado & 99 \\
\hline & \\
\hline & \\
\hline & \\
\hline
\end{tabular}


